\title{
Das Papsttum und das Erzbistum Salzburg (1060-1216)
}

\author{
RAINER MURAUER
}

\section{Untersuchungsgegenstand und Untersuchungszeitraum}

Die drastisch verstärkte Überlieferung von urkundlichen und erzählenden Nachrichten ab etwa 1060 nach einigen fast nachrichtenlosen Jahrzehnten lässt es plausibel erscheinen, die Darstellung mit Erzbischof Gebhard (1060-1088) zu beginnen. Allein bei Papsturkunden über die Verleihung des Palliums, die verhältnismäßig gut dokumentiert sind, lohnt sich ein Blick weiter zurück. Einen markanten Wendepunkt setzt die außergewöhnlich lange Regierungszeit Erzbischof Eberhards II. (1200-1246), der - rechnet man seine vierjährige Tätigkeit als Bischof des Salzburger Suffraganbistums Brixen (1196-1200) hin$\mathrm{zu}$ - genau ein halbes Jahrhundert dem Episkopat angehörte ${ }^{1}$. Da Eberhards Amtszeit weit über den im Netzwerk gesetzten Rahmen hinausgeht, ist es aus pragmatischen Motiven durchaus angemessen, den Schlussstrich im Jahre 1216 zu ziehen, welches das Ende des Pontifikats Innozenz' III. markiert, wenngleich dieses Jahr für Salzburg keine entscheidende Zäsur setzt.

Neben dem Erzbischof als politischem und religiösem Zentrum des Sprengels und seinem Domkapitel ist großes Augenmerk auf die zahlreichen Klöster der Benediktiner, Zisterzienser, Kartäuser und (Augustiner-)Chorherren zu legen. Eine Sonderrolle spielt das 1070/72 gegründete Eigenbistum Gurk, das für einige Jahrzehnte nicht einmal über ein eigenes Territorium verfügte und dessen Oberhirte vom Erzbischof ernannt wurde. Erst in der zweiten Hälfte des 12. Jahrhunderts begannen die Loslösungsbestrebungen, getragen vom Gurker Domkapitel, welches das Recht auf die Wahl seines Bischofs beanspruchte und eine Gleichstellung mit den übrigen Suffraganen Salzburgs (Passau, Freising, Regensburg und Brixen) anstrebte.

Die Dichte der Überlieferung im inneralpinen Raum kann sich keinesfalls mit jener in Regionen südlich der Alpen messen, weshalb es unumgänglich ist, nicht nur im Original überlieferte Stücke, sondern auch kopial überlieferte in die Betrachtung einzubeziehen. Trotzdem bleibt das Material - insbesondere für die Klöster - überaus lückenhaft.

1 Christine STÖLLINGER: Erzbischof Eberhard II. von Salzburg (1200-1246), Wien 1972 (phil. Diss.); zur Herkunft Eberhards (geboren um 1170) aus dem Geschlecht der Edelfreien von Regensberg (Thurgau) ebd. S. 1-15. 


\section{2. Überblick über die Papsturkunden}

Für den Untersuchungszeitraum 1070-1216 sind insgesamt 309 Papsturkunden bekannt, die an Empfänger in der Erzdiözese Salzburg beziehungsweise in dessen Eigenbistum Gurk adressiert waren. Davon sind 189 (also mehr als 60\%) im Original erhalten, die restlichen Stücke sind entweder durch kopiale Überlieferung auf uns gekommen oder nur dadurch bekannt, dass sie in einer anderen Urkunde erwähnt werden oder ihre Existenz wenigstens zu erschließen ist; dies trifft häufig bei päpstlichen Delegationsreskripten zu, die verloren sind, aber in einer Beurkundung des Urteils genannt werden.

In der Regel darf davon ausgegangen werden, dass jeder Adressat eines Papstschreibens - vor allem von Mandaten - ein Exemplar desselben erhielt, es also oft mehrere „Originale“ gab, was insbesondere für die statistische Auswertung von Belang ist. Allerdings sind längst nicht alle diese Stücke überliefert, sondern meist nur eine Ausfertigung. Zusätzliche Probleme ergeben sich, wenn das betreffende Mandat nicht im Archiv eines der Adressaten überliefert ist, sondern in jenem des Begünstigten, der das Mandat wahrscheinlich impetriert hat ${ }^{2}$. In einem derartigen Fall ist es mehr als fraglich, ob die Adressaten jeweils ein eigenes Exemplar erhielten, oder ob ihnen nicht lediglich der Begünstigte das Schreiben vorgelegt hat. Da jedoch viele Schreiben gar nicht mehr im Original erhalten sind, müssen derartige Überlegungen im spekulativen Bereich bleiben und wurden daher - unter bewusster Inkaufnahme dieser Unschärfe - für die Statistik nicht berücksichtigt. Nach Jahrzehnten unterglie-

2 Ziemlich eindeutig ist dies bei einem Mandat Innozenz' III. für die (Dom-)pröpste von Salzburg und Berchtesgaden (1213), das wohl über eine Klage von Abt und Konvent von Michaelbeuern impetriert wurde und nur im Archiv dieses Klosters überliefert ist. Zudem hat Innozenz dem Kloster zwei Tage später ein Schutzprivileg ausgestellt. Nichts liegt also näher als die Annahme, dass ein nach Rom entsandter Vertreter Michaelbeuerns das Mandat zusammen mit dem Privileg mitgenommen hat. Dr.: Salzburger Urkundenbuch, hg. v. Willibald Hauthaler/Franz Martin, Bde. 1-4, Salzburg 1916-1933, hier Bd. 3 S. 166 Nr. 661. Ein Delegationsreskript desselben Papstes für die Äbte von St. Lambrecht und Admont und den Dompropst von Gurk ist allein im Archiv einer Streitpartei, dem Benediktinerstift Seitenstetten, nicht aber bei den Adressaten überliefert, Urkundenbuch des Benedictiner-Stiftes Seitenstetten, ed. P. Isidor RAAB, Wien 1870 (Fontes rerum Austriacarum 2/33), S. 28 Nr. 20. Ein auf Klage des Klosters Viktring hin ergangenes Delegationsreskript Innozenz' III., das an den Erzbischof von Salzburg und den Archipresbyter von Völkermarkt adressiert war, ist in unmittelbarer zeitlicher Nähe zu drei Privilegien/Bestitzbestätigungen für Viktring (März 1202) ausgestellt worden; am ehesten hat ein Abgesandter Viktrings auch das Delegationsreskript empfangen und den beiden Adressaten vorgelegt (Dr.: Monumenta Ducatus Carinthiae [in Hinkunft: MDC] Bd. 1-4/1, hg. v. August von Jaksch, Klagenfurt 1896-1906, hier Bd. 4/1 S. 4-9 Nr. 1527-1530). 
dert ergibt sich auf dieser Grundlage folgende Verteilung der Papsturkunden (einschließlich der Kardinalsurkunden) ${ }^{3}$ :

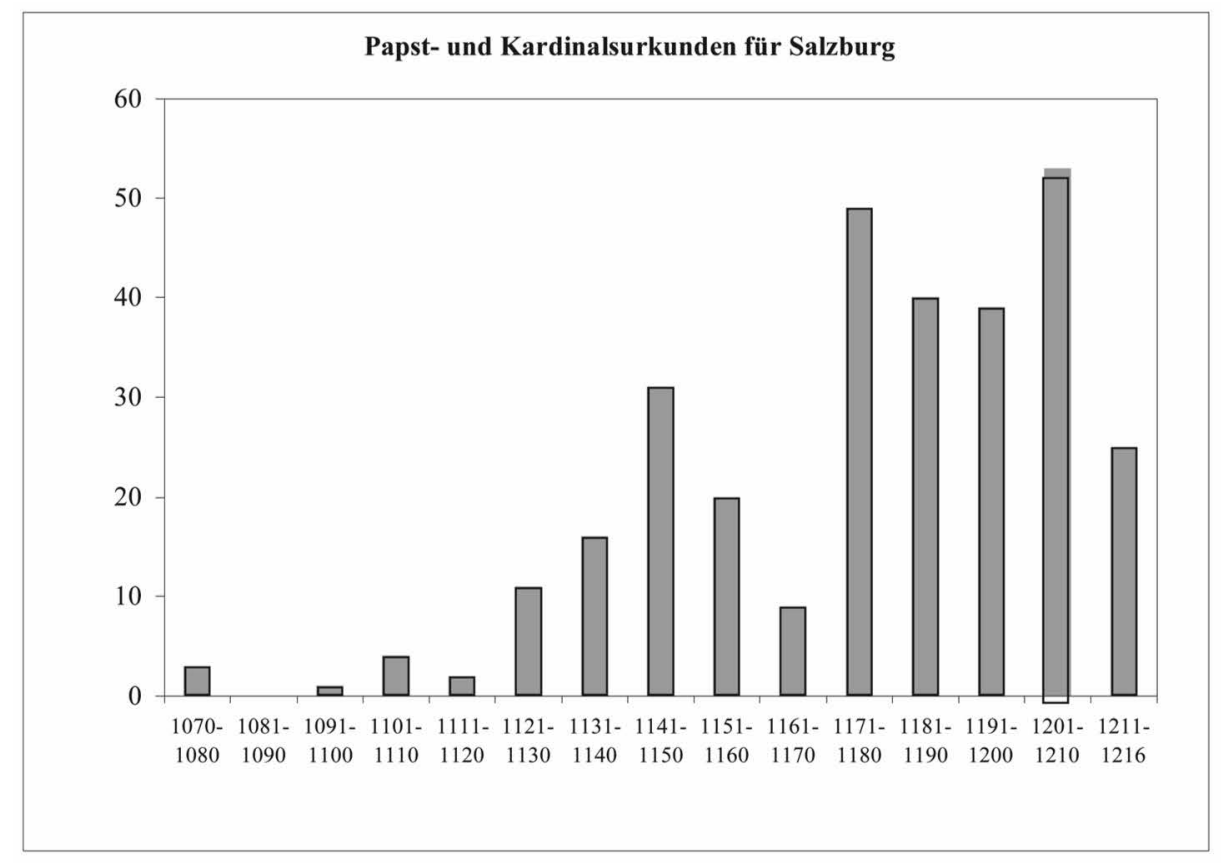

120 Stücke sind an die Salzburger „Zentrale“ adressiert; zahlenmäßig steht, wie nicht anders zu erwarten, der Erzbischof an der Spitze: Er wird bei 100 Papsturkunden als Empfänger genannt, 35 davon sind im Original überliefert. Inhaltlich sind diese Schreiben breit gestreut; sieben betreffen Verleihungen des Papstschutzes, sechsmal werden ihm andere Vorrechte verliehen. Fünfmal geht es um die Würde des ständigen Legaten in der gesamten Kirchenprovinz. Siebenmal wird der Erzbischof zu päpstlichen Synoden zitiert. So häufig wie kein anderer Kleriker wird er als päpstlich delegierter Richter eingesetzt, insgesamt sind sechzehn Delegationsreskripte überliefert beziehungsweise können erschlossen werden. Hervorzuheben sind ferner sechs Papstschreiben, die sich mit dem Alexandrinischen Schisma beschäftigen, welches auch ein Schisma im Erzbistum nach sich zog. Darüber hinaus sind weitere 50 Mandate zu verzeichnen, auf deren Inhalt weiter unten noch eingegangen wird. Hinzu kom-

3 Die Zahlen sind im Einzelnen: 1070-1080: drei Urkunden, 1081-1090: keine Urkunde, 1091-1100: eine Urkunde, 1101-1110: vier Urkunden, 1111-1120: zwei Urkunden, 1121-1130: elf Urkunden, 1131-1140: 16 Urkunden (davon 12 ab 1138), 11411150: 31 Urkunden, 1151-1160: 20 Urkunden, 1161-1170: neun Urkunden, 11711180: 49 Urkunden, 1181-1190: 40 Urkunden, 1191-1200: 39 Urkunden, 12011210: 59 Urkunden, 1210-1216: 25 Urkunden. 
men 19 Schreiben, die an das Domkapitel oder an eines seiner Mitglieder adressiert waren, zehn davon sind Besitzbestätigungen.

Die dominante Stellung des Erzbistums gegenüber seinem Eigenbistum wird schon durch den Zahlenvergleich mehr als deutlich. Der Gurker Bischof wird nur bei 13 Papsturkunden als Empfänger genannt. Das erst 1131 gegründete Domkapitel wiederum erhielt insgesamt 15 auf uns gekommene Papsturkunden im Untersuchungszeitraum, also nur unwesentlich weniger als das Salzburger Kollegium. Durch den langen Streit um das Recht zur Wahl eines Gurker Bischofs, welche zwischen dem Domkapitel und dem Salzburger Erzbischof jahrzehntelang umstritten war (circa 1145-1232) ${ }^{4}$, geriet das Domkapitel in den Fokus der Kurie, wo beide Parteien ihre Ansprüche geltend zu machen versuchten. Den Höhepunkt und zumindest vorläufigen Abschluss erreichte der Streit unter Innozenz' III.; neun der 15 Papsturkunden gehen auf ihn zurück, weil Gurker Prokuratoren ihre Aufenthalte an der Kurie auch zur Erledigung anderer Angelegenheiten nutzten: So erneuerte Innozenz fast zeitgleich mit der Bestätigung des Kompromisses über die Bischofswahl den Papstschutz für das Gurker Domkapitel und bestätigte die Schenkungen mehrerer Salzburger Oberhirten (1208) .

Nahezu jedes Kloster im Salzburger Diözesansprengel erhielt Papsturkunden, wobei die Zahlen der überlieferten Stücke stark voneinander abweichen. Insgesamt 149 Papsturkunden haben Empfänger in den Salzburger Klöstern und Stiften erhalten, sei es, dass der Abt, Propst oder eine andere Dignität genannt wird oder das Stück an den gesamten Konvent adressiert war. In dem kleinen Sprengel der Gurker Diözese gibt es kein Kloster. Die unterschiedlichen Zahlen mögen mit der unterschiedlichen Bedeutung der verschiedenen Institutionen zu tun haben, sicher aber auch mit dem Schicksal eines Klosters und seines Archivs in den folgenden Jahrhunderten. Besonders häufig bedacht wurden das steirische Benediktinerstift Admont, wo wir 15 überlieferte Papsturkunden zählen können, St. Paul im Lavanttal mit 13 und das AugustinerChroherrenstift Berchtesgaden mit zwölf. Demgegenüber ist etwa aus Rein, Vorau oder Frauenchiemsee nur je eine Papsturkunde erhalten geblieben.

Besonders intensiv bemühten sich die Klöster naturgemäß um den Papstschutz, vom Benediktinerstift Millstatt kennen wir sieben Schutzprivilegien, aus St. Paul im Lavanttal sogar acht. St. Peter im Salzburg, das mit dem Erzbistum am engsten verbundene Kloster, kann hingegen nur mit zwei überlieferten Schutzprivilegien aufwarten. Alles in allem erscheinen die zahlenmäßigen Unterschiede aber zu gering, um daraus Schlüsse über besondere Papstnähe oder Papstferne einer Institution ziehen zu können.

$4 \mathrm{Zu}$ diesem Streit ausführlich Rainer MURAUER: Die Geistliche Gerichtsbarkeit im Salzburger Eigenbistum Gurk, Wien/München 2009 (Veröffentlichungen des Instituts für Österreichische Geschichtsforschung 52).

5 Siehe unten S. 415f. Kap. 11.2. 
Kleriker, die keinem Kloster oder Stift als Mönch oder Chorherr angehörten, also Pfarrer, Archidiakone, Archipresbyter, tauchen nur dann aus dem Dunkel der Anonymität auf, wenn sie ein päpstliches Delegationsreskript erhielten. Am häufigsten wurde - wenig überraschend - der Erzbischof von Salzburg als delegierter Richter eingesetzt; immerhin sind acht Reskripte, die ihn in dieser Funktion benennen, entweder im Original oder kopial überliefert; noch einmal so viele können aus Erwähnungen in anderen Urkunden (Urteile, weitere Delegationen in derselben Sache) erschlossen werden. Neben dem Erzbischof ist der Abt von Raitenhaslach hervorzuheben, der immerhin in sechs Delegationsreskripten genannt wird, die alle aus den Pontifikaten Cölestins III. und Innozenz' III. stammen. Aber auch die Archidiakone von Pürgg, Friesach, Völkermarkt und Zeltschach, die Archipresbyter von Pürgg und Völkermarkt sowie die Pfarrer von Fischau am Steinfeld, Wiener Neustadt, St. Veit, Molzbichl und Tiffen finden sich unter den delegierten Richtern.

Vor der Regierungszeit Erzbischof Konrads I. (1106-1147) ist die Zahl der Papsturkunden minimal, ab den zwanziger Jahren des 12. Jahrhunderts sehen wir einen langsamen, aber fast stetigen Anstieg ${ }^{6}$, der zweimal in charakteristischer Weise unterbrochen wird. Für beide Einschnitte lassen sich plausible kirchenpolitische Gründe anführen. Zwar sind aus den dreißiger Jahren 16 Urkunden zu eruieren, immerhin fün mehr als im vorangegangenen Jahrzehnt, aber zwölf dieser 16 Stücke sind auf 1138 oder später zu datieren, also auf den Zeitraum nach dem Ende des Schismas zwischen Papst Innozenz II. (1130-1143) und dessen Gegenpapst Anaklet II.

Zeiten der Wirren wirken sich offenbar ungünstig auf die Rom-Kontakte und den Urkundenausstoß aus. Die sechziger Jahre des 12. Jahrhunderts zeigen ein gegenüber den Jahrzehnten davor und danach signifikant verringertes Aufkommen von Papsturkunden, gar eine Halbierung gegenüber den fünfziger Jahren, was man wiederum getrost den politischen Wirren der Zeit zuschreiben darf.

Erzbischof Eberhard I. (1147-1164) unterhielt in den ersten Jahren seiner Amtszeit noch exzellente Kontakte zu König Konrad III. (1138-1152), mit dem er mehrmals zusammentraf. Die Verschärfung der Auseinandersetzung zwischen Regnum und Sacerdotium unter Konrads Nachfolger Friedrich I. (1152-1190) zwang auch den Erzbischof zu einer Positionierung. Nach dem Zerwürfnis zwischen Kaiser und päpstlichen Gesandten auf dem Reichstag zu Besançon (1157), welches aus dem Standpunkt Papst Hadrians IV. (11541159), Friedrich habe das Kaisertum vom Papst als Lehen empfangen, resultier$\mathrm{te}^{7}$, nahm Eberhard in Übereinstimmung mit dem deutschen Episkopat zu-

6 Das letzte Jahrzehnt (1210-1216) muss wegen seiner Unvollständigkeit natürlich unter einem anderen Blickwinkel gesehen werden.

7 Zur Sache vgl. Walter HeINEMEYER: beneficium non feudum sed bonum factum. Der Streit auf dem Reichstag zu Besançon 1157, in: ADipl 15 (1969) S. 155-236. Allge- 
nächst für den Kaiser Partei ${ }^{8}$. Nach Hadrians Tod (1159) und der Wahl Alexanders III. (1159-1181) beziehungsweise des kaiserfreundlichen Gegenpapstes Viktor IV. sah sich der Erzbischof mit einem Schisma konfrontiert. Trotz seiner Parteinahme für Alexander, wodurch er auch in einen Gegensatz zur Mehrheit des deutschen Episkopats geriet, konnte der Erzbischof einen offenen Konflikt mit dem Kaiser vermeiden ${ }^{9}$. An Eberhards Seite verblieben Roman I. (1131-1167), der Bischof des Eigenbistums Gurk, und Hartmann von Brixen, während sich Regensburg eindeutig auf die kaiserliche Seite stellte, Passau und Freising wiederum neutral blieben. Im Gegensatz zu anderen Kirchenprovinzen, die sich relativ geschlossen für die eine oder andere Partei entschieden, war Salzburg also dreifach gespalten ${ }^{10}$. Dem Konzil von Pavia, das von Friedrich einberufen war, um Viktor IV. zum rechtmäßigen Papst erklären zu lassen, wusste sich Eberhard durch manche Täuschungsmanöver zu entziehen ${ }^{11}$.

Anfang der sechziger Jahre funktionierte die Kommunikation zwischen Papst und Erzbischof noch, wie das in der Admonter Briefsammlung überlieferte Schreiben Alexanders III. nachweist, mit welchem er Eberhard über die Exkommunikation des Kaisers und des Gegenpapstes informierte ${ }^{12}$.

Der Nachfolger Eberhards, Erzbischof Konrad II. (1164-1168), musste den nördlichen Teil seiner Erzdiözese aufgeben und sich nach Friesach und Admont zurückziehen, wo er - fern von seinem Bischofssitz - 1168 starb $^{13}$. Unter Konrads Nachfolger Adalbert III. wurde die kaiserliche Einmischung noch massiver ${ }^{14}$. Auf einem Regensburger Reichstag (1174) wurde der Erzbischof gar abgesetzt und ein Gegenerzbischof installiert, Propst Heinrich von Berchtesgaden. Adalberts geistliche Funktionen waren hiervon - da die Bischofsweihe natürlich gültig blieb - nicht betroffen. Das lokale Schisma fand

mein zum Verhältnis zwischen Friedrich und den Päpsten Johannes LAUDAGE: Alexander III. und Friedrich Barbarossa, Köln/Weimar/Wien 1997 (Forschungen zur Kaiser- und Papstgeschichte des Mittelalters, Beih. zu J. F. Böhmer RI 16).

8 Constitutiones et acta pubica imperatorum et regum I: 911-1197, ed. Ludwig WeILAND, Hannover 1893 (MGH Const. 1), S. 229-235, Nr. 164-168.

9 Vgl. Günther HöDL: Das Erzstift Salzburg und das Reich unter Kaiser Friedrich Barbarossa, in: Mitteilungen der Gesellschaft für Salzburger Landeskunde 14 (1974) S. 3755 .

10 Ebd. S. 39.

11 Heinz Dopsch: Salzburg im Hochmittelalter. Die äußere Entwicklung, in: Geschichte Salzburgs. Stadt und Land, Bd. 1: Vorgeschichte - Altertum - Mittelalter, 1. Teil, hg. v. Heinz DOPSCH, Salzburg ${ }^{2} 1983$, S. 229-336, hier S. $278 f$.

12 S. u. Kap. 3.6 mit Anm. 73.

13 Susanne WACH: Erzbischof Konrad II. Ein Beitrag zu seiner Biographie, Wien 1965 (phil. Diss.), S. $136 f$.

14 Christoph EGGER: Quellen zur Frühgeschichte des Schismas von 1159 im bayerischösterreichischen Raum: ein unbekannter Brief Gerhochs von Reichersberg?, in: MIÖG 112 (2004) S. 163-176. Roman DeUTINGER: Die Dietramszeller Kirchweihe von 1160 und die Formierung der alexandrinischen Partei in Bayern, in: Beiträge zur altbayerischen Kirchengeschichte 47 (2003) S. 33-50. 
ein Ende zeitgleich mit dem Alexandrinischen Schisma. Der Friedensschluss von Venedig zwischen Papst und Kaiser (1177) zog die Resignation beider Erzbischöfe nach sich, die Neuwahl fiel auf Kardinal Konrad von Wittelsbach, der auf das Erzbistum Mainz verzichtet hatte ${ }^{15}$. Schon in den siebziger Jahren ist aber eine drastische Vermehrung der Papsturkunden zu konstatieren.

Der Einschnitt durch das Epochenjahr 1198 - die völlig veränderte Überlieferungschance für Papsturkunden durch den Beginn der fast lückenlos im Vatikanischen Geheimarchiv erhaltenen Serie von Papstregistern - verändert die Zahlenbilanz tatsächlich; die Zahl der aus dem Pontifikat Innozenz' III. überlieferten Urkunden ist größer als die aus den Jahren davor, jedoch ist dies zum geringsten Teil auf das Vorhandensein der Kanzleiregister zurückzuführen $^{16}$. Lediglich ein Delegationsreskript in der Ehesache des Böhmenkönigs Otakar I. ist ausschließlich durch die Überlieferung im Register auf uns gekommen; ferner ein Mandat für Erzbischof Eberhard II., über den Babenbergerherzog Leopold VI. gegebenenfalls Bann und Interdikt zu verhängen ${ }^{17}$. Bei allen anderen Urkunden Innozenz' III. für unseren Untersuchungsraum liegt eine Empfängerüberlieferung vor. Generell ist die Zahl der erhalten gebliebenen Delegationsreskripte unter Innozenz III. viel größer als davor, was als Indiz für die verstärkte Anwendung dieses Instruments zur Untersuchung von lokalen Streitfällen gewertet werden darf, weniger als Hinweis auf eine verbesserte Überlieferungschance einzelner Stücke, die ja nach Durchführung des Auftrages beziehungsweise Ende des Prozesses rechtlich obsolet wurden. Insgesamt ist unter Innozenz III. nur eine leichte Zunahme von Papsturkunden zu konstatieren, ein mindestens so großer Einschnitt scheint die Beendigung des oben erwähnten Alexandrinischen Schismas zu sein, in welches auch das Erzbistum Salzburg verwickelt worden war.

Die Überlieferungschance von Privilegien (im Original) ist wesentlich gröBer als die von Mandaten aller Art, etwa Delegationsreskripten. So sind sechs der sieben Schutzprivilegien für den Erzbischof von Salzburg im Original erhalten, aber nur sechs von 16 Urkunden, in welchen der Erzbischof als Delegat mit einem päpstlichen Auftrag bedacht wird. Bei den Klöstern verhält es sich im Prinzip ähnlich; zehn der elf Privilegien für das Benediktinerstift St. Paul im Lavanttal sind im Original überliefert (das elfte ist übrigens eine - ebenfalls erhaltene - Fälschung), fünf von sieben Schutzprivilegien für Millstatt (wie auch für St. Lambrecht). Für die Chorherrenstifte gilt ein ähnlicher Befund wie für die Mönchsklöster: Sechs von acht Privilegien für Baumburg, alle fünf für Berchtesgaden sind im Original erhalten. Bei Klöstern, deren Urkundenbe-

$15 \mathrm{Zu}$ den politischen Ereignissen DopsCH: Salzburg im Hochmittelalter (wie in Anm. 11) S. 284-296.

$16 \mathrm{Zu}$ den päpstlichen Registern vor Innozenz III. vgl. Rudolf SCHIEFFER: Die päpstlichen Register vor 1198, in: Das Papsttum und das vielgestaltige Italien. Hundert Jahre Italia Pontificia, hg. v. Klaus HerBers/Jochen JohrendT, Berlin/New York 2009 (AAG, N. F. 5), S. 261-273.

17 Dr.: Migne PL 216, Sp. 150, Nr. 120 (1209). 
stand generell sehr klein ist, ist die Stichprobe der überlieferten Urkunden wenig bis gar nicht aussagekräftig

Andererseits ist von den insgesamt sieben uns bekannten Schreiben, die einen Salzburger Erzbischof zu einer päpstlichen Synode luden, und von drei weiteren, die einen anderen Kleriker aus dem Diözesangebiet nennen, kein einziges im Original erhalten geblieben. Von den sechzehn Delegationsreskripten für den Erzbischof sind nur sechs im Original überliefert, zwei weitere auf kopialem Wege, und acht können aus Erwähnungen in anderen Schreiben erschlossen werden. Etwas abweichend ist der Befund für das Zisterzienserstift Raitenhaslach, dessen Abt sechsmal als delegierter Richter nominiert wurde, wobei nicht weniger als fünf der entsprechenden päpstlichen Reskripte im Original erhalten blieben. Mehr als der Zufall der Überlieferung kann auch daraus nicht herausgelesen werden. Die für das Amt des delegierten Richters Ausersehenen sind in der Regel die Spitzen eines Bistums (Bischof, Dompropst, Domdekan) oder einer Klostergemeinschaft, also Äbte und Pröpste. Von den weiteren Dignitäten taucht nur der Dekan von Berchtesgaden auf.

\section{Papsturkunden für die Erzbischöfe von Salzburg}

Die ersten erhaltenen Papsturkunden aus unserem Untersuchungszeitraum betreffen das schon mehrfach dargestellte einschneidende Ereignis, die Gründung des Eigenbistums Gurk unter Alexander II. im Jahre $1070^{18}$ und die damit in ursächlichem Zusammenhang stehende Mahnung seines Nachfolgers Gregor VII. an Erzbischof Gebhard, Gurk mit Zehnten auszustatten (1075) ${ }^{19}$.

\subsection{Pallienverleihungen}

Die Verleihung der für die Befugnisse eines Metropoliten zentralen Insignie gab den Anlass für regelmäßige Kontaktaufnahmen zwischen Salzburg und Rom. Es sei daher gestattet, bei diesem Thema über den eigentlichen Untersuchungszeitraum hinauszugreifen. Nicht jede Pallienverleihung ist überliefert, aber ist gibt doch eine stattliche Anzahl von entsprechenden Urkunden. Schon für den ersten Metropoliten, Arn (785-821), ist eine Verleihungsurkunde überliefert. Der Inhalt des an einigen Stellen verderbten Stückes wird durch die annalistische und chronikale Überlieferung gestützt ${ }^{20}$.

18 Dr.: Salzburger UB (wie Anm. 2) Bd. 2 S. 169-171 Nr. 102; Reg.: GP 1 S. 17f. Nr. 40.

19 Dr.: Das Register Gregors VII., ed. Erich CASPAR, Berlin 1920-1923 (MGH Epp. sel. 2/1-2), II/77 S. 240f. (1075 Juni 17); Salzburger UB (wie Anm. 2) Bd. 2 S. 177 f. Nr. 109; Reg.: GP 1 S. 19 Nr. 43.

20 Dr.: Salzburger UB (wie Anm. 2) Bd. 2 S. 2-4 Nr. 2a (kopiale Überlieferung); Reg.: GP 1 S. 8 Nr. 7. Vgl. z. B. Annales Iuvanenses maiores ad a. 798, ed. Harry BRESS- 
Für die spätkarolingische Epoche sind Urkunden über Palliumsverleihungen nahezu lückenlos erhalten geblieben, so von Papst Eugen II. für Erzbischof Adalram (821-836) von 824 ${ }^{21}$, von Gregor IV. für Liupramm (836-859) von $837^{22}$, von Nikolaus I. für Adalwin (859-873) von $860^{23}$. Erzbischof Thietmar (873-907) erhielt das Pallium 877 von Papst Johannes VIII. ${ }^{24}$

Nach der vernichtenden Niederlage des bayerischen Heeres in der Schlacht von Preßburg gegen die Ungarn, in der auch Erzbischof Thietmar fiel (907), verlor das Erzbistum den größten Teil seines slawischen Missionsgebietes und fast alle dort erworbenen Besitzungen ${ }^{25}$. Auch die schriftliche Überlieferung ging offenbar drastisch zurück, zwischen 909 und 940 ist überhaupt keine Urkunde für Salzburger Empfänger überliefert; somit ist auch keine Bestätigung über einen zu vermutenden Palliumsempfang durch die Erzbischöfe Pilgrim I. (907-923), Adalbert I. (923-935), Egilolf (935-939) und Herold (939/940-958) zu bekommen. Auch die eigentliche Palliumsverleihung an Erzbischof Friedrich I. (958-991) ist nicht überliefert, allerdings erlaubte ihm Papst Johannes XII. 962, das Pallium, das ihm möglicherweise schon 958 verliehen worden war, an vier weiteren Festtagen zu tragen ${ }^{26}$. Von der Palliums-

LAU, in: MGH SS 30/2, Leipzig 1934, S. 727-744, hier S. 736; Conversio Bagoariorum et Carantanorum ad a. 798, ed. Fritz LOSEK: Die Conversio Bagoariorum et Carantanorum und der Brief des Erzbischofs Theotmar von Salzburg, Hannover 1997 (MGH Studien und Texte 15), S. 114, sowie das Schreiben Papst Leos III. an Karl den Großen bzw. die bayerischen Bischöfe über diesen Vorgang: Salzburger UB (wie Anm. 2) Bd. 2 S. 4f. Nr. 2b, S. 5-7 Nr. 2c.

21 Dr.: Salzburger UB (wie Anm. 2) Bd. 2 S. 19f. Nr. 7b (kopiale Überlieferung); Reg.: GP 1 S. 10 Nr. 13.

22 Dr.: Salzburger UB (wie Anm. 2) Bd. 2 S. 27-29 Nr. 13 (kopiale Überlieferung); Reg.: GP 1 S. 10 Nr. 14.

23 Dr.: Salzburger UB (wie Anm. 2) Bd. 2 S. 35f. Nr. 19 (kopiale Überlieferung), Reg.: GP 1 S. 11 Nr. 17.

24 Dr.: Salzburger UB (wie Anm. 2) Bd. 2 S. 45 Nr. 24b (im abschriftlich überlieferten Register Johannes' VIII. erhalten); Reg.: GP 1 S. 12 Nr. 24. Vgl. Dietrich LOHRMANN: Das Register Papst Johannes' VIII. Neue Studien zur Abschrift Reg. Vat. 1, zum verlorenen Originalregister und zum Diktat der Briefe, Tübingen 1968 (Bibliothek des Deutschen Historischen Instituts in Rom 30). Die Registerhandschrift ist in das 11. Jahrhundert zu datieren.

25 Zur Schlacht vgl. Annales Iuvanenses maximi ad a. 907, ed. Harry BRESSLAU, in: MGH SS 30/2, Leipzig 1934, S. 727-744, hier S. 742. Zur Teilnahme der bayerischen Bischöfe an der Schlacht Friedrich PRINZ: Klerus und Krieg im frühen Mittelalter, Stuttgart 1971 (Monographien zur Geschichte des Mittelalters 2) S. $143 \mathrm{f}$.

26 Dr.: Salzburger UB (wie Anm. 2) Bd. 2 S. 86-89 Nr. 49 = Die Papsturkunden 8961046, bearb. v. Harald ZIMMERMANN, 3 Bde., Wien ${ }^{2} 1988-1989$ (DÖAW, phil.-hist. Klasse 174, 177 u. 198), Bd. 1 S. 277-279 Nr. 152 (kopiale Überlieferung); Reg.: RI 2/5 Nr. 277; GP 1 S. 14 Nr. 31. Heinz DopSCH: Die Zeit der Karolinger und Ottonen, in: DERS.: Geschichte Salzburgs (wie in Anm. 11) Bd. 1 S. 157-228, hier S. 208 datiert die Pallienverleihung ohne Wenn und Aber ins Jahr 958; mangels Quellen muss dies dennoch Spekulation bleiben. 
verleihung an Friedrichs Nachfolger Hartwig (991-1023) durch Papst Johannes XV. im Jahre 993 haben wir wieder urkundliche Nachricht ${ }^{27}$.

Während aus der kurzen Amtszeit Bischof Gunthers (1023-1025), des Kanzlers Kaiser Heinrichs II., keine Nachrichten überliefert sind, ist die Palliumsverleihung für Thietmar II. (1025-1041) durch Papst Johannes XIX. (1026) auf uns gekommen. Wie die meisten frühen Papsturkunden für Salzburger Empfänger ist sie nicht im Original, sondern nur in den sogenannten Salzburger Kopialbüchern überliefert, daher in manchen Passagen fragwürdig; insbesondere ist die Datierung verderbt ${ }^{28}$.

Für die frühsalische Zeit ist erneut das Fehlen von Papsturkunden zu konstatieren, somit ist auch die Verleihung des Palliums an Erzbischof Balduin (1041-1060) nicht dokumentiert. Über die Übergabe des Palliums an Gebhard berichten die Gesta episcoporum Salisburgensium; hier erfahren wir auch, dass Gebhard offenbar nicht persönlich vor Papst Alexander II. erschien, sondern der (Dom-)propst Wezilin ihm 1062 das Pallium überbrachte ${ }^{29}$. Die erste im Original überlieferte Papsturkunde für Gebhard ist übrigens auf das Jahr 1070 datiert, als ihm Alexander II. die Erlaubnis erteilte, in seinem Sprengel ein Bistum zu gründen, und ihm dabei das Recht einräumte, Einsetzung, Investitur und Weihe des neuen Bischofs selbst vorzunehmen ${ }^{30}$.

Hinsichtlich Gebhards Nachfolger Thiemo (1090-1098) schweigt die urkundliche Überlieferung erneut; die Vita des Passauer Bischofs und päpstlichen Legaten Altmann (1065-1091) berichtet, dass Papst Urban II. ihm das Pallium gesendet habe, damit er es Thiemo übergebe ${ }^{31}$ - der zweite Nachweis einer indirekten Verleihung des Palliums über einen päpstlichen Mittelsmann, ohne

27 Dr.: Salzburger UB (wie Anm. 2) Bd. 2 S. 114f. Nr. 62 = ZimmeRmanN: Papsturkunden (wie Anm. 26) Bd. 1 S. 623f. Nr. <319 (kopiale Überlieferung). Das Stück ist teilweise verderbt. Vgl. dazu die einleitenden Bemerkungen der Edition und GP 1 S. 16 Nr. 36; RI 2/5 Nr. 719; Heinrich FiCHTENAU: Das Urkundenwesen in Österreich vom 8. bis zum frühen 13. Jahrhundert, Wien u. a. 1971 (MIÖG Ergänzungsbd. 23) S. 156.

28 Dr.: Salzburger UB (wie Anm. 2) Bd. 2 S. 129-131 Nr. 74 = ZimmeRmanN: Papsturkunden (wie Anm. 26) Bd. 2 S. 1072f. Nr. 566 (kopiale Überlieferung). Vgl. die Vorbemerkung und GP 1 S. 17 Nr. 37. An der Echtheit wird nicht gezweifelt.

29 Gesta archiepiscoporum Salisburgensium, ed. Wilhelm WATTENBACH, in: MGH SS 11, Hannover 1854, S. 1-103, hier S. 35 Z. 43-45.

30 Salzburger UB (wie Anm. 2) Bd. 2 S. 169-171 Nr. 102 (Original); Reg.: GP 1 S. 17 Nr. 40. Diese Papsturkunde und eine zwei Jahre später ausgestellte Urkunde König Heinrichs IV. (Salzburger UB [wie Anm. 2] Bd. 2 S. 171f. Nr. $103=$ MGH D H IV 253) leiteten die Gründung des ersten Salzburger Eigenbistums Gurk ein. Vgl. MURAUER: Gurk (wie Anm. 4) S. 13-30.

31 Vita Altmanni c. 30, ed. Wilhelm WattenBACH, in: MGH SS 12, Hannover 1856, S. 226-243, hier S. 238. Vgl. GP 1 S. 19 Nr. 45. Vgl. Gerold MeyeR von KNONAU: Jahrbücher des Deutschen Reiches unter Heinrich IV. und Heinrich V., 7 Bde., Berlin 1890-1909 (Jahrbücher der deutschen Geschichte 14), hier Bd. 4 S. 290f. mit Anm. 33. 
dass der gewählte und geweihte Erzbischof nach Rom gekommen wäre. Der kaiserliche Gegenerzbischof Berthold von Moosburg (1085-1106), der sich erst nach Thiemos Tod in Salzburg durchsetzen konnte, darf hier außer Betracht bleiben, da ihm der Zugang zum Pallium verwehrt blieb.

Für die Verleihung des Palliums an Konrad I. (1106-1147) gilt dasselbe wie für seinen Vorgänger Thiemo, nur erzählende Quellen berichten über dessen Empfang ${ }^{32}$, die urkundlichen Zeugnisse sind in den ersten fünfzehn Jahren seines Wirkens generell sehr spärlich. Trotz verdichteter Überlieferung um die Mitte des 12. Jahrhunderts hat sich auch kein urkundlicher Beleg der Verleihung des Palliums an Eberhard I. (1147-1164) erhalten, die Vita Eberhards und die Salzburger Annalistik bieten Abhilfe ${ }^{33} .1152$ (von Eugen III.) und 1157 (von Hadrian IV.) wurde ihm allerdings das Recht, das Pallium an bestimmten Tagen zu tragen, mittels Privileg bestätigt ${ }^{34}$.

1164/65 ist zum zweiten Mal - abermals nur von erzählenden Quellen dokumentiert, dass das Pallium nicht persönlich vom Erzbischof empfangen, sondern ihm von mehreren Gesandten überbracht wurde, die zu dem sich gerade in Frankreich aufhaltenden Papst Alexander III. reisten ${ }^{35}$. Der vom Passauer Bischofsstuhl nach Salzburg transferierte, aus dem österreichischen Herzogsgeschlecht der Babenberger stammende Konrad II. (1164-1168) zog es mitten im Alexandrinischen Schisma - wiewohl prinzipiell, wenn auch nicht so kompromisslos wie sein Vorgänger Eberhard I., auf Seiten des Papstes stehend $^{36}$ - vor, auf die Reise zu dem im Exil weilenden Alexander zu verzichten.

Umstritten war auch die Einsetzung seines Nachfolgers Adalbert III. (1168-1177, 1183-1200). Adalbert, der Sohn des böhmischen Königs Ladislaus (Wladislaw) und der Babenbergerin Gertrud, der Schwester seines Vorgängers Konrad II., wurde 1168 zum Bischof gewählt. Die Weihe zum Diakon, Pries-

32 Vgl. die Zusammenstellung bei GP 1 S. 20 Nr. 47; MEYER VON KNONAU (wie Anm. 31) Bd. 6 S. 32 mit Anm. 42.

33 Vita Eberhardi c. 4, ed. Wilhelm WATTEnBACH, in: MGH SS 11, Hannover 1854 (Nachdr. Stuttgart 1968), S. 84-103, hier S. 99; Annales s. Rudberti Salisburgenses ad a. 1147, ed. Wilhelm WatTeNBACH, in: MGH SS 9, Hannover 1851 (Nachdr. Stuttgart/New York 1963), S. 758-810, hier S. 775.

34 Dr.: Salzburger UB (wie Anm. 2) Bd. 2 S. 411f., S. 452-454 Nr. 295, 326; Reg.: GP 1 S. $25 \mathrm{Nr} .77,79$. Das erste der beiden Stücke ist im Original überliefert.

35 Die Datierungen weichen voneinander ab: Annales Reichersbergenses ad a. 1165, ed. Wilhelm WATTENBACH, in: MGH SS 17, Hannover 1861, S. 443-476, hier S. 471; Annales s. Rudberti ad a. 1164, ed. WATtenBACH (wie Anm. 33) S. 776. Reg.: GP 1 S. 31 Nr. *99; MDC (wie Anm. 2) Bd. 1 S. 190 Nr. 245.

36 Friedrich Barbarossa zitierte Konrad II. 1164 zu einem Hoftag nach Bamberg, strebte dessen Verurteilung durch ein bischöfliches Gericht an - was allerdings nicht zustande kam - und verweigerte ihm die Belehnung mit den Regalien. Vgl. DopsCH: Salzburg im Hochmittelalter (wie Anm. 11) S. 285. 
ter und Bischof empfing er im März $1169^{37}$. Erst acht Tage später erhielt er die Bestätigung der Wahl durch den Papst. Das Pallium wurde ihm durch Konrad von Wittelsbach, den Mainzer Erzbischof und Kardinallegaten, überbracht ${ }^{38}$. Nach Adalberts Deposition - eine direkte Folge des 1177 geschlossenen Friedensvertrages von Venedig zwischen Barbarossa und Alexander III. - fiel die Wahl auf eben jenen Konrad von Wittelsbach; während er auf die Mainzer Würde mit der Translation nach Salzburg verzichtete, behielt er das suburbikarische Bistum Sabina. Eine Verleihung des Palliums war in seinem Falle selbstredend nicht erforderlich. Nach Konrads Rückkehr nach Mainz (1183) wurde Adalbert zum zweiten Mal gewählt und wieder in Salzburg eingesetzt (bis $1200)^{39}$.

Danach wählte man wieder einen auswärtigen Bischof an die Spitze des Erzbistums, nämlich Eberhard, den Bischof von Brixen (1196-1200). Auch Eberhard verzichtete auf die Romreise. Er sandte vielmehr seinen Dompropst Berthold zur Einholung des Palliums. Papst Innozenz III. nutzte dieses Begehren, um die Postulation Eberhards zu verwerfen, die bereits von ihm vorgenommenen Amtshandlungen für ungültig zu erklären und ihn zur Rückkehr nach Brixen aufzufordern. Nach einer erneuten Wahl, die wiederum auf Eberhard fiel, und dem Tod des Dompropstes reiste der Elekt nun selbst nach Rom; er erreichte die Anerkennung durch den Papst und die Verleihung des Palliums ${ }^{40}$.

Papsturkunden über Palliumsverleihungen sind jedenfalls in der nachkarolingischen Zeit rar: Aus dem 10. Jahrhundert ist nur eine einzige einschlägige Urkunde überliefert (Hartwig, 991); Nämliches gilt für das 11. Jahrhundert (Thietmar II., 1026) - und darüber hinaus sind beide Urkunden nicht im Original erhalten geblieben. Sämtliche Verleihungen des 12. Jahrhunderts sind nur aus Chroniken und Annalen auf uns gekommen - was insofern erstaunt, als etwa seit 1120 ein deutlicher Anstieg der überlieferten Urkunden - auch Papsturkunden - für Salzburger Empfänger zu bemerken ist. Was bei Gebhard (1062) und Thiemo (1090) noch exzeptionell war - die Übergabe des Palliums durch einen päpstlichen Legaten - wird ab der Mitte des 12. Jahrhunderts zur Regel: Weder Konrad II. noch Adalbert III. nahm die Reise an den päpstlichen Hof auf sich. In beiden Fällen mag der Hinweis auf das Alexandrinische Schisma zur Begründung ausreichen (der Papst weilte damals auch nicht in Rom); schwieriger ist die Beurteilung der Handlungsweise Eberhards II. An seiner Parteinahme für den staufischen Thronprätendenten Philipp kann nicht gezweifelt werden, familiäre Rücksichten (sein Onkel Diethelm von Krenkin-

37 Chronicon Magni presbiteri ad. a. 1169, ed. Wilhelm WATTENBACH, in: MGH SS 17, Hannover 1861, S. 476-523, hier S. 489.

38 Chronicon Magni presbiteri ad. a. 1177 (wie Anm. 37) S. 503f.; GP 1 S. 31 Nr. ${ }^{*} 101$.

39 Vgl. Dopsch: Salzburg im Hochmittelalter (wie Anm. 11) S. $296 f$.

40 Annales s. Rudberti Salisburgensi ad a. 1200, ed. Wattenbach (wie Anm. 33) S. 779; MDC (wie Anm. 2) Bd. 1 S. 280f. Nr. 380f. 
gen war Bischof von Konstanz und ein einflussreicher Parteigänger Philipps von Schwaben) mögen eine wesentliche Rolle gespielt haben. Jedenfalls gehörte er 1199 als Elekt von Brixen zu den Unterzeichnern der als Speyrer Protest bekannten Intervention zahlreicher geistlicher und weltlicher Reichsfürsten zu Gunsten Philipps ${ }^{41}$. Hinzu kommt die schon beschriebene Auseinandersetzung um seinen Wechsel von Brixen nach Salzburg. Die zweite Wahl und die damit verbundene Stärkung seiner Position haben ihn anscheinend veranlasst, den direkten Kontakt mit dem Papst zu suchen.

\subsection{Verleihungen des päpstlichen Schutzes}

Eine größere Chance, der Nachwelt - auch im Original - erhalten zu bleiben, hatten die päpstlichen Schutzverleihungen, die anders als das Pallium, das nur dem jeweiligen Erzbischof-Elekten ad personam zugedacht war, dem privilegierten Institut einen auf Dauer angelegten Vorteil versprachen. Davon finden sich im 12. Jahrhundert mehrere: 1157 für Erzbischof Eberhard I. mit Bestätigung der Suffraganbistümer und - wie oben erwähnt - des Palliums ${ }^{42} ; 1179$ durch Alexander III. für Konrad III. mit Bestätigung der umstrittenen Investitur der Gurker Bischöfe ${ }^{43}$, ähnlich noch einmal durch Lucius III. für Konrad III. $1182^{44}$ und 1184 auf dem Konzil von Verona für Erzbischof Adalbert ${ }^{45}$; auf 1201 ist eine erneute Konfirmation durch Innozenz III. datiert ${ }^{46}$.

\subsection{Verleihung der Legatenwürde}

Erzbischof Eberhard I. wurde 1163 von Alexander III. zum legatum in regno Teutonico bestellt ${ }^{47}$ - eine Auszeichnung, die sicher auch mit seiner politischen Gesinnung in Verbindung zu bringen ist, war doch Eberhard zu jener Zeit der einzige prononciert alexandrinisch gesinnte Metropolit in Deutschland. Seit 1179 fungierte der Erzbischof als ständiger Legat (legatus natus) in seiner gesam-

41 Regestum Innocentii III papae super negotio Romani imperii (künftig: RNI), ed. Friedrich KemPF S. J., Roma 1947 (Miscellanea Historiae Pontificiae 12), S. 33-38 Nr. 14.

42 Dr.: Salzburger UB (wie Anm. 2) Bd. 2 S. 452-454 Nr. 326 (kopial überliefert); Reg.: GP 1 S. 25 Nr. 79.

43 Dr.: Salzburger UB (wie Anm. 2) Bd. 2 S. 577-580 Nr. 419 (Original); Reg.: GP 1 S. 40f. Nr. 134.

44 Dr.: Salzburger UB (wie Anm. 2) Bd. 2 S. 589-591 Nr. 428 (Original); Reg.: GP 1 S. 42 Nr. 140.

45 Dr.: Salzburger UB (wie Anm. 2) Bd. 2 S. 603-605 Nr. 442 (Original); Reg.: GP 1 S. 43 Nr. 142.

46 Dr.: Salzburger UB (wie Anm. 2) Bd. 3 S. 4-7 Nr. 537 (Original).

47 Dr.: Salzburger UB (wie Anm. 2) Bd. 2 S. 514f. Nr. 367 (Original); Reg.: GP 1 S. 30 Nr. 95. Das Schreiben ist an alle Bischöfe und Kleriker im Reich gerichtet. Das im Wiener Haus-, Hof- und Staatsarchiv aufbewahrte Exemplar ist jenes für Salzburg. 
ten Kirchenprovinz - die persönlich vorgetragene Bitte Erzbischof Konrads III. veranlasste den Papst zu diesem Schritt, wie er in einem Schreiben an alle Prälaten der Salzburger Kirchenprovinz mitteilte ${ }^{48}$; Lucius III. bestätigte diesen Status 1182 für Konrad und 1184 für dessen Nachfolger Adalbert III. ${ }^{49}$, Cölestin III. 1194 abermals für Adalbert ${ }^{50}$.

\subsection{Verleihung weiterer Vorrechte}

1026 wurde Erzbischof Thietmar II. von Papst Johannes XIX. neben dem Pallium auch das Recht verliehen, sich ein Kreuz vortragen zu lassen und an Festtagen auf einem rot gezierten Pferd zu reiten ${ }^{51}$. Diese Vorrechte sind zwar außergewöhnlich, jedoch keineswegs exklusiv dem Salzburger Oberhirten vorbehalten. Es sei hier nur auf die Papsturkunden für Magdeburg (1012), Mainz (1012), Hamburg (1047) und Trier (1049) verwiesen ${ }^{52} .1179$ wurden diese Vorrechte von Papst Alexander III. bestätigt ${ }^{53}, 1182$ und 1184 von Lucius III. ${ }^{54}$ Nur ungefähr zu datieren ist die von Hadrian IV. verfügte Ausweitung der Tage, an denen Priester und Diakone geweiht werden durften (circa $1157 / 59)^{55}$. 1211 erhielt Eberhard II. von Innozenz III. die Erlaubnis, Brandstiftern und anderen Verbrechern unter gewissen Bedingungen die Absolution zu erteilen ${ }^{56}$. Die Mitwirkung des Erzbischofs an der Wahl des Gurker Bischofs

48 Dr.: Salzburger UB (wie Anm. 2) Bd. 2 S. $580 f$. Nr. 420 (Original); Reg.: GP 1 S. 41 Nr. 135.

49 Dr.: Salzburger UB (wie Anm. 2) Bd. 2 S. 589-591 u. 603-605 Nr. 428 u. 442 (beide Originale); Reg.: GP 1 S. 42f. Nr. 140, 142.

50 Dr.: Salzburger UB (wie Anm. 2) Bd. 2 S. 666f. Nr. 493 (Original); Reg.: GP 1 S. 44 Nr. 149.

51 Dr.: Salzburger UB (wie Anm. 2) Bd. 2 S. 129-131 Nr. 74 (kopial überliefert). Vgl. Heinz DOPSCH: Legatenwürde und Primat der Erzbischöfe von Salzburg, in: Institutionen, Kultur und Gesellschaft im Mittelalter. Festschrift für Josef Fleckenstein zu seinem 65. Geburtstag, hg. v. Lutz FENSKE/Werner RÖSENER/Thomas ZOTZ, Sigmaringen 1984, S. 265-284.

$52 \mathrm{Zu}$ den bis 1046 verliehenen Vorrechten vgl. Jochen JOHRENDT: Papsttum und Landeskirchen im Spiegel der päpstlichen Urkunden (896-1046), Hannover 2004 (MGH Studien und Texte 33), S. 168-181.

53 Dr.: Salzburger UB (wie Anm. 2) Bd. 2 S. 577-580 Nr. 419 (Original); Reg.: GP 1 S. 40f. Nr. 134.

54 Dr.: Salzburger UB (wie Anm. 2) Bd. 2 S. 589-591 u. 603-605 Nr. 428 u. 442 (Originale). S. oben Anm. 49.

55 Dr.: Acta pontificum Romanorum inedita, ed. Julius von Pflugk-HaRtTung, 3 Bde., Tübingen/Stuttgart 1881-1886, hier Bd. 2 S. 363 Nr. 412 (Original); Reg.: GP 1 S. 26 Nr. 81. Winfried STELZER: Gelehrtes Recht in Österreich. Von den Anfängen bis zum frühen 14. Jahrhundert, Wien u. a. 1982 (MIÖG Ergänzungsbd. 26), S. 20 tritt für eine Datierung auf 1158 ein. Salzburger UB (wie Anm. 2) Bd. 4 S. 468f. Nr. 394.

56 Dr.: Salzburger UB (wie Anm. 2) Bd. 3 S. 144f. Nr. 643 (Original). 
regelte Innozenz III. 120857. 1216 erlaubte er Erzbischof Eberhard II. die Gründung eines weiteren Eigenbistums auf Herrenwörth im Chiemsee mit Einrichtung eines Sprengels ${ }^{58}$.

\subsection{Der Erzbischof als päpstlich delegierter Richter}

Erzbischof Konrad I. wurde - soweit wir wissen - nur einmal als delegierter Richter eingesetzt; er sollte 1144 im Auftrag Cölestins II. einen Streit zwischen den Klöstern Benediktbeuern und Admont um einen ins Kloster eingetretenen Adeligen entscheiden ${ }^{59}$.

Mehrfach wurde hingegen Konrads Nachfolger, Erzbischof Eberhard I., im Jahre 1151 von Papst Eugen III. mit der Entscheidung von Streitigkeiten beauftragt: Sowohl zwischen dem Abt von St. Lambrecht und der Gräfin Sophie von Schala als auch zwischen den Äbten von Göttweig und Rott am Inn führte er einen Vergleich herbei ${ }^{60}$. Päpstliche Delegationsreskripte sind in beiden Fällen nicht überliefert, wohl aber erzbischöfliche Schreiben an die Streitparteien über das Ergebnis. Ebenfalls 1151 verklagte der Abt der Zisterze Baumgartenberg den Bischof von Passau vor dem Papst wegen des Nachlasses Ottos von Machland, und Erzbischof Eberhard erhielt seinen dritten nachweisbaren Auftrag in diesem Jahr ${ }^{61}$.

Aus den folgenden Jahrzehnten - bis Ende der achtziger Jahre des 12. Jahrhunderts - ist keine Mitgliedschaft eines Erzbischofs in einem Richterkollegium bekannt. Dies mag an der unübersichtlichen politischen Lage in- und au-

57 Dr.: Salzburger UB (wie Anm. 2) Bd. 3 S. 111-115 Nr. 619 (Original).

58 Dr.: Salzburger UB (wie Anm. 2) Bd. 3 S. 200-202 Nr. 692 (Original). Vgl. Engelbert WALLNER: Das Bistum Chiemsee im Mittelalter (1215-1508), Rosenheim 1967 (Quellen und Darstellungen zur Geschichte der Stadt und des Landeskreises Rosenheim 5), S. 11.

59 Dr.: Urkundenbuch des Herzogthums Steiermark, ed. Joseph vON ZAHN, Bde. 1-3, Graz 1875-1903, hier Bd. 1 S. 224f. Nr. 215 (Original); Reg.: GP 2/1 S. 73 Nr. 6.

60 Dr.: Salzburger UB (wie Anm. 2) Bd. 2 S. 398-400 u. 404-406 Nr. 283 u. 288 (nur in den von Eberhard I. ausgestellten Urkunden über den jeweiligen Vergleich erwähnt); Reg.: GP 1 S. 104 Nr. *4 bzw. S. 236 Nr. *7. Vgl. Rainer MuRaueR: Geistliche Gerichtsbarkeit und Rezeption des neuen Rechts im Erzbistum Salzburg im 12. Jahrhundert, in: Römisches Zentrum und kirchliche Peripherie. Das universale Papsttum als Bezugspunkt der Kirchen von den Reformpäpsten bis zu Innozenz III., hg. v. Jochen JOHRENDT/Harald MÜlLER, Berlin/New York 2008 (NAAG 2), S. 259-284, hier S. 275.

61 Dr.: Urkundenbuch des Landes ob der Enns (Oberösterreich), Bd. 1 u. 2, Wien 1852 u. 1856, hier Bd. 2, S. 253f. Nr. 169 (überliefert in einem aus dem 14. Jahrhundert stammenden Urbar und Kopialbuch von Baumgartenberg); Reg.: GP 1 S. 218 Nr. 2. De facto handelte es sich hier - wenn auch der Begriff nicht verwendet wird - um eine Appellation Baumgartenbergs mit der Begründung, der vom Generalkapitel des Zisterzienserordens delegierte Abt von Citeaux habe falsche Zeugen gehört, die der Bischof von Passau präsentierte habe. 
Berhalb der Kirchenprovinz (Alexandrinisches Schisma) oder auch an der fehlenden Überlieferung einschlägiger Schriftstücke liegen.

1189 ernannte Papst Clemens III. (1187-1191) ein für diese Aufgabe eigentlich typisches Dreierkollegium, bestehend aus Erzbischof Adalbert III., dem Bischof von Gurk und dem Abt von Ossiach, das den Streit zwischen dem Kloster St. Georgen am Längsee und dem Propst von Maria Saal entscheiden sollte ${ }^{62}$.

Erzbischof Adalbert III. wurde 1196 zusammen mit den Äbten von St. Peter und Raitenhaslach zum delegierten Richter in einem Streit zwischen dem Salzburger Domkapitel und dem Augustiner-Chorherrenstift Berchtesgaden bestellt $t^{63}$. Erhalten blieb auch ein Mandat Cölestins von 1197, das die drei delegierten Richter auffordert, trotz der Weigerung der Berchtesgadner, sich ihrem Spruch zu unterwerfen, in der Sache weiter vorzugehen ${ }^{64}$.

Aus einem Delegationsreskript Cölestins III. für den Abt von St. Peter und zwei Prälaten aus dem Bistum Freising (1196) lässt sich ein nicht erhaltenes Mandat an den Erzbischof erschließen, dem Augustiner-Chorherrenstift Gars am Inn eine umstrittene Kapelle wegzunehmen ${ }^{65}$. Nur aus dem von Erzbischof Eberhard II. circa 1202 gefällten Urteil im Streit zwischen dem Kloster St. Lambrecht und dem Ritter Otakar von Schlierbach ist ein Delegationsauftrag Innozenz' III. zu ermitteln ${ }^{66}$. Zusammen mit seinem Dompropst und seinem Domdekan wurde Eberhard 1202 die Entscheidung eines Streites zwischen den Pröpsten von Gars und $\mathrm{Au}$ am Inn anvertraut ${ }^{67}$. Im gleichen Jahr sollte er zusammen mit dem Archipresbyter von Völkermarkt auf Klage des Klosters Viktring hin gegen die Erben des Grafen von Bogen einschreiten ${ }^{68}$. Aus einem Urteil Eberhards von 1208 ergibt sich, dass er zusammen mit dem Abt von Garsten und dem Archidiakon Grauscharn als delegierter Richter im Streit zwischen dem Benediktinerstift Melk und den Johannitern von Mailberg tätig war $^{69}$. Aus einem Schreiben Innozenz' III. an Patriarch Wolfger von Aquileia lässt sich eine Delegation Eberhards zusammen mit dem Gurker Bischof in Sachen von Wolfgers Translation von Passau nach Aquileia erschließen (circa

62 Dr.: MDC (wie Anm. 2) Bd. 3 S. $510 f$. Nr. 1361 (Original); Reg.: GP 1 S. 116 Nr. 9. Vgl. Murauer: Gurk (wie Anm. 4) S. 44f.

63 Dr.: Salzburger UB (wie Anm. 2) Bd. 2 S. 683f. Nr. 505 (Original); Reg.: GP 1 S. 51 Nr. 18.

64 Dr.: Salzburger UB (wie Anm. 2) Bd. 2 S. 702 f. Nr. 517 (Original); Reg.: GP 1 S. 51f. Nr. 19.

65 Reg.: GP 1 S. 80 Nr. *4. Siehe unten S. 399 (zu St. Peter).

66 Dr.: Salzburger UB (wie Anm. 2) Bd. 3 S. 16 Nr. 545 (Urkunde Eberhards II.): ... ex delegatione domni pape.

67 Reg.: PotThast 1635 (Original).

68 Dr.: MDC (wie Anm. 2) Bd. 4/1 S. 4f. Nr. 1528 (Original).

69 Erwähnt in Salzburger UB (wie Anm. 2) Bd. 3 S. 116f. Nr. 621 (Urkunde Eberhards II.). 
$1204)^{70} .1206$ wurde Eberhard vom Papst mit einer heiklen politischen Mission betraut (zusammen mit Domdekan Dietmar von Gurk und Abt Wolfram von Admont), nämlich im Eheprozess des Böhmenkönigs Otakar I. (1198$1230)^{71}$. Aus dem im päpstlichen Register überlieferten Delegationsreskript ergibt sich, dass der Erzbischof in dieser Sache schon einem anderen Kollegium angehörte, dessen Tätigkeit zeitlich nicht näher zu bestimmen ist ${ }^{72}$.

\subsection{Päpstliche Schreiben im Zusammenhang mit dem Alexandrinischen Schisma}

1160, rund ein halbes Jahr nach seiner Wahl zum Papst, erging das erste einschlägige Schreiben Papst Alexanders III.; er klagte Erzbischof Eberhard II. und dessen Suffraganen über die Repressionsmaßnahmen Barbarossas und löste sie von ihrem Treueid gegenüber dem von ihm gebannten Kaiser ${ }^{73}$. Das Briefbuch Eberhards, das dieses Schreiben überliefert, enthält auch einen anderen Papstbrief zum Konflikt zwischen Alexander und Barbarossa sowie dem Gegenpapst Viktor IV. (1161) ${ }^{74}$. 1162 erteilte Alexander III. Eberhard I. Anweisungen für sein unmittelbar bevorstehendes Zusammentreffen mit Barbarossa ${ }^{75}$. Im Jahr darauf lobte er ihn und seine Suffragane in einem auf dem Konzil von Tours ausgestellten Schreiben für ihre standhafte Haltung und suchte sie darin

70 Reg.: MDC (wie Anm. 2) Bd. 1 S. 296 Nr. 404 (nur erwähnt in einem Schreiben an den Patriarchen).

71 Dr.: Die Register Innocenz' III., 9: 9. Pontifikatsjahr, 1206/1207. Texte, bearbeitet von Othmar HAgENEDER/Andrea SOMMERLECHNER gemeinsam mit Christoph EGGER/Herwig WeIGL, Wien 2004 (Publikationen der Abteilung für historische Studien des Österreichischen Kulturinstituts in Rom 2/1/9), IX/60 S. 108-110 (kopial überliefert). Zur Sache Karl RicHTER: Die böhmischen Lander im Früh- und Hochmittelalter, in: Handbuch der Geschichte der böhmischen Länder, Bd. 1: Die böhmischen Länder von der archaischen Zeit bis zum Ausgang der hussitischen Revolution, hg. v. Karl BosL, Stuttgart 1967, S. 165-347, hier S. 269f.; Eduard WinkelmanN: Philipp von Schwaben und Otto IV. von Braunschweig I: König Philipp von Schwaben 1197-1208, Leipzig 1873 (Jahrbücher der deutschen Geschichte), S. 188f., 283-294; Helene TillmanN: Papst Innocenz III., Bonn 1954 (Bonner Historische Forschungen 3), S. $278 \mathrm{f}$.

72 Dr.: Register Innocenz' III., 9 (wie Anm. 71) IX/60 S. 108 Z. 15-19 (nur erwähnt). Die Kodelegaten waren der Erzbischof von Magdeburg und der Propst des dortigen Kollegiatsstiftes St. Peter.

73 Dr.: Die Admonter Briefsammlung nebst ergänzenden Briefen, ed. Günther HödL/Peter Classen, München 1983 (MGH Epp. DK 6), S. 103-106 Nr. 53 (kopial überliefert); Reg.: GP 1 S. 27 Nr. 85.

74 Dr.: Admonter Briefsammlung (wie Anm. 73) S. 118-121 Nr. 65 (kopiale Überlieferung); Reg.: GP 1 S. 27 Nr. 87.

75 Dr.: Admonter Briefsammlung (wie Anm. 73), S. 129-131, 146-148 Nr. 73, 87 (aus Briefbuch Eberhards); Reg.: GP 1 S. 29f. Nr. 93, 94. 
zu bestärken ${ }^{76}$. In diesen Komplex gehört im weiteren Sinne auch das Schreiben Alexanders III. an Erzbischof Adalbert, in dem er ihm Unterstützung gegen seine Feinde zusicherte, die ihn auf dem Regensburger Hoftag abgesetzt hatten (1174), eine Vorgehensweise, die der Papst für ungültig erklärte ${ }^{77}$.

\subsection{Sonstige päpstliche Schreiben für den Erzbischof}

Nach der Kritik Gregors VII. an Erzbischof Gebhard wegen der nachlässigen Durchsetzung der Zölibatsbestimmungen im Salzburger Klerus ${ }^{78}$ wurde Gebhard zwei Jahre später (1075) erneut ermahnt, weil er dem von ihm gegründeten (Eigen-)Bistum Gurk den diesem zustehenden Zehnt vorenthielt ${ }^{79}$.

Hier ist ferner der Auftrag von 1095 an den Salzburger Erzbischof zu nennen, den Erzbischof von Mailand (mit-)zuweihen ${ }^{80} .1194$ befahl Papst Cölestin III. Erzbischof Adalbert III., die dem Abt von Viktring gehörende Kapelle zu Friesach, die der römischen Kirche infolge einer jährlichen Zinszahlung direkt unterstand, zu weihen oder durch einen seiner Suffragane weihen zu lassen ${ }^{81}$.

Natürlich spielte auch die Exekution päpstlicher Rechtsakte eine gewichtige Rolle, etwa die Deposition hochrangiger Kleriker. 1106 sollte der neugewählte Erzbischof Konrad I. einen von Papst Paschalis II. exkommunizierten Gurker intrusus aus dem Amt entfernen ${ }^{82}$. Nur ungenau zu datieren, nämlich auf 1157-1159, ist der Auftrag Hadrians IV. an Erzbischof Eberhard I. und dessen Regensburger Suffragan, den Abt von Biburg wieder in sein Amt ein-

76 Dr.: Admonter Briefsammlung (wie Anm. 73), S. 202f. Nr. 2 (Original); Reg.: GP 1 S. 30 Nr. 96; MDC (wie Anm. 2) Bd. 1 S. 184 Nr. 238.

77 Nur überliefert im Chronicon Magni presbiteri ad. a. 1174, ed. WATTENBACH (wie Anm. 37) S. 499 = Admonter Briefsammlung (wie Anm. 73), S. 213f. Anhang Nr. 9 ; Reg.: GP 1 S. 36 Nr. 116.

78 Gregor wirft dem Erzbischof vor, bezüglich der Zölibatsbestimmungen für den Klerus, die auf einer römischen Synode in seiner Anwesenheit festgelegt worden seien, nachlässig und ungehorsam zu sein. Das Stück hat nur eine Datierung nach der Indiktion, das Inkarnationsjahr fehlt. Zu anderen, wenig überzeugenden Versuchen, die Synode umzudatieren (auf die Fastensynode Gregors VII. von 1074), vgl. DOPSCH: Salzburg im Hochmittelalter (wie in Anm. 11) Bd. 1 S. 239 mit Anm. 84. GP 1 S. 18f. Nr. 42.

79 Dr.: Register Gregors VII., ed. CaSPAR (wie Anm. 19) II/77 S. 240f. (1075 Juni 17). Vgl. GP 1 S. 19 Nr. 43.

80 Reg.: GP 1 S. 19 Nr. *46. Den Auftrag Papst Urbans II. überliefert allein Bernold von Konstanz: Die Chroniken Bertholds von Reichenau und Bernolds von Konstanz 1054-1100, ed. Ian S. RoBinson, Hannover 2003 (MGH SS rer. Germ. N. S. 14), S. 522. Eine urkundliche Überlieferung liegt nicht vor.

81 Dr.: Salzburger UB (wie Anm. 2) Bd. 2 S. 667f. Nr. 494 (Original); Reg.: GP 1 S. 111 Nr. 5.

82 Das Mandat ist nicht überliefert, wir kennen seinen Inhalt nur aus dem Chronicon Gurcense, ed. Wilhelm WATTENBACH, in: MGH SS 23, Hannover 1874, S. 8-10, hier S. 9: Huic Conrado dominus Paschalis papa iniunxit, ut Perhtoldum intrusum Gurcensis ecclesie, quem ipse excommunicaverat, removeret; Reg.: GP 1 S. 125 Nr. *3. 
zusetzen $^{83}$. Circa 1117 beauftragte Papst Paschalis II. Konrad I. mit der Überbringung eines für den Bischof Hartwig I. von Regensburg (1106-1126) bestimmten päpstlichen Schreibens und mit der Untersuchung der wegen des Vergehens der Simonie erfolgten Absetzung des Abtes von St. Emmeram ${ }^{84}$. Papst Calixt II. trug ihm auf, einen vom Augsburger Bischof geweihten Priester aufzunehmen (circa 1121/1123) ${ }^{85}$ und ermächtigte ihn zur Absetzung des unkanonisch gewählten Bischofs Hugo von Brixen (circa 1124) ${ }^{86}$. Honorius II. mahnte auf eine Klage des Freisinger Bischofs und seiner Kirche hin Konrad, von Anfeindungen gegen diesen abzusehen $(1125)^{87}$ : Hinsichtlich bereits vom Papst entschiedener Fragen gezieme es dem Erzbischof nicht, eine nochmalige Antwort aus Rom zu erfragen oder zu erwarten ${ }^{88}$.

1150 wurde Eberhard II. von Eugen III. die Verkündigung der Exkommunikation des Sohnes des Pfalzgrafen aufgetragen, der Bischof Otto von Freising während der Messfeier mit Schmährufen beleidigt hatte; ferner sollte er den Tegernseer Mönchen, die zahlreiche Klagen vorbrachten, Gerechtigkeit verschaffen $^{89}$. Einer von Eberhards Nachfolgern, Adalbert III., sollte im Auftrag Papst Alexanders III. die Exkommunikation eines Gegners Erzbischof Konrads von Mainz, der seit 1173 wieder als Legat in Bayern wirkte und später selbst Salzburger Oberhirte wurde, verkünden $(1173 / 74)^{90} .1174$ erhielt Adalbert einen weiteren Auftrag, die Gegner Konrads, Brandstifter und Kirchenräuber, zu bannen ${ }^{91}$. 1190 befahl Clemens III. Adalbert, eine Exkommunikationssentenz gegen die Chorherren von Herzogenburg, die unter Missachtung eines Urteils eines von seinem Vorgänger Lucius III. delegierten Richterkollegiums gefällt worden war, wieder aufzuheben. Das päpstliche Mandat ist aller-

83 Dr.: Admonter Briefsammlung (wie Anm. 72), S. 49 f. Nr. 13 (überliefert im Briefbuch Eberhards aus dem 12. Jahrhundert); Reg.: GP 1 S. 316 Nr. 3.

84 Dr.: Migne PL 163 Sp. 441 Nr. 532f. Vgl. GP 1 S. 286f. Nr. 7f. Beide Schreiben sind im Briefbuch Erzbischof Eberhards I. überliefert. Die Datierung stammt von Brackmann.

85 Dr.: Migne PL 163 Sp. 1304 Nr. 247 (Abschrift); Reg.: GP 1 S. 20 Nr. 51.

86 Dr.: Migne PL 163 Sp. 234 Nr. 242 (Abschrift); Reg.: GP 1 S. 20 Nr. 52; MDC (wie Anm. 2) Bd. 3 S. 243 Nr. 604 (Teilabdruck).

87 Dr.: Migne PL 166 Sp. 1303 Nr. 100 (Abschrift); Reg.: GP 1 S. 333 Nr. 10.

88 Dr.: Gerhohi praepositi Reichersbergensis libelli selecti, ed. Ernst SACKUR, Hannover 1897 (MGH Ldl 3), S. 178 (nur erwähnt); Reg.: GP 1 S. 21 Nr. `54 (1124-1126).

89 Dr.: Die Tegernseer Briefsammlung des 12. Jahrhunderts, ed. Werner BERGMANN/Helmut PleCHL, Hannover 2002 (MGH Epp. DK 8), S. 122f. Nr. 92; Reg.: GP 1 S. 364 Nr. 4. S. Helmut PLECHL: Die Tegenseer Handschrift Clm 19411. Beschreibung und Inhalt, in: DA 18 (1962) S. 418-501.

90 Nur erwähnt in einem Schreiben Erzbischof Konrads von Mainz. Dr.: Mainzer Urkundenbuch, Bd. 2: Die Urkunden seit dem Tode Erzbischof Adalberts I. (1137) bis zum Tode Erzbischof Konrads (1200), bearb. von Peter AcHT, Bd. 2/1 (1137-1175), Darmstadt 1968, S. 596f. Nr. 355; Reg.: GP 1 S. 35 Nr. *112.

91 Dr.: MDC (wie Anm. 2) Bd. 3 S. 445f. Nr. 1188 (Original); Reg.: GP 1 S. 115 Nr. 5. Zur Legation Konrads s. u. Kap. 12. 
dings nicht überliefert, wir kennen seinen Inhalt nur aus einem Schreiben des Papstes an den Abt von Zwettl und den Propst von St. Pölten, in dem er den Adressaten auftrug, den Erzbischof dementsprechend zu ermahnen ${ }^{92}$.

Circa 1138/42 sollte Konrad I. im Auftrage Innozenz' II. zusammen mit seinen Suffraganen aus Regensburg und Passau einen Grafen und dessen Ministerialen mahnen, ein Eigengut, das die Mutter des Grafen einst dem Kloster Baumburg geschenkt hatte, dem Kloster zu restituieren ${ }^{93}$. Genau zu datieren (auf den 6. Dezember 1142), weil im Original in Form einer Littera clausa überliefert, ist der ähnlich gelagerte Auftrag desselben Papstes an Konrad, den Grafen von Lechsgemünd zur Rückgabe eines päpstlichen Privilegs und einiger Besitztümer an das Kloster Rott am Inn zu veranlassen ${ }^{94} .1145$ trug Eugen III. Konrad auf, Wernhard von Julbach und dessen Familie zu ermahnen, das Stift Berchtesgaden hinsichtlich seiner Besitzungen und der Vogtei in Frieden $\mathrm{zu}$ lassen und für die bereits zugefügten Schäden Genugtuung zu leisten, und gab zugleich seiner Verwunderung Ausdruck, warum der Erzbischof auf ein entsprechendes (nicht überliefertes) Mandat Innozenz' II. nicht reagiert habe ${ }^{95}$. 1158 wurde Eberhard von Papst Hadrian IV. beauftragt, für die Restitution eines zwischen den Klöstern St. Lambrecht und Rein umstrittenen Eigenguts an St. Lambrecht Sorge zu tragen ${ }^{96} .1177$ trug Alexander III. dem Erzbischof Adalbert auf, die Rückgabe eines entfremdeten Allods an das Kloster Tegernsee anzumahnen ${ }^{97}$. Im gleichen Jahr befahl er Adalberts Nachfolger Konrad III. und dem Gurker Bischof Roman II., über eine Klage des Abtes von St. Paul im Lavanttal gegen dessen Feinde einzuschreiten ${ }^{98} .1189$ sollte der wieder auf den Erzbischofsstuhl zurückgekehrte Adalbert III. laut einem Mandat Clemens' III. die Leute des Kärntner Herzogs, die das Frauenkloster St. Georgen am Längsee bedrängten, davon abhalten und den Bischof von Brixen mahnen, Angehörige seines Sprengels zur Restitution eines St. Georgen geraubten Gu-

92 Dr.: Wilhelm BIELSKY: Die ältesten Urkunden des Kanonikatsstiftes Sanct Georgen in Unterösterreich von 1112 bis 1244, in: Archiv für Kunde österreichischer Geschichtsquellen 9 (1853) S. 235-304, hier S. 267 Nr. 15; Reg.: GP 1 S. 242 Nr. `9, 10.

93 Dr.: Pflugk-Harttung (wie Anm. 55) Bd. 2 S. 320 Nr. 358 (Original); Reg.: GP 1 S. 77 Nr. 5.

94 Dr.: Migne PL 179 Sp. 609 Nr. 541 (Original); Reg.: GP 1 S. 357 Nr. 2.

95 Dr.: Albert BRACKMANN: Die Kurie und die Salzburger Kirchenprovinz, Berlin 1912 (Studien und Vorarbeiten zur GP 1), S. 191f. (kopial überliefert); Reg.: GP 1 S. 61f. Nr. $\star 5,8$.

96 Nur erwähnt in einer Sentenz Eberhards von 1159; Dr.: UB Steiermark (wie Anm. 59) Bd. 1 S. 382-387 Nr. 401; Reg.: GP 1 S. 99 Nr. ^2. Vgl. BRACKMANN (wie Anm. 95) S. 200.

97 Überliefert im Tegernseer Briefbuch. Vgl. GP 1 S. 367 Nr. 13.

98 Dr.: MDC (wie Anm. 2) Ergänzungsheft zu Band I-IV: 1111-1269, ed. August voN JAKSCH, Klagenfurt 1915, S. 11 Nr. $1228 \mathrm{a}=3056$ (Kopie); Reg.: GP 1 S. 120 Nr. 5. 
tes zu zwingen ${ }^{99} .1197$ befahl Cölestin III. Adalbert, dem unmittelbar dem Heiligen Stuhl unterstehenden Stift Berchtesgaden (nullo mediante) für die Brandschatzung in Reichenhall und die der Saline auf dem Tuval (dem heutigen Gutratsberg) zugefügten Schäden Genugtuung zu leisten; andernfalls sollten ihn die Bischöfe von Bamberg und Eichstätt sowie der Abt des Benediktinerklosters Ensdorf (Diözese Regensburg) von Amt und Pfründe suspendieren ${ }^{100}$. Adalberts Nachfolger Eberhard II. wurde der unrechtmäßigen Entfremdung einer Kirche beschuldigt; auf Klage des Priesters jener Kirche befahl Innozenz III. Eberhard die Restitution derselben (1215) ${ }^{101}$. Finanzielle Implikationen enthielt auch das Mandat Innozenz' II. von 1143 für Konrad III., einen Adeligen, der mit seiner Tochter in das Kloster Benediktbeuern eingetreten, dann jedoch nach Admont übergewechselt war, zur Rückkehr zu zwingen wobei er, wie er es versprochen hatte, seine Besitztümer Benediktbeuern hinterlassen sollte ${ }^{102}$.

1177 wurde Adalbert befohlen, gegen einen Kleriker, der Zehnte des Frauenklosters St. Georgen am Längsee in Besitz genommen und damit einen Laien belehnt hatte, sowie gegen zwei Untertanen des Markgrafen der Steiermark, die jenem Kloster Eigengut entfremdet hatten, vorzugehen, diese zur sofortigen Rückgabe der Güter oder zur Leistung einer angemessenen Genugtuung zu zwingen, andernfalls jedoch zu exkommunizieren ${ }^{103}$. In eine Urkunde Erzbischof Konrads III. wurde Papst Lucius' III. Mandat inseriert, dem Gurker Domkapitel entzogene Zehnte zu restituieren oder durch andere zu ersetzen $^{104}$. Um 1196 trug Cölestin III. Erzbischof Adalbert III. auf, die Ablieferung des rechtmäßigen und vollen Zehnts an das Stift Admont durchzusetzen ${ }^{105}$.

Die Zehntfreiheit des Zisterzienserordens war Gegenstand eines Mandats Lucius' III. (1185), das an Erzbischof Adalbert, dessen Suffragane und alle Kleriker der Kirchenprovinz adressiert war; sie sollten alle Laien, welche die Zis-

99 Dr.: MDC (wie Anm. 2) Bd. 3 S. 511f. Nr. 1362 (Original); Reg.: GP 1 S. 116 Nr. 10.

100 Dr.: Salzburger UB (wie Anm. 2) Bd. 2 S. 703f. Nr. 518 (Kopialbuch der jura des Klosters Berchtesgaden); Reg.: GP 1 S. 64 Nr. 21 und S. 46 Nr. 158.

101 Dr.: Salzburger UB (wie Anm. 2) Bd. 3 S. 189f. Nr. 682 (Original).

102 Dr.: UB Steiermark (wie Anm. 59) Bd. 1 S. 221 Nr. 212 (Kopialbuch); Reg.: GP 2 S. 72 Nr. 5.

103 Dr.: MDC (wie Anm. 2) Bd. 3 S. 462 Nr. 1224 (Original); Reg.: GP 1 S. 115f. Nr. 7.

104 Dr.: MDC (wie Anm. 2) Bd. 1 S. 242 Nr. 324 (nur Text der Papsturkunde); Salzburger UB (wie Anm. 2) Bd. 2 S. 594-596 Nr. 433 (Bischofsurkunde von 1183); Reg.: GP 1 S. 131 Nr. 8 (ca. 1182).

105 Das Stück ist nur durch eine Erwähnung in dem als Folge des päpstlichen Auftrags ergangenen undatierten Mandat des Erzbischofs an alle Kleriker der Erzdiözese überliefert. Dr.: Salzburger UB (wie Anm. 2) Bd. 2 S. 598 Nr. 436b = UB Steiermark (wie Anm. 59) Bd. 1 S. 710 Nr. 721; Reg.: GP 1 S. 94 Nr. 19, wo das Stück ohne nähere Begründung auf 1196 datiert wird. 
terze Waldsassen diesbezüglich schädigten, exkommunizieren, Kleriker und Mönche gegebenenfalls von ihren Ämtern suspendieren ${ }^{106}$. Betreffs der Zisterze Raitenhaslach sind zwei ähnliche Mandate Innozenz' III. für Erzbischof Eberhard III. (einschließlich der Suffragane und des gesamten Klerus) von 1209 und 1214 bekannt ${ }^{107}$.

Aus einer Urkunde Konrads I. geht hervor, dass Innozenz II. ihm befohlen habe, dem Eigenbistum Gurk einen Sprengel zu geben (circa 1131) ${ }^{108} .1141$ schärfte Innozenz II. Konrad I. ein, die Anliegen des Klosters Münchsmünster zu erfuillen ${ }^{109}$. Innozenz III. mahnte 1213 in dem endlosen Streit um die Gurker Bischofswahl Erzbischof Eberhard II., die Wahl in der vorgeschriebenen Weise durchzuführen ${ }^{110}$.

Papst Eugen III. trug 1152 Erzbischof Eberhard II. und dessen Amtskollegen von Bremen und Trier sowie zahlreichen Reichsbischöfen auf, eine Translation des Bischofs von Naumburg-Zeitz nach Magdeburg - u. a. mittels Intervention bei König Friedrich I. - zu verhindern ${ }^{111}$. Nicht genau datierbar ist die Mahnung Innozenz' II. an Erzbischof Konrad I. (circa 1138/43), die Chorherren von Berchtesgaden zur fortwährenden Beachtung der AugustinerRegel anzuhalten ${ }^{112} .1164$ erhielt Eberhard von Papst Alexander III. Anweisungen betreffend Gerhoch von Reichersberg ${ }^{113}$; ein derartiges Schreiben hat-

106 Dr.: Pflugk-Harttung (wie Anm. 55) Bd. 1 S. 322 Nr. 370 (Original); Reg.: GP 1 S. 308 Nr. 1.

107 Dr.: Die Urkunden des Klosters Raitenhaslach 1034-1350, ed. Edgar KRAUSEN, Bd. 1, München 1959 (Quellen und Erörterungen zur bayerischen Geschichte. N. F. 17/1), S. 73f. Nr. 74 bzw. S. 67 f. Nr. 69 (beide Originale).

108 Dr.: MDC (wie Anm. 2) Bd. 1 S. 97-103 Nr. 61a (nur erwähnt); ferner zwei Verfälschungen (Nr. 61 b, c) mit Erweiterung des Territoriums (1172/1177, 1216/18); Reg.: GP 1 S. $125 f$. Nr. 5.

109 Reg.: GP 1 S. 22 Nr. 58 und S. 313 Nr. 6 (nur chronikal überliefert).

110 Dr.: Salzburger UB (wie Anm. 2) Bd. 3 S. 167-169 Nr. 663 (Original).

111 Dr.: Ottonis et Rahewini gesta Friderici I. imperatoris, ed. Georg WAITZ, Hannover/Leipzig 1912 (MGH SS rer. Germ. [46]), S. 108-110 (kopiale Überlieferung); Reg.: RI 4/2/1 Nr. 127; GP 1 S. 25 Nr. 78. Vgl. Michele MacCarRone: Papato e Impero dalla elezione di Federico I alla morte di Adriano IV (1152-1159), Roma 1959, S. 33f.

112 Dr.: Insert in Gerhoch von Reichersbergs Commentarius in Psalmum LXIV (Gerhohi praepositi Reichersbergensis libelli selecti [wie Anm. 88], S. 456); Reg.: GP 1 S. 61 Nr. 6.

113 Dr. Gerhohi praepositi Reichersbergensis libelli selecti (wie Anm. 88) S. 399-411 (nur erwähnt in Gerhochs Brief an die Kardinäle); Reg.: GP 1 S. 201 Nr. 3. Zu Gerhoch vgl. Peter Classen: Gerhoch von Reichersberg. Eine Biographie mit einem Anhang über die Quellen, ihre handschriftliche Überlieferung und ihre Chronologie, Wiesbaden 1960. 
ten bereits 1144 die Oberhirten Konrad I. von Salzburg und Roman I. von Gurk empfangen ${ }^{114}$.

Zwei Indulgenzen sind noch hinzuzufügen. Circa 1157/59 erlaubte Papst Hadrian IV. dem Erzbischof Eberhard I. und dessen Suffraganen, Priester und Diakone nicht nur an den Quatembern, sondern auch am Palm- und Karsamstag zu weihen ${ }^{115}$. 1171 gestattete Papst Alexander III. Erzbischof Adalbert die Absolution von Brandstiftern und Schismatikern nach angemessener Buße ${ }^{116}$. 1185 wurde Erzbischof Adalbert das Kloster Rott am Inn von Lucius III. kommendiert $^{117}$.

Spannungen mit weltlichen Fürsten waren ebenfalls Anlass für päpstliche Mandate. 1195 trug Cölestin III. Adalbert auf, Herzog Friedrich II. von Österreich zu mahnen, das restliche Lösegeld König Richards von England zurückzugeben $^{118}$. 1215 verbot Innozenz III. Eberhard II. die Einhaltung eines Herzog Leopold VI. gegebenen Versprechens, demzufolge er vakante Lehen oder Kirchen nur auf Bitten des Herzogs vergeben sollte, da jenes Versprechen unkanonisch sei ${ }^{119}$.

Konrad I. erhielt 1138 ein Papstschreiben in einer gewissermaßen „,persönlichen" Angelegenheit; Innozenz II. antwortete ihm auf sein Rücktrittsgesuch, welches er abschlägig beschied ${ }^{120}$. 1197 drohte Cölestin III. Erzbischof Adalbert III. die Deposition für den Fall an, dass er das Stift Berchtesgaden nicht für die Brandschatzung in (Reichen-)Hall entschädige ${ }^{121} .1202$ ermächtigte Innozenz III. Adalberts Nachfolger Eberhard II., die von Adalbert verschleuderten Besitzungen wieder zurückzufordern - ein Zugeständnis, mit dem er Eber-

114 Dr.: Insert in Gerhoch von Reichersbergs Commentarius in Psalmum XXIV (Gerhohi praepositi Reichersbergensis libelli selecti [wie Anm. 88] S. 420); Reg.: GP 1 S. 194 Nr. 15.

115 Dr.: Salzburger UB (wie Anm. 2) Bd. 4 S. 468f. Nr. 394 (Original).

116 Dr. UB ob der Enns (wie Anm. 61) Bd. 1 S. 346 Nr. 123; Reg.: GP 1 S. 33 Nr. *105. Der Papstbrief wird lediglich im Reichersberger Traditionscodex erwähnt.

117 Dr.: MonBoica Bd. 1 S. 368 Nr. 13 (Original); Reg.: GP 1 S. 358 Nr. 8.

118 Nur inseriert in der Chronik des Magnus von Reichersberg, Dr.: Chronicon Magni presbiteri ad. a. 1195, ed. WATTENBACH (wie Anm. 37) S. 522; Reg.: Urkundenbuch zur Geschichte der Babenberger in Österreich 4/1: Ergänzende Quellen 976-1194, bearb. von Heinrich FichtenAU, Wien 1968, S. 237 Nr. 944; GP 1 S. 45 Nr. 153. Zur Gefangennahme des englischen Königs auf der Rückreise vom Dritten Kreuzzug durch den damaligen Herzog Leopold V. und der Freilassung gegen Zahlung eines Lösegelds (1194) Heinrich FiCHTENAU: Akkon, Zypern und das Lösegeld für Richard Löwenherz, Wien 1966 (Archiv für österreichische Geschichte 125) S. 11-32.

119 Dr.: Salzburger UB (wie Anm. 2) Bd. 3 S. 191 Nr. 684 (Original).

120 Dr.: Migne: PL 179, Sp. 361 Nr. 314 (kopial überliefert); Reg.: MDC (wie Anm. 2) Bd. 1 S. 119 Nr. 101; GP 1 S. 22 Nr. 57. Vgl. Vita Chunradi archiepiscopi Salisburgensis, ed. Wilhelm WATteNBACH, in: MGH SS 11, Hannover 1854, S. 62-77, hier S. 77.

121 Salzburger UB (wie Anm. 2) Bd. 2 S. $703 f$. Nr. 518 (kopial überliefert); Reg.: GP 1 S. 64 Nr. 21 und S. 46 Nr. 158. 
hards prostaufische Haltung im Thronstreit (er hatte im Jänner jenes Jahres den Protest von Halle ${ }^{122}$ unterzeichnet) in eine neutrale abmildern konnte ${ }^{123}$. Erneute, allerdings weitgehend fruchtlose Ermahnungen in Sachen Thronstreit sind aus 1203 und 1205 überliefert ${ }^{124}$. Sogar als Innocenz selbst schon mit Philipp von Schwaben verhandelte (1206), wies er Eberhards Bitten um Entbindung vom Gehorsam in dieser Angelegenheit zurück ${ }^{125}$. Nach Philipps Ermordung (1208) drängte der Papst Eberhard vehement zur Anerkennung Ottos IV. ${ }^{126}$

\section{Das Domkapitel}

\subsection{Bestätigungen von Besitz und der Augustinerregel für das Domkapitel}

Besitzbestätigungen sind nach Einführung der Augustinerregel im Domkapitel, die unter Erzbischof Konrad I. erfolgte und von Papst Calixt II. 1123 bestätigt wurde $^{127}$, von etlichen Päpsten des 12. Jahrhunderts vorgenommen worden, so von Honorius II. (1125, zusammen mit der Bestätigung der Augustinerregel) ${ }^{128}$. Spätere Konfirmationen enthalten zudem die Verleihung des päpstlichen Schutzes; so handhabten es Innozenz II. $(1139)^{129}$, Eugen III. $(1147)^{130}$, Hadrian IV. (1157) $)^{131}$, Urban III. (1186) $)^{132}$ und Innozenz III. (1200) ${ }^{133}$. Auf Eugen III. wurde übrigens circa 1168/1170 in Salzburg eine Fälschung fabriziert, die dem Domkapitel viel weitergehende Rechte zusprach, darunter das Archidiakonat, das Appellationsgericht und das Besetzungsrecht mehrerer

122 Dr.: RNI (wie Anm. 41) S. 162-166, 260, 284f. Nr. 61, 103, 115 (kopiale Überlieferung).

123 Dr.: Salzburger UB (wie Anm. 2) Bd. 3 S. $30 f$. Nr. 556 (kopial überliefert).

124 Dr.: RNI (wie Anm. 41) S. 235-237 Nr. 90 (kopiale Überlieferung).

125 Dr.: ebd., S. 326-330 Nr. 139 (kopiale Überlieferung).

126 Dr.: ebd., S. 352f., 356f. Nr. 154, 147 (kopiale Überlieferung).

127 Dr.: Salzburger UB (wie Anm. 2) Bd. 2 S. 195-197 Nr. 128 (Original); Reg.: GP 1 S. 47f. Nr. 1.

128 Dr.: Salzburger UB (wie Anm. 2) Bd. 2 S. 202f. Nr. 133 (Original); Reg.: GP 1 S. 48 Nr. 2.

129 Dr.: Salzburger UB (wie Anm. 2) Bd. 2 S. 276f. Nr. 192 (Original); Reg.: GP 1 S. 48 Nr. 3.

130 Dr.: Salzburger UB (wie Anm. 2) Bd. 2 S. 368f. Nr. 255 (Orginal); Reg.: GP 1 S. 48 Nr. 4.

131 Dr.: Salzburger UB (wie Anm. 2) Bd. 2 S. 457-459 Nr. 329 (Original); Reg.: GP 1 S. 49 Nr. 6.

132 Dr.: Salzburger UB (wie Anm. 2) Bd. 2 S. 607-609 Nr. 446 (Original); Reg.: GP 1 S. 50 Nr. 14.

133 Dr.: Salzburger UB (wie Anm. 2) Bd. 3 S. 1f. Nr. 534 (Original). 
Propsteien sowie die freie Wahl des Dompropstes ${ }^{134}$. Bestätigungen sonstiger Besitztümer sind kaum überliefert. Wir wissen nur, dass 1179 Alexander III. dem Kapitel eine ihm von Erzbischof Konrad III. verliehene Martinskirche im Lungau bestätigte ${ }^{135}$.

\subsection{Mandate für das Domkapitel}

1172 schrieb Papst Alexander III. in Beantwortung eines vermutlich 1170 an ihn gerichteten Schreibens, das Klage führte über die kritische Lage im Erzbistum, dem Salzburger Dompropst Siboto und den anderen Mitgliedern des Domkapitels sowie dem Bischof und dem Dompropst von Gurk über die den Erzbischof Adalbert betreffenden Probleme ${ }^{136}$; dieser Brief wurde auf einem kaiserlichen Hoftag in Salzburg verlesen, wo ein weiterer Brief Alexanders überbracht wurde, dessen Inhalt nicht auf uns gekommen ist ${ }^{137}$. Abermals mahnte dieser Papst den Dompropst und das Domkapitel 1174, wobei er die Wahl Heinrichs, des Propstes von Berchtesgaden, zum Gegenerzbischof kassierte und sie zur Rückkehr unter die Obödienz Adalberts drängte ${ }^{138}$. Circa 1186/87 forderte Urban III. den Dompropst Gundaker zur Wiederherstellung der Disziplin im Domkapitel auf ${ }^{39}$.

1185 war der Dompropst Mitglied eines von Papst Lucius III. bestellten vierköpfigen Gremiums von Exekutoren, dessen übrige Mitglieder aus der Diözese Passau stammten; sie sollten einen vom Passauer Bischof Diepold eingesetzten intrusus vom Amt des Abtes von Kremsmünster entfernen, die Wahl entscheiden und Diepold zu einer Romreise anhalten ${ }^{140}$. Circa 1186/87 wurde der Salzburger Dompropst zusammen mit den Äbten der Benediktinerklöster Garsten und Seitenstetten sowie dem Propst von St. Florian, die wiederum alle der Diözese Passau angehörten, von Papst Urban III. abermals mit der Unter-

134 Dr.: Salzburger UB (wie Anm. 2) Bd. 2 S. 369-372 Nr. *256; Reg.: GP 1 S. 49 Nr. +5 .

135 Dr.: Salzburger UB (wie Anm. 2) Bd. 2 S. 583 Nr. 423 (Original); Reg.: GP 1 S. 50 Nr. 12.

136 Dr.: MDC (wie Anm. 2) Bd. 1 S. $206 f$. Nr. 272 (Original); Reg.: GP 1 S. 33 Nr. 106. Das in der päpstlichen Kanzlei einlaufende Schreiben der Salzburger Prälaten: GP 1 S. 32 Nr. 102. Ein zweites Schreiben des Papstes aus dem Jahr 1172, wo er strikten Gehorsam gegenüber Adalbert forderte, richtete sich nur an die Dompröpste von Salzburg und Gurk (Dr.: MDC [wie Anm. 2] Bd. 1 S. 206-209 Nr. 275; Reg.: GP 1 S. 34 Nr. 110 - nur abschriftlich überliefert).

137 GP 1 S. 34 Nr. *107; MDC (wie Anm. 2) Bd. 1 S. 207 Nr. 273.

138 Nur im Chronicon Magni presbiteri ad a. 1174, ed. WATTENBACH (wie Anm. 37) S. $500=$ Admonter Briefsammlung (wie Anm. 73) S. 211-213 Anhang Nr. 8; Reg.: GP 1 S. 36 Nr. 115.

139 Dr.: Salzburger UB (wie Anm. 2) Bd. 4 S. 471 Nr. 399 (aus Traditionskodex); Reg.: GP 1 S. 51 Nr. 15.

140 Dr.: Brackmann (wie Anm. 95) S. 211f. (Original); Reg.: GP 1 S. 213 Nr. 2. 
suchung der Abtwahl in Kremsmünster beauftragt ${ }^{141} .1211$ erhielt der Domdekan ein Delegationsreskript Innozenz' III. im Streit zwischen den Klöstern Admont und St. Peter in Salzburg (zusammen mit dem Abt von Raitenhaslach) ${ }^{142}$.

Die Verhängung des Kirchenbanns wurde nicht nur dem Erzbischof, sondern auch anderen Klerikern aufgetragen; 1195 mussten der Abt von St. Peter und der Salzburger Domdekan im Auftrag Cölestins III. die Gegner des Chorherrenstifts Baumburg bannen ${ }^{143} .1213$ sollten der Dompropst und der Domdekan zusammen mit den entsprechenden Funktionsträgern des Stiftes Berchtesgaden gegen den Untervogt von Michaelbeuern vorgehen ${ }^{144}$.

\section{Reisen des Salzburger Klerus nach Rom}

Auch zu diesem Thema gibt es wenige Hinweise. Wir wissen, dass Erzbischof Eberhard II. im März 1202 zu den Überbringern des schon erwähnten Protests von Halle gehörte, der im Jänner jenes Jahres abgefasst worden war $^{145}$. Aus einem die Gurker Bischofswahl regelnden Schreiben Innozenz' III. für den Salzburger Erzbischof geht hervor, dass der Gurker Dompropst Otto als Vertreter des Kapitels 1213 in Rom anwesend war, während sich der Erzbischof durch einen Prokurator vertreten ließ. Ferner zitierte der Papst beide Kontrahenten für den Allerheiligentag jenes Jahres erneut nach Rom, wobei der Propst weitere Domherren mitzubringen hatte, die als Zeugen gehört werden sollten ${ }^{146}$.

\section{Schreiben an alle Prälaten/alle Gläubigen der Salzburger/Gurker Kirche}

Solche Schreiben, die nicht an bestimmte - namentlich genannte oder durch ihre Funktion definierte - Empfänger verschickt wurden, sind selten. Ein Schreiben Cölestins III. erging 1194 an alle Gläubigen der Diözesen Salzburg,

141 Dr. UB ob der Enns (wie Anm. 61) Bd. 2 S. 404f. Nr. 274 (kopiale Überlieferung); Reg.: GP 1 S. 214 Nr. 7.

142 Dr.: Salzburger UB (wie Anm. 2) Bd. 3 S. 153f. Nr. 649 (nur erwähnt in der Urkunde der beiden Richter).

143 Dr.: MonBoica Bd. 2 S. 194 Nr. 13 (kopial überliefert); Reg.: GP 1 S. 78 Nr. 9.

144 Dr.: Salzburger UB (wie Anm. 2) Bd. 3 S. 166 Nr. 661 (Original).

145 Dies geht aus der Antwort Innozenz' III. auf den Protest hervor: RNI (wie Anm. 41)

S. 166-175 Nr. 62; das Protestschreiben ebd. S. 162-166 Nr. 61.

146 Dr.: Salzburger UB (wie Anm. 2) Bd. 3 S. 168 Nr. 663 (Original). 
Passau und Gurk und mahnte sie, Gesandten des neu errichteten Hospitals am Pyhrn bei Bedarf Almosen für das Spital zu geben ${ }^{147}$.

1173 schärfte Alexander III. dem gesamten Klerus des Erzbistums Gehorsam gegenüber Adalbert ein ${ }^{148} .1177$ endete der Konflikt damit, dass Alexander die Resignation Adalberts und die Wahl des bisherigen Mainzer Erzbischofs und Kardinalbischofs von Sabina, Konrads III., bestätigte ${ }^{149}$. Den Pröpsten der Salzburger Stifte verbot Innozenz III. 1201, Besitzungen ohne Zustimmung des jeweiligen Konvents zu veräußern ${ }^{150}$.

\section{Anwesenheit auf päpstlichen Synoden}

\subsection{Anwesenheit des Erzbischofs bei päpstlichen Synoden}

Ein Mahnschreiben Papst Gregors VII., das wahrscheinlich auf $1074 \mathrm{zu}$ datieren ist, gibt Hinweis auf Erzbischof Gebhards Präsenz auf der Synode Alexanders II. von 1063 $3^{151}$. 1071 wurde Gebhard noch von Alexander II. zu einer Synode in Mainz zitiert ${ }^{152}$. Aus dem Bericht Ottos von Freising wissen wir von Erzbischof Konrads I. Präsenz auf einer Synode Papst Innozenz' II. in Clermont im November 1130 $0^{153} .1147$ lud Eugen III. Erzbischof Eberhard II. zur am 21. März 1148 angesetzten Synode von Troyes, die dann allerdings in Reims stattfand ${ }^{154}$. Der kaiserliche Gegenpapst Viktor IV. zitierte denselben Erzbischof und den gesamten Klerus der Kirchenprovinz 1161 zum Konzil von Cremona $^{155}$. 1177 wurde Erzbischof Adalbert III. von Papst Alexander III. nach Venedig beordert; Hintergrund war das Salzburger Schisma, in dem Adalbert vom Papst Unterstützung erfuhr und ein gerechtes Urteil in Aussicht gestellt bekam ${ }^{156}$. 1178 erfolgte die Zitation Konrads III. für den 18. Februar

147 Dr.: UB ob der Enns (wie Anm. 61) Bd. 2 S. 445f. Nr. 303 (Original); Reg.: GP 1 S. 223 Nr. 2.

148 Dr.: MDC (wie Anm. 2) Bd. 1 S. 211 Nr. 278 (Original); Reg.: GP 1 S. 35 Nr. 111.

149 Dr.: Chronicon Magni presbiteri ad. a. 1177, ed. Wattenbach (wie Anm. 37) S. 505; Reg.: GP 1 S. 39f. Nr. 130.

150 Dr.: Salzburger UB (wie Anm. 2) Bd. 3 S. 7 Nr. 538 (Original). Das Kopfregest gibt den Adressatenkreis nicht richtig wieder.

151 Register Gregors VII., ed. CASPAR (wie Anm. 19) I/30 S. 50 ([1073] November 15).

152 Annales Altahenses maiores ad a. 1071, ed. Edmund vON OEFELE, Hannover 1891 (MGH SS rer. Germ. 4), S. 82; GP 1 S. 18 Nr. 41.

153 Otto von Freising, Chronica sive Historia de duabus civitatibus lib. VII c. 18, ed. Adolf HofMEISTER, Hannover/Leipzig 1912 (MGH SS rer. Germ. 45), S. 334.

154 Reg.: GP 1 S. 24 Nr. 71 (aus der Collectio canonum Ivos von Chartres).

155 Dr.: MGH Const. 1 S. 579 Nr. 403 (kopiale Überlieferung); Reg.: GP 1 S. 27 Nr. 86.

156 Dr.: Tegernseer Briefsammlung, ed. PleChl/Bergmann (wie Anm. 89) S. 291f. Nr. 262; Reg.: GP 1 S. 38 Nr. 125. 
1179 zum Dritten Laterankonzil ${ }^{157}$. Eberhard II. war zusammen mit siebzig anderen Metropoliten Teilnehmer des Vierten Lateranum $(1215)^{158}$.

\subsection{Anwesenheit von weiteren Salzburger/Gurker Geistlichen bei päpstlichen Synoden}

1134 lud Innozenz II. die Äbte aller unter dem päpstlichen Schutz stehenden Salzburger Klöster zu dem für Pfingsten 1135 angesetzten Konzil von Pisa ${ }^{159}$. 1178 bestellte Papst Alexander III. neben Erzbischof Konrad III. auch dessen Suffragane, die Äbte, Pröpste und Dekane aus der Kirchenprovinz zum Dritten Laterankonzil $1^{160}$. 1184 war der Gurker Dompropst Hertnid auf dem Konzil von Verona ${ }^{161}$. Für das IV. Lateranum ist zumindest die Anwesenheit von Bischof Heinrich II. von Gurk (1214-1217) belegt ${ }^{162}$.

\section{Papsturkunden für Klöster des Salzburger Diözesansprengels im Einzelnen}

Einen wesentlichen Bestandteil der überlieferten Urkunden bilden die Verleihungen des päpstlichen Schutzes, die häufig mit Bestätigungen des Klosterbesitzes verknüpft wurden und als Gegenleistung die Zahlung eines jährlichen Zinses an die Kurie einforderten. Manch ,ältere“ Papsturkunde (aus der ersten Hälfte des 12. Jahrhunderts) enthält zwar nicht wortwörtlich die Unterstellung unter die protectio apostolica, umschreibt diesen Zustand aber mit anderen Worten, die der Sache recht nahe kommen. Es gibt sogar Klöster, von denen keine andere Papsturkunde als ein Schutzprivileg überliefert ist. Ist die Überlieferung reichhaltiger, so ist das älteste Stück fast immer ein Schutzprivileg; Beispiele hiefuir sind St. Peter in Salzburg, Michaelbeuern, St. Lambrecht, Millstatt, St. Paul im Lavanttal, Viktring, Raitenhaslach, Berchtesgaden, St. Zeno in Reichenhall, Baumburg. Andererseits empfing Ossiach nur Delegationsreskripte, ein Privileg fehlt (wie für Maria Saal). Die weitere Aufschlüsselung der Papsturkunden für Institutionen in der Diözese von Salzburg gliedert sich nach Benediktinerstiften, Zisterzen, Kartausen, Augustiner-Chorherrenstiften, Kollegiatstiften sowie Frauenklöstern.

157 Vgl. GP 1 S. 40 Nr. 132 (kopial Überliefert).

158 Annales s. Rudberti Salisburgenses ad a. 1215 (wie Anm. 33) S. 780.

159 Dr.: UB Steiermark (wie Anm. 59) Bd. 1 S. 152 Nr. 146 (kopial überliefert, fälschlich auf 1133 datiert) = MDC (wie Anm. 2) Bd. 3 S. 257f. Nr. 646; MDC (wie Anm. 2) Bd. 1 S. 257f. Nr. 636. Reg.: GP 1 S. 21f. Nr. 56.

$160 \mathrm{Vgl}$. GP 1 S. 40 Nr. 132 (kopial Überliefert).

161 Nur in einem Briefbuch des Klosters St. Peter in Salzburg bezeugt; Dr.: MDC (wie Anm. 2) Bd. 1 S. $248 f$. Nr. 330.

162 Vgl. MDC (wie Anm. 2) Bd. 1 S. 346f. Nr. 453, 454 (abschriftlich überliefert). 


\subsection{Benediktinerstifte}

Für das zweifellos älteste und bedeutendste Kloster im Erzbistum, St. Peter in Salzburg, sind Urkunden überliefert, die es unter päpstlichen Schutz stellten und die Besitztümer bestätigten, so von Eugen III. von $1146^{163}$; die nächste Schutzverleihung ist allerdings sechs Jahrzehnte jünger, sie stammt von Innozenz III. (1206) ${ }^{164}$. Wie das Domkapitel ließ auch St. Peter eine Urkunde auf Eugen III. fälschen, um für vom Erzbischof verliehene Vorrechte eine päpstliche Bestätigung zu bekommen ${ }^{165}$.

Als delegierter Richter wurde der Abt von St. Peter von Papst Lucius III im Streit zwischen einem Passauer Kanoniker und den Chorherren von Herzogenburg eingesetzt (zusammen mit dem Abt von Heiligenkreuz und dem Propst von Klosterneuburg, die ebenfalls zur Passauer Diözese gehörten) ${ }^{166}$. 1196 erhielt der Abt ein päpstliches Delegationsreskript zusammen mit dem Erzbischof und dem Abt von Raitenhaslach ${ }^{167} ; 1197$ erging in dieser Sache ein weiteres päpstliches Mandat an denselben Personenkreis ${ }^{168} .1196$ ernannte Cölestin III. die Äbte von St. Peter in Salzburg und Ebersberg sowie den Propst von St. Andrä in Freising zu delegierten Richtern in einem Streit zwischen den Klöstern Gars und Au wegen einer Kapelle - mit dem Auftrag, diese an Gars zu restituieren ${ }^{169}$. Aus dem Delegationsreskript lässt sich ein nicht erhaltenes, von $\mathrm{Au}$ impetriertes älteres und jenem anderen Delegationsreskript daher widersprechendes päpstliches Mandat an den Erzbischof erschließen, den Garsern die umstrittene Kapelle wegzunehmen ${ }^{170}$. Die delegierten Richter von 1196 (allerdings ohne den Abt von St. Peter) sprachen diese gemäß ihrem Auf-

163 Dr.: Salzburger UB (wie Anm. 2) Bd. 2 S. 345-347 Nr. 241 (Original); Reg.: GP 1 S. 53 Nr. 1.

164 Dr.: Salzburger UB (wie Anm. 2) Bd. 3 S. 72-74 Nr. 590 (Original).

165 Dr.: Salzburger UB (wie Anm. 2) Bd. 2 S. 387-390 Nr. *273; Reg.: GP 1 S. 54 Nr. 2. Es geht um das Wahlrecht des Abtes bei Erzbischofswahlen, den Vorrang bei Prozessionen vor dem Domkapitel und die freie Abtwahl. Die Fälschung dürfte während eines zwischen 1439 und 1487 an der Kurie geführten Prozesses zwischen St. Peter und dem Domkapitel entstanden sein, vgl. Salzburger UB (wie Anm. 2) Bd. 2 S. 281, Einleitung zu Nr. ${ }^{*} 195$.

166 Reg.: GP 1 S. 55 Nr. ${ }^{\star} 5$ (ca. 1181-1185). Das Stück ist nicht überliefert, sondern nur aus der Erwähnung in einem weiteren in dieser Sache ergangenen Delegationsreskript Lucius' III. von 1185 und in einem Mandat Urbans III. für Herzogenburg von 1186 bekannt (Reg.: GP 1 S. 241 Nr. 6, 7).

167 Dr.: Salzburger UB (wie Anm. 2) Bd. 2 S. $683 f$. Nr. 505 (Original). Siehe oben S. 386 Kap. 3.5.

168 Dr.: Salzburger UB (wie Anm. 2) Bd. 2 S. $702 f$. Nr. 517 (Original). Siehe oben S. 386 Kap. 3.5.

169 Dr.: Pflugk-Harttung (wie Anm. 55) Bd. 2 S. 401 Nr. 458 (Original); Reg.: GP 1 S. $80 f$. Nr. 5.

170 Reg.: GP 1 S. 80 Nr. *4. Siehe oben S. 386 Kap. 3.5. 
trag dem Kloster Gars zu ${ }^{171} .1195$ schließlich sollten der Abt von St. Peter und der Salzburger Domdekan im Auftrag Cölestins III. die Gegner des Chorherrenstifts Baumburg bannen ${ }^{172} .1205$ ist der Abt wieder zusammen mit seinem Kollegen aus Raitenhaslach und dem Propst von Ranshofen (Diözese Passau) wegen des Streites um die Saline auf dem Tuval in päpstlichem Auftrag tätig ${ }^{173}$. Aus einer Urkunde Abt Simons, die nicht genau datierbar ist (1211-1218), wissen wir ferner, dass er als von Innozenz III. oder Honorius III. delegierter Richter in einem Streit zwischen dem Domkapitel und einem Laien zum Einsatz kam, wobei ihm freigestellt war, den Streit als iudex oder arbiter zu entscheiden ${ }^{174}$.

Die Päpste Innozenz II. (1137) ${ }^{175}$ und Lucius III. (1182) $)^{176}$ bestätigten Michaelbeuern samt seinen Besitzungen. In dem feierlichen Privileg von 1137 ist auch der an den Heiligen Stuhl zu zahlende jährliche Zins und die freie Abtwahl festgelegt. Das Schreiben Lucius' III. enthält ferner die förmliche Verleihung des päpstlichen Schutzes. Aber schon das Privileg Innozenz' II. beschreibt das Kloster als ad ius et proprietatem sancte Romane ecclesie specialius pertinere, womit es auch zu den Schutzpriviliegien gerechnet werden darf ${ }^{177}$. 1213 erneuerte Innozenz III. den Papstschutz, wobei das Kloster nun nullo mediante dem Heiligen Stuhl unterstand ${ }^{178}$.

Die erste, jedoch nicht im Original erhaltene Papsturkunde für das 1074 gegründete Stift Admont geht auf Paschalis II. zurück, der 1104 die Besitzungen bestätigte ${ }^{179}$. Auch ein Schreiben Innozenz' II. von 1139 für das unter Abt Wolfhold (1115-1138) gegründete Admonter Frauenkloster ist nur kopial ïberliefert ${ }^{180}$, wie auch die Schutzverleihung für das Männerkloster durch denselben Papst $(1139)^{181}$ und deren jeweilige Bestätigung durch Lucius II.

171 Dr.: Salzburger UB (wie Anm. 2) Bd. 2 S. 700-702 Nr. 516 (Urteil der delegierten Richter); vgl. GP 1 S. 80 f. Nr. 5.

172 Dr.: MonBoica Bd. 2 S. 194 Nr. 13 (kopial überliefert); Reg.: GP 1 S. 78 Nr. 9.

173 Dr.: Salzburger UB (wie Anm. 2) Bd. 3 S. 65 Nr. 585 (Original).

174 Dr.: Salzburger UB (wie Anm. 2) Bd. 3 S. 138f. Nr. 637 (nur erwähnt in Urkunde des Abtes, der eine Definitivsentenz fällte).

175 Dr.: Salzburger UB (wie Anm. 2) Bd. 2 S. 262-264 Nr. 178 (Original); Reg.: GP 1 S. 56f. Nr. 1.

176 Dr.: Salzburger UB (wie Anm. 2) Bd. 2 S. 591f. Nr. 429 (Original); Reg.: GP 1 S. 57 Nr. 2.

177 Salzburger UB (wie Anm. 2) Bd. 2 S. 262 Nr. 178.

178 Dr.: Salzburger UB (wie Anm. 2) Bd. 3 S. 166f. Nr. 662 (Original).

179 Dr.: UB Steiermark (wie Anm. 59) Bd. 1 S. 113f. Nr. 96 (auf 1105 datiert, kopiale Überlieferung); Reg.: GP 1 S. 90 Nr. 1.

180 Dr.: UB Steiermark (wie Anm. 59) Bd. 1 S. 178f. Nr. 176 (kopial überliefert); Reg.: GP 1 S. 90 f. Nr. 3.

181 Dr.: UB Steiermark (wie Anm. 59) Bd. 1 S. 179-181 Nr. 177 (kopial überliefert); Reg.: GP 1 S. 91 Nr. 4. 
$(1144)^{182}$, Alexander III. $(1171)^{183}$, Lucius III. (1185) ${ }^{184}$ und Urban III. $(1187)^{185}$. Gleiches gilt für ein Schreiben Urbans III. an den Abt (1185), das dessen Eingreifen in Kremsmünster in einer Auseinandersetzung mit einem intrusus einforderte ${ }^{186}$.

Die erste originale Papsturkunde ist ein Schreiben Alexanders III. für den Abt, das die Wahl der Äbtissinnen in dem ihm unterstehenden Frauenkloster regelte $(1171)^{187}$; an jenem Tag, an dem Alexander auch den schon erwähnten Papstschutz erneuerte, bestätigte er dem Stift außerdem mehrere Schenkungen verschiedener Salzburger Erzbischöfe $\mathrm{f}^{188}$. Wenige Wochen später bekräftige Alexander die dem Abt zustehenden Rechte in mehreren Frauenklöstern ${ }^{189}$.

Von Innozenz III. ist ein Mandat im Original überliefert (1210), demzufolge der Abt zusammen mit dem Abt von Viktring und dem Propst von Seckau für die Beachtung einer vom Salzburger Erzbischof verhängten Bannsentenz sorgen sollte ${ }^{190}$. Als delegierten Richter finden wir den Abt 1198 (zusammen mit dem Abt von St. Lambrecht und dem Gurker Dompropst) ${ }^{191}$. Auch im Eheprozess König Otakars I. von Böhmen wurde er von Innozenz III. - an der Seite des Salzburger Erzbischofs und des Gurker Domkdekans - eingesetzt $(1206)^{192}$. Ein anderes Mal war der Abt von Viktring (zusammen mit dem Abt von St. Paul) Kodelegat des Admonter Abtes bei einem Auftrag Innozenz' III. $(1214)^{193}$. Ebenfalls 1214 sollte er einen Streit zwischen den Klöstern Formbach und Vorau untersuchen, diesmal an der Seite zweier Passauer Prälaten, nämlich der Pröpste von St. Pölten und Waldhausen ${ }^{194}$.

182 Dr.: UB Steiermark (wie Anm. 59) Bd. 1 S. 225-227 Nr. 216 (kopial überliefert); Reg.: GP 1 S. 91f. Nr. 8.

183 Dr.: UB ob der Enns (wie Anm. 61) Bd. 2 S. 336 Nr. 232; UB Steiermark (wie Anm. 59) Bd. 1 S. 507-511 Nr. 543 (kopial überliefert); Reg.: GP 1 S. 92 Nr. 11.

184 Dr.: UB Steiermark (wie Anm. 59) Bd. 1 S. 611-617 Nr. 641(kopial überliefert); Reg.: GP 1 S. 93f. Nr. 16.

185 Dr.: UB Steiermark (wie Anm. 59) Bd. 1 S. 659-666 Nr. 684 (kopial überliefert); Reg.: GP 1 S. 94 Nr. 18.

186 Dr.: UB ob der Enns (wie Anm. 61) Bd. 2 S. 395f. Nr. 268 (kopiale Überlieferung); Reg.: GP 1 S. 214 Nr. 5.

187 Dr.: MDC (wie Anm. 2) Bd. 3 S. 432f. Nr. 1150; UB Steiermark (wie Anm. 59) Bd. 1 S. 505f. Nr. 514 (Original); Reg.: GP 1 S. 92f. Nr. 12.

188 Dr.: UB Steiermark (wie Anm. 59) Bd. 1 S. 507-511 Nr. 543 (kopial überliefert); Reg.: MDC (wie Anm. 2) Bd. 3 S. 432 Nr. 1148.

189 Dr.: MDC (wie Anm. 2) Bd. 3 S. 433f. Nr. 1151; UB Steiermark (wie Anm. 59) Bd. 1 S. 512 Nr. 544 (Original); Reg.: GP 1 S. 93 Nr. 13.

190 Dr.: Salzburger UB (wie Anm. 2) Bd. 3 S. 136 Nr. 635 (Original).

191 Dr.: UB Seitenstetten, ed. Raab (wie Anm. 2) S. 28 Nr. 20 (Original).

192 Dr.: Register Innocenz' III., 9 (wie Anm. 71) IX/60 S. 108-110 (kopial überliefert).

193 Dr.: Salzburger UB (wie Anm. 2) Bd. 3 S. 186 Nr. 678 (nur erwähnt). S. unten S. 405 mit Anm. 242 zu Viktring, dort auch zur Überlieferung des Auftrags.

194 Dr.: UB Steiermark (wie Anm. 59) Bd. 2 S. 190f. Nr. 126 (Original). 
Die ersten überlieferten Papsturkunden aus St. Lambrecht sind Besitzbestätigungen, von Paschalis II. (1109) ${ }^{195}$ und Honorius II. (1126) ${ }^{196}$. Beide Stücke enthalten auch eine Zinsverpflichtung des Klosters, verwenden aber noch nicht den Begriff des päpstlichen Schutzes; dieser kommt erst in einem Privileg Eugens III. (1148) ${ }^{197}$. Das Schutzprivileg wurde erneut bestätigt von Hadrian IV. $(1155)^{198}$ und Alexander III. (1178) $)^{199}$, wobei letzterer nur auf die drei älteren Privilegien, nicht aber auf jenes Hadrians verwies. Hadrian IV. nahm 1158 ferner mehrere Zellen des Klosters in den päpstlichen Schutz ${ }^{200}$. Ein Schutzprivileg ist auch von Innozenz III. überliefert (1206) ${ }^{201}$. Als delegierter Richter tritt der Abt nur 1198 zusammen mit dem Dompropst von Gurk und dem Abt von Admont in Erscheinung ${ }^{202}$.

Calixt II. nahm Millstatt 1122 in den päpstlichen Schutz und setzte den Zins fest ${ }^{203}$; 1177 folgte Alexander III. seinem Beispiel ${ }^{204}$, verwies jedoch neben Calixt auch auf seine Vorgänger Innozenz II. und Eugen III., deren Privilegien jedoch nicht erhalten sind ${ }^{205}$. Weitere Schutzprivilegien kennen wir von Urban III. (1187) $)^{206}$ und Innozenz III. (1201 ${ }^{207}$ beziehungsweise $\left.1207^{208}\right)$. Eine lediglich in der sogenannten „Millstätter Registratur“ von 1600 auszugsweise überlieferte Urkunde Alexanders III. berichtet von der päpstlichen Bestätigung einer nahe Pordenone gelegenen Kapelle $(1177)^{209}$. Innozenz bestätigte 1207 den Verzicht des Vogtes auf eine vom Kloster jährlich zu entrichtende Abga$b^{210}$. Ein Millstätter Mönch namens Hermann wurde 1203 von Innozenz III.

195 Dr.: ebd., Bd. 1 S. 114-116 Nr. 97 (Kopialbuch); Reg.: GP 1 S. 103 Nr. 1.

196 Dr.: UB Steiermark (wie Anm. 59) Bd. 1 S. 130-132 Nr. 116 (Original); Reg.: GP 1 S. 103 Nr. 2.

197 Dr.: UB Steiermark (wie Anm. 59) Bd. 1 S. 285-287 Nr. 277 (Kopialbuch); Reg.: GP 1 S. 103 f. Nr. 3.

198 Dr.: UB Steiermark (wie Anm. 59) Bd. 1 S. 345-348 Nr. 356 (Original); Reg.: GP 1 S. 104 Nr. 5.

199 Dr.: UB Steiermark (wie Anm. 59) Bd. 1 S. 559-561 Nr. 594 (Original); Reg.: GP 1 S. 105 Nr. 9.

200 Dr.: UB Steiermark (wie Anm. 59) Bd. 1 S. 352 f. Nr. 360 (Original; auf 1155 datiert); Reg.: GP 1 S. 104f. Nr. 6. Zur Datierung auf 1158 vgl. BRACKMANN (wie Anm. 95) S. 200.

201 Dr.: UB Steiermark (wie Anm. 59) Bd. 2 S. 122-125 Nr. 80 (Original).

202 Dr.: UB Seitenstetten, ed. Raab (wie Anm. 2) S. 28 Nr. 20.

203 Dr.: MDC (wie Anm. 2) Bd. 3 S. $229 f$. Nr. 570 (Original); Reg.: GP 1 S. 107 Nr. 1.

204 Dr.: MDC (wie Anm. 2) Bd. 3 S. 456-458 Nr. 1216 (Original); Reg.: GP 1 S. 107 Nr. 4.

$205 \mathrm{Zu}$ den Deperdita GP 1 S. 107 Nr. 2f.

206 Dr.: MDC (wie Anm. 2) Bd. 3 S. 502-504 Nr. 1340 (Original); Reg.: GP 1 S. 108 Nr. 6.

207 Dr.: MDC (wie Anm. 2) Bd. 3 S. 587f. Nr. 1507 (Original).

208 Dr.: ebd., Bd. 4/1 S. 35f. Nr. 1604 (Original).

209 Reg.: ebd., Bd. 3 S. 461 Nr. 1221; GP 1 S. 108 Nr. *5.

210 Dr.: MDC (wie Anm. 2) Bd. 4/1 S. 35 Nr. 1603 (Original). 
in ein Kollegium delegierter Richter in einem Streit zwischen dem Domkapitel von Gurk und dem Pfarrer von Tainach berufen ${ }^{211}$.

Verleihungen des päpstlichen Schutzes mit Besitzbestätigung und Festlegung des jährlichen Zinses kennen wir für das Kloster St. Paul im Lavanttal von Urban II. (1099) $)^{212}$, Innozenz II. (1140) $)^{213}$, Alexander III. (1177) $)^{214}$, Lucius III. (1184) $)^{215}$ und Cölestin III. (1196); die den Namen Cölestins als Aussteller tragende Urkunde ist allerdings eine Fälschung ${ }^{216} .1177$ erweiterte Alexander die Privilegierung, indem er dem Abt die Inful verlieh und die unbefristete Freiheit von Neubruchzehnten ${ }^{217}$; ihm folgten diesbezüglich 1195 Cölestin III., der zur Inful noch den Ring hinzufügte ${ }^{218}$, sowie Innozenz III. (1215) ${ }^{219}$. 1172 bestätigte Alexander dem Stift zudem den Besitz der Kirche St. Martin im Granitztal ${ }^{220}$, was Lucius III. 1184 wiederholte ${ }^{221}$. Innozenz III. wiederum bestätigte 1202 den Besitz einer Kapelle ${ }^{222}$.

Ferner ist eine (seit mindestens 1861) verlorene Indulgenz Innozenz' II. zu verzeichnen, deren Text aus älteren Abschriften bekannt ist, derzufolge das Kloster keine im Namen des Papstes oder eines seiner Legaten geforderte Zahlung zu leisten habe ohne Vorweis des entsprechenden Mandats $(1140)^{223}$.

Eine Klage des Zisterzienserklosters Viktring gegen Reinbert von Mureck nahm Innozenz III. zum Anlass, den Abt von St. Paul zusammen mit jenem von Ossiach und dem Archipresbyter von Völkermarkt zu delegierten Richtern zu ernennen (1210) $)^{224} .1214$ wurde der Abt von Innozenz III. zum dele-

211 Erschlossen aus dem Urteil der Richter (Dr.: ebd., Bd. 1 S. 287-289 Nr. 394). Kodelegaten waren der Archidiakon der Windischen Mark und der Pfarrer von St. Veit. Zur Sache Murauer: Gurk (wie Anm. 4) S. 50 f.

212 Dr.: MDC (wie Anm. 2) Bd. 3 S. 204-206 Nr. 508 (Original); Reg.: GP 1 S. $118 f$. Nr. 1.

213 Dr.: MDC (wie Anm. 2) Bd. 3 S. 284-286 Nr. 732 (Original); Reg.: GP 1 S. $119 f$. Nr. 2.

214 Dr.: MDC (wie Anm. 2) Bd. 3 S. $458-460$ Nr. 1217 (Original); Reg.: GP 1 S. 120 Nr. 3.

215 Dr.: MDC (wie Anm. 2) Bd. 3 S. $493-495$ Nr. 1308 (Original); Reg.: GP 1 S. 121 Nr. 8.

216 Dr.: MDC (wie Anm. 2) Bd. 3 S. 569-571 Nr. 1467 (Fälschung ca. 1225-1240); Reg.: GP 1 S. 121f. Nr. 10. Vgl. MDC (wie Anm. 2) Ergänzungsheft, ed. JAKSCH (wie Anm. 98) S. 12f.

217 Dr.: MDC (wie Anm. 2) Bd. 3 S. 460f. Nr. 1220 (Original); Reg.: GP 1 S. 120 Nr. 4.

218 Dr.: MDC (wie Anm. 2) Bd. 3 S. 565f. Nr. 1453 (Original); Reg.: GP 1 S. 121 Nr. 9.

219 Dr.: MDC (wie Anm. 2) Bd. 4/1 S. 77f. Nr. 1716 (Original).

220 Dr.: ebd., Bd. 3 S. 434f. Nr. 1158 (Original); Reg.: GP 1 S. 120 f. Nr. 6.

221 Dr.: MDC (wie Anm. 2) Bd. 3 S. 492 Nr. 1306 (Original); Reg.: GP 1 S. 121 Nr. 7.

222 Dr.: MDC (wie Anm. 2) Bd. 4/1 S. 9f. Nr. 1531 (Original).

223 Dr.: ebd., Bd. 3 S. 284 Nr. 731 (abschriftlich überliefert).

224 Dr.: ebd., Bd. 4/1 S. $50 f$. Nr. 1642 (Original). 
gierten Richter in einem Streit zwischen dem Erzbischof und der Gurker Kirche bestellt (zusammen mit den Äbten von Viktring und Admont) ${ }^{225}$.

Dreimal wird der Abt von Ossiach als päpstlich delegierter Richter genannt. 1189 ist er zusammen mit Erzbischof Adalbert III. und dem Gurker Bischof Mitglied eines von Clemens III. eingesetzten Kollegiums ${ }^{226}$. Die zweite Nennung stammt aus dem Jahr 1210, als ihm Innozenz III. auftrug, zusammen mit dem Abt von St. Paul und dem Archipresbyter von Völkermarkt eine Klage des offenbar recht streitlustigen Konvents von Viktring zu untersuchen $^{227}$. Das dritte Mal ist der Abt von Ossiach zusammen mit dem Abt von Viktring im Einsatz (1216), wobei das Delegationsreskript nicht auf uns gekommen ist, wir den Vorgang nur aus dem Urteil der Richter kennen ${ }^{228}$. Ein Privileg ist für Ossiach nicht überliefert.

Für Seon liegt ein abschriftlich überliefertes, auf 999 datiertes Privileg Silvesters II. vor, das die Besitztümer und die freie Abtwahl sowie die Vogtei bestätigte $^{229}$. Ebenfalls nur kopial überliefert ist die Bestätigung des SilvesterPrivilegs durch Innozenz II. (1139), die auch die Zinszahlung an die Kurie festsetzte ${ }^{230}$.

Einmal wird der Abt als delegierter Richter eingesetzt, zusammen mit dem Bischof von Brixen und dem Archipresbyter von Grauscharn (Pürgg im Ennstal), um einen Streit zwischen dem Salzburger Erzbischof und dem Stift Berchtesgaden zu untersuchen (1206) 231 .

Für das Benediktinerkloster Sankt Veit (Neumarkt-St. Veit) ist lediglich ein Schutzprivileg Alexanders III. von 1177 überliefert ${ }^{232}$.

\subsection{Zisterzen}

Bei der Zisterze Viktring beginnt die Reihe der Papsturkunden mit einer Schutzverleihung, die auch die Zisterzienserregel vorschrieb und die Besetzung der Vogtei regelte. Sie stammt von Eugen III. (1146) ${ }^{233}$. Bereits zwei Monate später (Jänner 1147) stellte er ein weiteres, im Wortlaut nur geringfügig geän-

225 Dr.: Salzburger UB (wie Anm. 2) Bd. 3 S. 186 Nr. 678 (nur erwähnt). Siehe unten

S. $405 \mathrm{zu}$ Viktring, dort auch zur Überlieferung des Auftrags.

226 Dr.: MDC (wie Anm. 2) Bd. 3 S. $510 f$. Nr. 1361 (Original); Reg.: GP 1 S. 116 Nr. 9.

Vgl. Murauer: Gurk (wie Anm. 4) S. 44f.

227 Dr.: MDC (wie Anm. 2) Bd. 4/1 S. $50 f$. Nr. 1642 (Original).

228 Dr.: MDC (wie Anm. 2) Bd. 1 S. 350 f. Nr. 459 (nur erwähnt).

229 Dr.: MonBoica Bd. 2 S. 123 Nr. 1 (Kopialbuch); Reg.: GP 1 S. 73 Nr. 1.

230 Dr.: MonBoica Bd. 2 S. 127 Nr. 4 (kopiale Überlieferung); Reg.: GP 1 S. 74 Nr. 2.

231 Dr.: Salzburger UB (wie Anm. 2) Bd. 3 S. $70 f$. Nr. 588 (Original).

232 Dr.: MonBoica Bd. 5 S. 239 Nr. 4 (abschriftliche Überlieferung); Reg.: GP 1 S. $87 f$.

Nr. 1.

233 Dr.: MDC (wie Anm. 2) Bd. 3 S. $316 f$. Nr. 816 (Original); Reg.: GP 1 S. 110 Nr. 1. 
dertes Privileg für denselben Abt (Eberhard) aus ${ }^{234} .1193$ ist eine Schutzverleihung durch Cölestin III. zu verzeichnen, die hier auch eine in eine Grangie umgewandelte Kirche umfasste, für die ein jährlicher Zins zu zahlen war $^{235}$. 1194 dehnte Cölestin den Schutz auf die Kirche Köttmannsdorf aus und bestätigte alle eventuell noch zu erwerbenden Benefizien ${ }^{236}$. Im Umfeld der Schutzverleihung durch Innozenz III. (1202) sind innerhalb weniger Tage drei Papsturkunden für Viktring ausgestellt worden. Neben einem feierlichen, die einzelnen Besitzungen namentlich aufzählenden, mit den Unterschriften der Kardinäle versehenen Schutzprivileg vom 19. März ${ }^{237}$ erhielt Viktring noch ein weiteres, textlich stark verkürztes Schutzprivileg (11. März) ${ }^{238}$ und die Bestätigung eines vom Erzbischof und vom Herzog von Österreich geschenkten Gute $^{239}$. Möglicherweise reichte das bescheidenere Privileg den Bedürfnissen der Zisterzienser nicht, weshalb man acht Tage später ein umfangreicheres und genaueres impetrierte. Eine weitere päpstliche Besitzbestätigung stammt aus dem Jahre $1206^{240}$.

Ein Mandat für den Abt können wir erst im Pontifikat Innozenz' III. feststellen $(1210)^{241} .1214$ erhielt der Abt ein Delegationsreskript Innozenz', von dem wir nur wissen, weil der Abt seinen beiden Kodelegaten, den Äbten von Admont und St. Paul im Lavanttal, schrieb, er könne den päpstlichen Auftrag wegen der anstehenden Reise zum Generalkapitel der Zisterzienser nicht wahrnehmen; es ist dies der einzige dokumentierte Fall einer tatsächlichen Anwendung der bekannten Quod si non omnes-Formel im Untersuchungszeitraum $^{242} .1216$ war der Abt zusammen mit seinem Kollegen aus Ossiach in einem anderen Auftrag Innozenz' III. im Einsatz $z^{243}$.

Raitenhaslach nahm Eugen III. 1147 in den päpstlichen Schutz ${ }^{244}$; ihm tat es 1180 Alexander III. gleich ${ }^{245}$, sowie (1195) Cölestin III. ${ }^{246}$ Ein Privileg In-

234 Dr.: MDC (wie Anm. 2) Bd. 3 S. 320 f. Nr. 824 (Original); Reg.: GP 1 S. 111 Nr. 2.

235 Dr.: MDC (wie Anm. 2) Bd. 3 S. 554f. Nr. 1433 (Original); Reg.: GP 1 S. 111 Nr. 3.

236 Dr.: MDC (wie Anm. 2) Bd. 3 S. 557 Nr. 1438 (Original); Reg.: GP 1 S. 111 Nr. 4.

237 Dr.: MDC (wie Anm. 2) Bd. 4/1 S. 6-9 Nr. 1530 (Original).

238 Dr.: ebd., S. 4 Nr. 1527 (Original).

239 Dr.: ebd., S. 5f. Nr. 1529 (Original).

240 Dr.: ebd., S. 26 Nr. 1581 (Original).

241 Dr.: Salzburger UB (wie Anm. 2) Bd. 3 S. 136 Nr. 635 (Original). Siehe auch oben S. 403f. zu Admont.

242 Dr.: ebd., S. 186 Nr. 678 (nur erwähnt). Zu den Formeln vgl. Brigitte Meduna: Studien zum Formular der päpstlichen Justizbriefe von Alexander III. bis Innocenz III. (1159-1216): die non-obstantibus-Formel, Wien 1989 (SB ÖAW, phil.-hist. K1.536).

243 Dr.: MDC (wie Anm. 2) Bd. 1 S. 350f. Nr. 459. Die Delegation lässt sich nur aus dem Urteil der beiden Richter erschließen.

244 Dr.: Krausen (wie Anm. 107) S. 9-11 Nr. 6 (Fälschung aufgrund eines vernichteten Originals); Reg.: GP 1 S. 85 Nr. 2.

245 Dr.: Krausen (wie Anm. 107) S. 28-30 Nr. 27 (Original); Reg.: GP 1 S. 86 Nr. 4.

246 Dr.: Krausen (wie Anm. 107) S. 43f. Nr. 45 (Original); Reg.: GP 1 S. 86 Nr. 6. 
nozenz' III. ist auf 1202 datiert $^{247}$, ein Schutzprivileg auf $1214^{248} ; 1209$ bestätigte er dem Kloster die vom Erzbischof überlassenen Einkünfte an der Saline zu Hallein ${ }^{249}$.

1196 erhielt der Abt ein päpstliches Delegationsreskript zusammen mit dem Erzbischof und dem Abt von St. Peter ${ }^{250} ; 1197$ erging in dieser Sache ein weiteres päpstliches Mandat an denselben Personenkreis ${ }^{251}$. Auch Innozenz III. berief 1200 den Abt in ein Kollegium von delegierten Richtern zusammen mit den Bischöfen von Passau und Freising; sie erhielten zwei Aufträge: Einerseits hatten sie eine Klage des Salzburger Domkapitels gegen seinen Erzbischof zu untersuchen, andererseits die Voruntersuchung für die Heiligsprechung Bischof Virgils zu führen ${ }^{252}$. Kollege des Abtes von St. Peter (und des Propstes von Ranshofen) war der Abt von Raitenhaslach auch in einer von Innozenz III. eingesetzten Kommission in Sachen der Saline auf dem Tuval $(1205)^{253}$. 1211 erhielt der Abt ein weiteres Delegationsreskript Innozenz' III. (zusammen mit dem Salzburger Domdekan) ${ }^{254}$.

Der Abt von Raitenhaslach und der Propst von Au sollten zusammen mit dem Freisinger Dompropst im Auftrag Cölestins III. den Bruder eines verstorbenen Priesters zur Einhaltung der testamentarischen Bestimmungen und zur Restitution der dem Kloster Baumburg entfremdeten Güter zwingen (1196) ${ }^{255}$.

Für die Zisterze Rein ist lediglich ein Schutzprivileg Eugens III. aus dem Jahr 1147 überliefert ${ }^{256}$.

\subsection{Kartausen}

Lediglich zwei Schutzprivilegien sind in der in der Untersteiermark (heute Slowenien) gelegenen Kartause Geirach zu verzeichnen, von Alexander III.

247 Dr.: KRAUSEN (wie Anm. 107) S. 49f. Nr. 54 (Original). Es handelt sich hierbei vermutlich um jenes Privileg, welches erwirkt zu haben sich Erzbischof Eberhard II. 1203 rühmte, Salzburger UB (wie Anm. 2) Bd. 3 S. 46 f. Nr. 569.

248 Dr.: KRAUSEN (wie Anm. 107) S. 74-79 Nr. 75 (Original).

249 Dr.: ebd., S. 66 Nr. 68 (Original).

250 Dr.: Salzburger UB (wie Anm. 2) Bd. 2 S. $683 f$ f. Nr. 505 (Original). Siehe auch oben S. 386 Kap. 3.5.

251 Dr.: ebd., Bd. 2 S. 702 f. Nr. 517 (Original). Siehe auch oben S. 386 Kap. 3.5.

252 Dr.: ebd., Bd. 3 S. 3 Nr. 535 (Original) bzw. Bd. 4 S. 474f. Nr. 405; Reg.: KRAUSEN (wie Anm. 107) S. 49 Nr. 53. Die Stücke sind auf den 30. September bzw. 1. Oktober 1200 datiert.

253 Dr.: Salzburger UB (wie Anm. 2) Bd. 3 S. 65 Nr. 585 (Original).

254 Dr.: ebd., Bd. 3 S. 153f. Nr. 649 (nur erwähnt in einer Urkunde der beiden Richter).

255 Dr.: Pflugk-Harttung (wie Anm. 55) Bd. 1 S. 372 Nr. 434 (Original); Reg.: GP 1 S. 78 Nr. 11 = KRAUSEN (wie Anm. 107) S. 44 Nr. 46.

256 Dr.: UB Steiermark (wie Anm. 59) Bd. 1 S. S. $270 f$. Nr. 260 (Original); Reg.: GP 1 S. 98f. Nr. 1. 
$(1173 / 74)^{257}$ und Lucius III. (1185 $)^{258}$. Auch für Seitz sind nur vier Urkunden überliefert. Die älteste überlieferte Papsturkunde ist ein Mandat Alexanders III. von $1177^{259}$. In den päpstlichen Schutz wurde die Kartause erst von Lucius III. genommen $(1185)^{260}$, von dem auch eine Indulgenz auf uns gekommen ist (ebenfalls 1185$)^{261}$; ferner bestätigte er vom Markgrafen der Steiermark geschenktes Eigengut (wiederum 1185) ${ }^{262}$.

\subsection{Augustiner-Chorherrenstifte}

Für das Augustiner-Chorherrenstift Vorau ist nur ein Schutzprivileg mit Bestätigung der Augustiner-Regel von Alexander III. (1171) überliefert ${ }^{263}$. Wie in Vorau steht auch bei Seckau am Beginn eine Schutzverleihung durch Innozenz II. $(1143)^{264}$, der eine Verleihung durch Alexander III. (1171) folgt ${ }^{265}$. Beide Privilegien bestätigten auch die Augustiner-Regel. Als delegierten Richter finden wir den Propst nur zweimal, zunächst 1202 zusammen mit dem Archidiakon von Friesach ${ }^{266} .1210$ folgte ein weiteres Mandat Innozenz' III., das auch an die Äbte von Admont und Viktring adressiert war ${ }^{267}$.

Für das Augustiner-Chorherrenstift Gars am Inn setzt die Überlieferung von Papsturkunden relativ spät ein, erst mit Alexander III. Wohl 1172 trug er den Klerikern im Archidiakont Gars auf, dem Propst Heinrich I. von Gars Gehorsam zu erweisen ${ }^{268}$. Sein Nachfolger Lucius III. nahm das Stift 1185 in

257 Dr.: UB Steiermark (wie Anm. 59) Bd. 1 S. 530f. Nr. 558 (Abschrift); Reg.: GP 1 S. 137f. Nr. 1 = MDC (wie Anm. 2) Bd. 1 S. 214 Nr. 280.

258 Dr.: UB Steiermark (wie Anm. 59) Bd. 1 S. 606 Nr. 635 (Original); Reg.: GP 1 S. 138 Nr. 2 = MDC (wie Anm. 2) Bd. 1 S. 249 Nr. 332.

259 Dr.: UB Steiermark (wie Anm. 59) Bd. 1 S. 554f. Nr. 590 (Original); Reg.: GP 1 S. 135 Nr. 3.

260 Dr.: UB Steiermark (wie Anm. 59) Bd. 1 S. 607 Nr. 636 (Original); Reg.: GP 1 S. 136 Nr. 5.

261 Dr.: UB Steiermark (wie Anm. 59) Bd. 1 S. 605f. Nr. 634 (Original); Reg.: GP 1 S. 136 Nr. 4.

262 Dr.: UB Steiermark (wie Anm. 59) Bd. 1 S. 609 Nr. 638 (Original); Reg.: GP 1 S. 136 Nr. 7.

263 Dr.: UB Steiermark (wie Anm. 59) Bd. 1 S. 498-501 Nr. 539 (kopiale Überlieferung); Reg.: GP 1 S. 97 Nr. 1.

264 Dr.: UB Steiermark (wie Anm. 59) Bd. 1 S. 219f. Nr. 211 (Original); Reg. GP 1 S. 100 Nr. 1.

265 Dr.: UB Steiermark (wie Anm. 59) Bd. 1 S. 501-505 Nr. 540 (Original); Reg. GP 1 S. 100 f. Nr. 2.

266 Dr.: MDC (wie Anm. 2) Bd. 1 S. 284f. Nr. 389 (Original).

267 Dr.: Salzburger UB (wie Anm. 2) Bd. 3 S. 136 Nr. 635 (Original). Siehe auch oben S. 404 zu Admont.

268 Dr.: Die Traditionen, Urkunden und Urbare des Stiftes Gars, ed. Heiner HofmanN, München 1983 (Quellen und Erörterungen zur bayerischen Geschichte N. F. 31) S. $87 f$. Nr. 4 (Original); Reg.: GP 1 S. 80 Nr. 1 (zu 1171/72). 
den päpstlichen Schutz ${ }^{269}$, Clemens III. wiederholte 1189 dieses Privileg ${ }^{270}$. 1197 bestätigte Cölestin III. ein von päpstlich delegierten Richtern gefälltes Urteil im schon erwähnten Streit zwischen Gars und $\mathrm{Au}^{271}$.

Das erste Schutzprivileg für Au am Inn, das auch die Augustiner-Regel bestätigte, stammt von Alexander III. (1178); in diesem wird eine nicht erhaltene Vorurkunde Hadrians IV. (1154/59) erwähnt ${ }^{272}$. Alle weiteren Au betreffenden Schreiben stammen von Cölestin III. 1196 bestätigte er einen Besitztausch mit dem Bischof von Regensburg ${ }^{273}$. Im gleichen Jahr schrieb er noch einmal an den Propst von Au, um die Vogtnachfolge zu regeln ${ }^{274}$. Wiederum 1196 erging ein Mandat Cölestins an den Propst von Au (zusammen mit dem Bischof von Passau und dem Propst von Freising), nämlich einen Salzburger miles zur Wiedergutmachung der Baumburg zugefügten Schäden anzuhal$\operatorname{ten}^{275}$.

Circa 1102/05 nahm Papst Paschalis II. jene Güter Berchtesgadens unter den päpstlichen Schutz, die von den bisherigen Eigentümern für die Gründung gestiftet worden waren ${ }^{276}$. 1121 bestätigte Calixt II. die Augustiner-Regel, die Vogtei und die Höhe des an die römische Kirche zu entrichtenden jährlichen Zinses $^{277}$. Weitere Bestätigungen der Schutzverleihung und der Regel sind überliefert von Innozenz II. (1142) ${ }^{278}$, Eugen III. (1145) $)^{279}$ und Hadrian IV. $(1157)^{280}$.

Für Berchtesgaden, das mehr Kontakte nach Rom hatte als die anderen Klöster und Stifte, sind nicht nur Privilegien überliefert. Innozenz II. mahnte die Chorherren zur strikten Einhaltung der Augustiner-Regel (circa

269 Dr.: HofmanN (wie in Anm. 268) S. 91-93 Nr. 6 (Original); Reg.: GP 1 S. 80 Nr. 2

270 Dr.: HofmanN (wie in Anm. 268) S. 94-96 Nr. 7 (Original); Reg.: GP 1 S. 80 Nr. 3

271 Dr.: Hofmann (wie in Anm. 268) S. 101f. Nr. 12 (Original); Reg.: GP 1 S. 81 Nr. 6. Zum Delegationsreskript siehe oben Anm. 169.

272 Dr.: Bullarium Lateranense sive collectio privilegiorum apostolicorum a sancta sede canonicis regularibus ordinis sancti Augustini congregationis Salvatoris Lateranensis concessorum, Romae 1727, Appendix S. 1 (Original); Reg.: GP 1 S. 82f. Nr. 1, 2.

273 Dr.: MonBoica Bd. 1 S. 223 Nr. 8 (Original); Reg.: GP 1 S. 83 Nr. 3.

274 Dr.: BRACKMANN (wie Anm. 95) S. 198f. (kopiale Überlieferung); Reg.: GP 1 S. 83 Nr. 4.

275 Dr.: Pflugk-Harttung (wie Anm. 55) Bd. 1 S. 377 Nr. 440 (Original); Reg.: GP 1 S. 78 Nr. 12; Zur Berufung des Propstes von Au in ein anderes Kollegium von delegierten Richtern durch Cölestin (1196) siehe oben bei Anm. 255 zu Raitenhaslach.

276 Dr.: Migne PL 163 Sp. 368 Nr. 411 (Original); Notitia fundationis et traditionum S. Georgii in Nigra silva, ed. Oswald HoLDER-EGGER, in: MGH SS 15/2, Hannover 1888, S. 1005-1023, hier S. 1066 (nach Traditionscodex); Reg.: GP 1 S. 60 Nr. 1.

277 Dr.: Migne PL 163 Sp. 1206 Nr. 132 (Original); Reg.: GP 1 S. 60 Nr. 2.

278 Dr.: Migne PL 179 Sp. 573 Nr. 513 (Original); Reg.: GP 1 S. 60f. Nr. 4.

279 Dr. Migne PL 180 Sp. 1057 Nr. 41 (Original); Reg.: GP 1 S. 62 Nr. 9.

280 Dr.: Salzburger UB (wie Anm. 2) Bd. 2 S. 457-459 Nr. 329 (Original); Reg.: GP 1 S. 63 Nr. 13. 
1138/43) ) $^{281}$ und Hadrian IV. (circa 1157/59) zum Gehorsam gegenüber Propst Heinrich $^{282}$. Wahrscheinlich 1147 bestätigte Eugen III. den von Erzbischof Eberhard II. herbeigefuihrten Vergleich zwischen dem Kloster und Wernhard von Julbach ${ }^{283}$. Wohl 1154 sicherte Anastasius IV. dem Propst Hilfe gegen alle Schurken $\mathbf{z u}^{284}$. Vermutlich auf 1197 ist ein Mandat Cölestins III. zu datieren, in welchem er Propst und Chorherren auffordert, einer Vorladung der päpstlich delegierten Richter im Streit um die Saline auf dem Tuval Folge zu leisten $^{285}$. Mit diesem Prozess hängt auch ein Schreiben Innozenz' III. von 1206 für den Propst und die Kanoniker zusammen, mit welchem er die Einhaltung eines in der Sache ergangenen Schiedsspruches Erzbischof Adalberts III. anordnete $^{286} .1213$ beauftragte Innozenz III. den Propst und den Dekan zusammen mit dem Dompropst und dem Domdekan, gegen den Untervogt des Klosters Michaelbeuern einzuschreiten ${ }^{287}$.

Auch für St. Zeno in Reichenhall ist eine überdurchschnittlich große Zahl päpstlicher Privilegien mit Schutzverleihung, Bestätigung der AugustinerRegel und der Besitzungen überliefert, und zwar zunächst aus dem Pontifikat Lucius' II. (1144) ${ }^{288}$; dieses Privileg erfuhr Bestätigungen von seinen Nachfolgern Eugen III. (zweimal im Jahre 1146 für zwei verschiedene Pröpste) ${ }^{289}$, Hadrian IV. (1157) ${ }^{290}$ und Alexander III. (1169) $)^{291}$. Die beiden letztgenannten Privilegien enthalten zudem eine Bestätigung der Exemtion St. Zenos von der Gerichtsbarkeit des Salzburger Archidiakons. Cölestin III. stellte 1195 ein weiteres Schutzprivileg aus ${ }^{292}$. Nicht im Original ist ein Mandat Alexanders III. für den Propst überliefert (1177), in dem er ihn beauftragt, die Gegner des Klos-

281 Dr.: Pflugk-Harttung (wie Anm. 55) Bd. 2 S. 319 Nr. 355 (Original); Reg.: GP 1 S. $61 \mathrm{Nr} .7$. Vgl. Das diesbezügliche Mandat für Erzbischof Konrad I. (oben Anm. 112).

282 Dr.: Pflugk-Harttung (wie Anm. 55) Bd. 2 S. 363 Nr. 413 (Original); Reg.: GP 1 S. 63 Nr. 15.

283 Dr.: BRACKMANN (wie Anm. 95) S. 192f. (aus dem Berchtesgadener Privilegienbuch); Reg.: GP 1 S. 62 Nr. 11. Zu dem Streit siehe auch oben Anm. 95.

284 Dr.: Pflugk-Harttung (wie Anm. 55) Bd. 2 S. 356 Nr. 404 (Original); Reg.: GP 1 S. 62 Nr. 12.

285 Deperditum. Erwähnt im Schreiben Cölestins an die delegierten Richter, Dr.: Salzburger UB (wie Anm. 2) Bd. 2 S. 702f. Nr. 517; Reg.: GP 1 S. 51f. Nr. 19. Siehe oben Anm. 64.

286 Dr.: Salzburger UB (wie Anm. 2) Bd. 3 S. $71 f$. Nr. 589 (Original).

287 Dr.: ebd., Bd. 3 S. 166 Nr. 661 (Original).

288 Dr.: MonBoica Bd. 3 S. 530 Nr. 3 (Original); Reg.: GP 1 S. 66 Nr. 1.

289 Dr.: MonBoica Bd. 3 S. 532 Nr. 4 (Original); Reg.: GP 1 S. 66 Nr. 2; bzw. Dr.: MonBoica Bd. 3 S. 534 Nr. 5 (Original); Reg.: GP 1 S. 66f. Nr. 3.

290 Dr.: MonBoica Bd. 3 S. 537 Nr. 7 b (Original); Reg.: GP 1 S. 67 Nr. 4.

291 Dr.: MonBoica Bd. 3 S. 544 Nr. 13 (Original); Reg.: GP 1 S. 67 Nr. 5.

292 Dr.: MonBoica Bd. 3 S. 552 Nr. 19 (Original); Reg.: GP 1 S. 67 Nr. 7. 
ters Tegernsee in Reichenhall zu interdizieren und zu exkommunizieren sowie zur Wiedergutmachung der Schäden anzuhalten ${ }^{293}$.

Das Augustiner-Chorherrenstift Herrenchiemsee, aus dem 1216 das Eigenbistum Chiemsee hervorging und dessen Kanoniker dort dann das Domkapitel bildeten, verfügt über Schutzprivilegien mit Bestätigung der Augustiner-Regel und der Besitzungen von Innozenz II. (1142) $)^{294}$ und Hadrian IV. (1157) $)^{295}$. Ein Schreiben Alexanders III. von 1171/72, das anders als die eben genannten Privilegien jeder feierlichen Form entbehrte, nahm das Stift abermals in den päpstlichen Schutz und bestätigte die Besitzungen, erwähnte aber die Augustiner-Regel nicht ${ }^{296}$.

Baumburg ist ebenfalls verhältnismäßig reich mit Papsturkunden gesegnet. Nicht eindeutig datierbar ist die Schutzverleihung durch Paschalis II. (circa $1102 / 1105)^{297}$; Gleiches gilt für die einschlägige Urkunde Honorius' II. (11251130), die neben Schutzverleihung und Besitzbestätigung auch die Zinszahlung und die freie Propstwahl festlegte ${ }^{298}$. Mit einigen Erweiterungen über die Vogtwahl wurden diese Privilegien von Innozenz II. (1139) ${ }^{299}$ und Lucius II. $(1145)^{300}$ bestätigt. 1141 bestätigte Innozenz II. die Schenkung einer Kirche an Baumburg durch den Bischof von Regensburg und führte die AugustinerRegel ein ${ }^{301}$. Eine abermalige Bestätigung all dessen (unter Einschluss der Regel) geht auf Lucius III. (1185) zurück ${ }^{302}$, dem Clemens III. 1189 folgte $^{303}$. Von Cölestin III. ist keine Bestätigung der Privilegien überliefert, lediglich die eines erworbenen Eigenguts und von Weingärten (1195) ${ }^{304}$. Mandate und Delegationsresripte für Mitglieder des Konvents von Baumburg sind nicht bekannt.

\subsection{Kollegiatstifte}

Anders als für Baumburg ist für das Kollegiatstift Maria Saal kein einziger päpstlicher Schutzbrief überliefert; die erste Urkunde für den Propst stammt

293 Das Schreiben ist nur in einem Brief Propst Ottos von Reitenbuch an den Abt von Tegernsee erwähnt, GP 1 S. 367f. Nr. *14.

294 Dr.: Pflugk-Harttung (wie Anm. 55) Bd. 2 S. 326 Nr. 365 (Original); Reg.: GP 1 S. 70 Nr. 1.

295 Dr.: MonBoica Bd. 2 S. 388 Nr. 7 (Original); Reg.: GP 1 S. 70 Nr. 2.

296 Dr.: BrackmanN (wie Anm. 95) S. 197 (Original); Reg.: GP 1 S. $70 f$. Nr. 3.

297 Dr.: MonBoica Bd. 2 S. 179 Nr. 2 (kopiale Überlieferung); Reg.: GP 1 S. 76 Nr. 1.

298 Dr.: MonBoica Bd. 2 S. 180 Nr. 3 (Original); Reg.: GP 1 S. 76 Nr. 2.

299 Dr.: MonBoica Bd. 2 S. 184 Nr. 5 (Original); Reg.: GP 1 S. 76 Nr. 3.

300 Dr.: MonBoica Bd. 2 S. 187 Nr. 8 (Original); Reg.: GP 1 S. 77 Nr. 6.

301 Dr.: MonBoica Bd. 2 S. 186 Nr. 7 (aus Kopialbuch); Reg.: GP 1 S. 77 Nr. 4.

302 Dr.: Pflugk-Harttung (wie Anm. 55) Bd. 1 S. 327 Nr. 375 (Original); Reg.: GP 1

S. 77 Nr. 7.

303 Dr.: MonBoica Bd. 2 S. 191 Nr. 10 (Original); Reg.: GP 1 S. 78 Nr. 8.

304 Dr.: MonBoica Bd. 2 S. 194 Nr. 12 (Original); Reg.: GP 1 S. 78 Nr. 10. 
von Alexander III. (1177), mit welcher er ein (nicht erhaltenes) Urteil des Salzburger Erzbischofs zugunsten Maria Saals bestätigte ${ }^{305}$. Ferner muss Urban III. dem Propst die Kapelle St. Donat verliehen haben $(1185 / 87)^{306}$, wovon wir aber nur wissen, weil diese Gegenstand eines Streites mit St. Georgen am Längsee wurde, in dessen Verlauf Papst Clemens III. delegierte Richter bestell$\mathrm{te}^{307}$.

1188 war Propst Ekkehard zusammen mit Bischof Dietrich von Gurk und Archidiakon Hermann Mitglied eines von Clemens III. eingesetzten Kollegiums delegierter Richter ${ }^{308}$. Unter Innozenz III. wurde sein Nachfolger Heinrich auf Klage des Abtes von Viktring gegen einen Salzburger miles zusammen mit den Pfarrern von Molzbichl und Tiffen in ein solches Gremium berufen $(1206)^{309} .1211$ gab wieder eine Klage des Viktringer Abtes den Anstoß, um den Propst mit der Untersuchung eines Streitfalles zu beauftragen; Kodelegaten waren die Archidiakone von Völkermarkt und Zeltschach. Wir dürfen aus dieser Parallelität den Schluss ziehen, dass die klagende Partei zumindest den Propst von Maria Saal für das Richterkollegium nominiert hat, wahrscheinlicher aber das ganze Dreierkollegium impetriert hat ${ }^{310}$.

\subsection{Frauenklöster}

Für das Benediktinerinnenstift Frauenchiemsee kennen wir nur die Schutzverleihung durch Innozenz II. (1141), der auch die Besitzungen bestätigte ${ }^{311}$. Die erste Schutzverleihung für das Frauenkloster St. Georgen am Längsee mit einer Besitzbestätigung stammt aus dem Jahr 1174 (Alexander III.) ${ }^{312}$, eine weitere von 1189 (Clemens III.) ${ }^{313}$. Ob Göß im 11./12. Jahrhundert ein Kanonissenstift oder eines der Benediktinerinnen war, lässt sich kaum sagen ${ }^{314}$. Bereits

305 Dr.: MDC (wie Anm. 2) Bd. 3 S. 463f. Nr. 1227 (Original); Reg.: GP 1 S. 112 Nr. 1. Vgl. Peter G. Tropper: Dom- oder Stiftskirche Maria Saal? Zu den kirchlichen Institutionen Kollegiatstift, Propstei und Dechantei in Maria Saal, in: Marktgemeinde Maria Saal: Geschichte, Kultur, Natur. Ein Gemeindebuch für alle, hg. v. Alfred OGRIS/Wilhelm WADL, Klagenfurt 2007, S. 331-344.

306 GP 1 S. 112 Nr. $\star 2$.

307 Siehe unten S. 414 Kap. 11.1.

308 Siehe unten S. 413 Kap. 11.1. Das Reskript wird nur in einer Urkunde des Erzbischofs erwähnt; Dr.: Salzburger UB (wie Anm. 2) Bd. 2 S. 616f. Nr. 455; Reg.: GP 1 S. 108 Nr. $\left.{ }^{\star} 7\right)$.

309 Dr.: MDC (wie Anm. 2) Bd. 4/1 S. 28 Nr. 1585 (Original).

310 Dr.: ebd., S. 54f. Nr. 1654 (Original).

311 Dr.: MonBoica Bd. 2 S. 447 Nr. 3 (nur kopial überliefert); Reg.: GP 1 S. 72 Nr. 1.

312 Dr.: MDC (wie Anm. 2) Bd. 3 S. 442-444 Nr. 1182 (Original); Reg.: GP 1 S. 114f. Nr. 4.

313 Dr.: MDC (wie Anm. 2) Bd. 3 S. 512f. Nr. 1363 (Original); Reg.: GP 1 S. 116 Nr. 11.

314 Vgl. zur Forschungsdiskussion Murauer: Gurk (wie Anm. 4) S. 19. 
unmittelbar nach der Gründung (1020) nahm Papst Benedikt VIII. (10121020) das Kloster in den päpstlichen Schutz (wenn auch die explizite Formulierung fehlt) und legte die Höhe des jährlich zu zahlenden Zinses fest ${ }^{315}$. Eine formelle Schutzverleihung mit Besitzbestätigung ist von Eugen III. überliefert $(1148)^{316}$.

\section{Sonstige Kleriker}

Kleriker, die nicht einem der bedeutenden Klöster oder Stifte angehörten, tauchen nur selten auf - und zwar erst mit dem Pontifikat Innozenz' III., und ausschließlich als delegierte Richter in lokalen, aber auch überregionalen Streitigkeiten; zweimal wird der Archipresbyter von Grauscharn (Pürgg am Grimming, im steirischen Ennstal) von Innozenz III. als delegierter Richter berufen (- einmal zusammen mit dem Bischof von Brixen und dem Abt von Seeon $(1206)^{317}$, das andere Mal (1211) zusammen mit den Pfarrern von Wiener Neustadt und Fischau am Steinfeld ${ }^{318}$; wieder ein anderes Mal (1202) der Archidiakon von Grauscharn (zusammen u. a. mit Erzbischof Eberhard II.) ${ }^{319}$. Vor 1214 war ein Archidiakon von Grauscharn (vielleicht dieselbe Person) zusammen mit seinem Kollegen aus Zeltschach und dem Erzbischof mit der Untersuchung eines Streites zwischen Formbach und Vorau betraut, wobei wir hier ausnahmsweise etwas über die Ausführung des Auftrages erfahren; es war schließlich der Archidiakon von Grauscharn allein, der den Auftrag ausführte und ein Urteil fällte, das jedoch keinen Bestand hatte, da es erst nach einer rechtmäßigen Appellation an den Papst ausgesprochen worden war und zudem auf einem unter Fälschungsverdacht stehenden Privileg beruhte; folglich wurde es von der Gegenpartei angefochten und die Sache einem anderen Richterkollegium anvertraut ${ }^{320}$. Auch der Archdiakon von Friesach fungiert einmal als delegierter Richter (1202, gemeinsam mit dem Propst von Seckau) ${ }^{321}$. Der Archipresbyter von Völkermarkt hatte 1202 zusammen mit dem Salzburger Erzbischof eine Klage des Klosters Viktring gegen die Erben des Grafen von Bogen zu untersuchen ${ }^{322} .1210$ wurde der Archipresbyter wieder in einer von

315 Dr.: UB Steiermark (wie Anm. 59) Bd. 1 S. 717 f. Nr. 726 (nur im Codex Udalrici überliefert); Reg.: GP 1 S. 96 Nr. 1.

316 Dr.: UB Steiermark (wie Anm. 59) Bd. 1 S. $287-289$ Nr. 278 (Original); Reg.: GP 1 S. 96 Nr. 2.

317 Dr.: Salzburger UB (wie Anm. 2) Bd. 3 S. $70 f$. Nr. 588 (Original).

318 Dr.: ebd., Bd. 3 S. 139-141 Nr. 639 (nur erwähnt in einer Urkunde Erzbischof Eberhards II.).

319 Dr.: ebd., Bd. 3 S. 116f. Nr. 621 (nur erwähnt in einem Urteil Eberhards).

320 Dr.: UB Steiermark (wie Anm. 59) Bd. 2 S. $190 f$. Nr. 126 (nur erwähnt in einem neuen Delegationsreskript).

321 Dr.: MDC (wie Anm. 2) Bd. 1 S. 284f. Nr. 389 (Original).

322 Dr.: ebd., Bd. 4/1 S. 4f. Nr. 1528 (Original). 
Viktring angestoßenen Sache als delegierter Richter nominiert, diesmal zusammen mit den Äbten von Ossiach und St. Paul im Lavanttal ${ }^{323} .1203$ war der Pfarrer von St. Veit (zusammen mit einem Millstätter Mönch) und dem Archidiakon der Windischen Mark Mitglied eines von Innozenz III. eingesetzten Kollegiums delegierter Richter ${ }^{324}$.

\section{Laien als Empfänger von Papsturkunden}

Als einziger weltlicher Empfänger einer Papsturkunde ist Herzog Bernhard von Kärnten (1202-1256) festzumachen, den Innozenz III. 1209 mahnte, den Gösser Nonnen, als deren Vogt der Herzog fungierte, seinen besonderen Schutz angedeihen zu lassen ${ }^{325}$.

\section{Das Bistum Gurk}

\subsection{Der Bischof von Gurk}

Die an den Bischof von Gurk gerichteten Schreiben sind weit weniger zahlreich als die an den Erzbischof, von dem er im Untersuchungszeitraum aufgrund der komplizierten Stellung als „Eigenbistum“ de facto weitgehend abhängig war. Das enge Zusammenwirken mit dem Metropoliten wird nicht zuletzt dadurch dokumentiert, dass etliche dieser Schriftstücke sowohl an den Gurker als auch an den Salzburger Oberhirten ergingen. Dies traf etwa für das schon erwähnte, Gerhoch von Reichersberg betreffende Schreiben Lucius' II. (1144) zu, das an Konrad I. von Salzburg und Roman I. von Gurk (11311167) gerichtet war $^{326}$. An Erzbischof Konrad III. und Bischof Roman II. (1174-1179) erging nach einer Klage des Abtes von St. Paul im Lavanttal der Befehl Alexanders III., gegen dessen Feinde einzuschreiten (1177) ${ }^{327}$.

1172 sind Bischof und Dompropst von Gurk sowie der Salzburger Dompropst und die Salzburger Domherren Adressaten eines Schreibens Alexanders III. ${ }^{328}$ Nicht überliefert ist das Mandat Lucius' III. für Bischof Dietrich I.

323 Dr.: ebd., S. 50f. Nr. 1642 (Original).

324 Erschlossen aus dem Urteil der Richter (Dr.: ebd., Bd. 1 S. 287-289 Nr. 394).

325 Dr.: ebd., Bd. 3 S. 49 Nr. 1639 (Original).

326 Dr.: Insert in Gerhoch von Reichersbergs Commentarius in Psalmum XXIV (Gerhohi praepositi Reichersbergensis libelli selecti [wie Anm. 88], S. 420); Reg.: GP 1 S. 194 Nr. 15.

327 Dr.: MDC (wie Anm. 2) Ergänzungsheft, ed. JAKSCH (wie Anm. 98) S. 11 Nr. 1228a $=3056$ (Abschrift); Reg.: GP 1 S. 120 Nr. 5. Siehe oben Anm. 98.

328 Dr.: MDC (wie Anm. 2) Bd. 1 S. 206f. Nr. 272 (Original); Reg.: GP 1 S. 33 Nr. 106. Siehe oben Anm. 136. 
(1179-1194), das die Schenkung eines Lehens an die Kartause Seitz anordnete; es wird lediglich in der Schenkungsurkunde des Bischofs von 1187 erwähnt $^{329}$.

1188 wurde Dietrich von Papst Clemens III. als delegierter Richter zusammen mit seinem Archidiakon und dem Propst von Maria Saal in einer Streitsache zwischen Millstatt und dem Abt von Lieseregg eingesetzt ${ }^{330} ; 1189$ ist er zusammen mit Erzbischof Adalbert III. und dem Abt von Ossiach Mitglied eines anderen von Clemens III. eingesetzten Kollegiums ${ }^{331}$. Innozenz III. betraute Bischof Walther (1200-1213) zusammen mit Erzbischof Eberhard II. mit der Aufgabe, Bischof Wolfger von Passau die Erlaubnis zur Translation auf den Stuhl des Patriarchen von Aquileia zu erteilen (1204) ${ }^{332}$.

Aus dem Jahr 1172 stammt eine im Original überlieferte Urkunde Alexanders III., die nur an Bischof Heinrich I. (1167-1174) von Gurk adressiert ist und mit der er die bestehenden Grenzen der Diözese und das Vikariat im Erzbistum bestätigte ${ }^{333}$; eine erneute Bestätigung erfolgte $1176^{334}$. Auch in dem noch zu gründenden Salzburger (Eigen-)Bistum Chiemsee erhielt Bischof Heinrich II. (1214-1217) die Rechte des Vikars (1216) ${ }^{335} .1177$ gewährte Alexander III. Bischof Roman II. das Recht, dem Erzbischof Priester für die auf dem Grund und Boden seines Bistums gelegenen Kapellen zu präsentieren ${ }^{336}$.

Päpstliche Schutzprivilegien für den Bischof von Gurk sind nur zwei an der Zahl überliefert; hierbei dürfte es sich um Eventualausfertigungen handeln, da beide Stücke fast gleichlautend sind und an aufeinander folgenden Tagen ausgestellt wurden (20./21. März [1186]); das zweite unterscheidet sich vom ersten lediglich durch das Fehlen der namentlichen Aufzählung der Gurker Güter $^{337}$. Bei an alle Salzburger Suffragane adressierten Papstschreiben darf vermutet werden, dass ein Exemplar auch für den Bischof von Gurk bestimmt war, ohne dass dies mit Sicherheit nachzuweisen wäre ${ }^{338}$.

329 Dr.: MDC (wie Anm. 2) Bd. 1 S. 2152 Nr. 336 (Urkunde des Bischofs von Gurk); Reg.: GP 1 S. 129 Nr. $\star 26$.

330 Dr.: Salzburger UB (wie Anm. 2) Bd. 2 S. 616f. Nr. 455 (Das Delegationsreskript ist nur erwähnt in der Beurkundung des Urteils durch Erzbischof Adalbert III.); Reg.: GP 1 S. 108 Nr. ${ }^{*} 7$. Vgl. Murauer: Gurk (wie Anm. 4) S. 47, 72f.

331 Dr.: MDC (wie Anm. 2) Bd. 3 S. 510f. Nr. 1361 (Original); Reg.: GP 1 S. 116 Nr. 9. Vgl. Murauer: Gurk (wie Anm. 4) S. 44f. Siehe. oben Anm. 62.

332 Reg.: MDC (wie Anm. 2) Bd. 1 S. 296 Nr. 404 (nur erwähnt in einem Schreiben an den Patriarchen).

333 Dr.: ebd., S. 209 Nr. 276 (Original); Reg.: GP 1 S. 126 Nr. 11.

334 Dr.: MDC (wie Anm. 2) Bd. 1 S. 223f. Nr. 294 (Original); Reg.: GP 1 S. 127 Nr. 15.

335 Dr.: MDC (wie Anm. 2) Bd. 1 S. 348-350 Nr. 456 (Original).

336 Dr.: ebd., Bd. 1 S. 226 Nr. 298 (Original); Reg.: GP 1 S. $127 f$. Nr. 17.

337 Dr.: MDC (wie Anm. 2) Bd. 1 S. 250-252 Nr. 334f. (Original); Reg.: GP 1 S. $128-$ $130 \mathrm{Nr} .27 \mathrm{f}$.

338 Dr.: Salzburger UB (wie Anm. 2) Bd. 3 S. 3f. Nr. 536 (1201, Original) bzw. MDC (wie Anm. 2) Bd. 3 S. 587 Nr. 1505 (1201, Original). 


\subsection{Das Domkapitel von Gurk}

Das erst 1131 gegründete Domkapitel wurde schon wesentlich früher als der Bischof mit Schutzprivilegien bedacht, nämlich von Lucius II. (1145) ${ }^{339}$ und Alexander III. (1169) ${ }^{340} .1184$ folgte ein das Alexander-Privileg als Vorurkunde benutzendes Privileg Lucius' III. ${ }^{341}$, sowie 1208 eines Innozenz' III. ${ }^{342}$. Wie bei den entsprechenden Urkunden für die Salzburger Domherren sind die vier Stücke original überliefert. Die Schenkungen verschiedener Salzburger Erzbischöfe bestätigte Innozenz III. drei Tage vor der Ausstellung seines Schutzprivilegs $(1208)^{343}$; zwei Tage danach beglaubigte Innozenz den von ihm vermittelten Kompromiss im Streit um die Bischofswahl ${ }^{344}$. Ferner wurden dem Dompropst und dem Kapitel die lange umstrittene Pfarre St. Lorenzen am Steinfeld sowie die Pfarre Glantschach von Innozenz III. bestätigt (jeweils 1204) ${ }^{345}$; ebenfalls im Jahre 1204 wurde ein zu Gunsten des Kapitels gefällter Schiedsspruch über die Oblai der Kirche Lorenzenberg päpstlicherseits bestätigt $^{346}$ sowie 1213 ein Gütertausch zwischen dem Domkapitel und einem Kärntner Adeligen ${ }^{347}$.

Mandate sind zwei zu verzeichnen, die beide sowohl an den Salzburger als auch an den Gurker Dompropst adressiert waren, das ältere zusätzlich noch an den Gurker Bischof und die Salzburger Domherren ${ }^{348}$. Beide betrafen die Regierung der Erzdiözese unter dem umstrittenen Adalbert (1172). Ferner ist ein Delegationsreskript von 1188 für den Archidiakon Hermann zu nennen, das

339 Dr.: MDC (wie Anm. 2) Bd. 1 S. 129-132 Nr. 136 (Original); Reg.: GP 1 S. 130 Nr. 1. Die Echtheit dieses Stückes muss in Zweifel gezogen worden; und wenn es nicht ge- oder verfälscht wurde, so ist es wohl erschlichen worden, da die Salzburger Privilegien, welche die Einsetzung des Bischofs betreffen (Salzburger UB [wie Anm. 2] Bd. 2 S. 169-171 Nr. 102 bzw. MGH D H IV 253), nicht erwähnt werden; außerdem wurde es in den folgenden Prozessen von Gurker Seite nie vorgelegt. Vgl. MURAUER: Gurk (wie Anm. 4) S. 102f.; STElzer (wie Anm. 55) S. 56.

340 Dr.: MDC (wie Anm. 2) Bd. 1 S. 195-197 Nr. 256 (Original); Reg.: GP 1 S. $130 f$. Nr. 2.

341 Dr.: MDC (wie Anm. 2) Bd. 1 S. 246-248 Nr. 329 (Original); Reg.: GP 1 S. 132 Nr. 9.

342 Dr.: MDC (wie Anm. 2) Bd. 1 S. 319-322 Nr. 421 (Original).

343 Dr.: ebd., Bd. 1 S. 312 Nr. 419 (Original).

344 Dr.: Salzburger UB (wie Anm. 2) Bd. 3 S. 111-115 Nr. 619 (Original).

345 Dr.: MDC (wie Anm. 2) Bd. 1 S. 298 Nr. 406 (Original) bzw. S. 294 Nr. 401 (Original). Zu St. Lorenzen MURAUER: Gurk (wie Anm. 4) S. 143-152.

346 Dr.: MDC (wie Anm. 2) Bd. 1 S. 298 Nr. 407 (Original).

347 Dr.: ebd., S. 340 f. Nr. 444 (Original).

348 Dr.: ebd., Bd. 1 S. 206f. Nr. 272 (Original); Reg.: GP 1 S. 33 Nr. 106; Dr.: MDC (wie Anm. 2) Bd. 1 S. 206-209 Nr. 275; Reg.: GP 1 S. 34 Nr. 110 - nur abschriftlich überliefert. Siehe oben Anm. 136. 
auch an Bischof Dietrich I. und den Propst von Maria Saal erging ${ }^{349}$. Innozenz III. ernannte den Dompropst 1198 zum delegierten Richter in einem Streit zwischen dem Pfarrer von Vöcklabruck und dem Abt von Seitenstetten ${ }^{350}$. Der Domdekan wurde von Innozenz III. 1206 zum delegierten Richter in der Ehesache des Böhmenkönigs Otakar I. ernannt (gemeinsam mit dem Erzbischof und dem Abt von Admont $)^{351}$.

\section{Kardinalsurkunden - Legatenurkunden}

Diese sind in unserem Untersuchungszeitraum nicht sehr zahlreich. Erstmals taucht ein apostolischer Legat 1126 auf; Kardinalbischof Aegidius von Frascati, von dessen Legation wir keine weitere Nachricht haben, verkündete die Weihe des Friedhofes der Benediktinerabtei Arnoldstein in Kärnten ${ }^{352}$. Vermutlich 1161 bestärkte Kardinalbischof Hubald von Ostia (1158-1181), der spätere Papst Lucius III., Erzbischof Eberhard II. in seiner Haltung im Alexandrinischen Schisma ${ }^{353}$.

Legaten, die speziell für die Belange des Erzbistums Salzburg aus Rom entsandt wurden, finden sich nicht in den Quellen. Die Reise des Kardinals Hildebrand im Jahre 1171 musste, obwohl die Salzburger Kleriker freies Geleit für ihn erwirkt hatten, abgebrochen werden, da ihm die Rektoren des Lombardenbundes in Treviso deren Fortsetzung verunmöglichten - aus Furcht, der Papst wolle hinter ihrem Rücken Frieden mit dem Kaiser schließen ${ }^{354}$. Wir kennen lediglich Legaten, die sich auf ihren Reisen nach Ungarn beziehungsweise ins Reich mit Salzburger Angelegenheiten befassten. 1176 teilte der nach Ungarn entsandte Legat Walter, Kardinalbischof von Albano, dem Salzburger

349 Siehe oben S. 414 mit Anm. 330 Kap. 11.1 (Das Reskript wird nur in einer Urkunde des Erzbischofs erwähnt; Dr.: Salzburger UB [wie Anm. 2] Bd. 2 S. 616f. Nr. 455).

350 Dr.: UB Seitenstetten, ed. RAAB (wie Anm. 2) S. 28 Nr. 20 (Original). Als Kodelegaten fungierten die Äbte von Admont und St. Lambrecht.

351 Dr.: Register Innocenz' III., 9 (wie Anm. 71) IX/60 S. 108-110 (kopial überliefert).

352 Dr.: MDC (wie Anm. 2) Bd. 3 S. 251 Nr. 617 (kopiale Überlieferung); Reg.: GP 1 S. 134 Nr. 1. Zu Aegidius Rudolf Hüls: Kardinäle, Klerus und Kirchen Roms 10491130, Tübingen 1977 (Bibliothek des Deutschen Historischen Instituts in Rom 48), S. $142 \mathrm{f}$.

353 Dr.: Admonter Briefsammlung (wie Anm. 73), S. 121 Nr. 66; Reg.: GP 1 S. 28 Nr. 88 (überliefert im Codex epistolaris Eberhards II.). Zu Hubald Werner MALECZEK: Papst und Kardinalskolleg von 1191 bis 1216. Die Kardinäle unter Coelestin III. und Innocenz III., Wien 1984 (Publikationen des Historisches Instituts beim Österreichischen Kulturinstitut in Rom 1/6), S. 407 (Index). Zwei Schreiben Eberhards an den Kardinaldiakon von SS. XII Apostoli stammen wahrscheinlich ebenfalls aus dem Jahr 1161: GP 1 S. 28f. Nr. 89f.

354 Zur Legation Hildebrands Werner OHNSORGE: Päpstliche und gegenpäpstliche Legaten in Deutschland und Skandinavien 1159-1181, Berlin 1929 (Historische Studien 188), S. $49 f$. 
Klerus mit, dass er alle Gegner Erzbischof Adalberts von ihren Ämtern suspendiert habe, und forderte sie zugleich zum Gehorsam gegenüber dem Erzbischof auf $^{355}$.

Petrus de Bono, Kardinalpresbyter von S. Susanna (1173-1187), entschied 1179 einen Streit zwischen dem Erzbischof Konrad III. und dem Propst von Waldhausen (Oberösterreich) um den Besitz einer Kapelle zugunsten des Erzbischofs $^{356}$. Diese Sentenz ist die einzige Kardinalsurkunde, die im Untersuchungszeitraum in Salzburg ausgestellt wurde. Im Jahr darauf bestätigte Petrus de Bono zusammen mit Kardinalbischof Petrus von Frascati (1179-1182) auf Bitten Erzbischof Konrads III. ein von delegierten Richtern gefälltes Urteil im Streit um die Gurker Bischofswahl ${ }^{357}$.

Für die gesamte Kirchenprovinz Salzburg zuständig war hingegen unter Alexander III. Erzbischof Konrad von Mainz, der als Auswärtiger auch dem Kardinalskollegium angehörte. Von April 1169 bis Jänner 1171 und wiederum 1173 reiste er durch Süddeutschland ${ }^{358}$. Die von ihm überlieferten Urkunden richten sich jedoch überwiegend an Empfänger in den Suffraganbistümern, nicht an solche in der Erzdiözese oder deren Eigenbistum Gurk; eine Ausnahme stellt nur eine Bitte an Erzbischof Adalbert III. dar, eine von Papst Alexander III. verhängte Exkommunikation zu verkünden ${ }^{359}$.

355 Der im ungarischen Raab (Györ) ausgestellte Brief wurde inseriert in das Chronicon Magni presbiteri ad a. 1176, ed. WattenBACH (wie Anm. 37) S. 501f. Vgl. GP 1 S. 37f. Nr. 119-122. Zu Walter, als Bischof von Albano (1158-1178) der Zweite dieses Namens, vgl. Barbara ZENKER: Die Mitglieder des Kardinalkollegiums von 1130 bis 1159, Würzburg 1964, S. 39.

356 Dr.: Salzburger UB (wie Anm. 2) Bd. 2 S. 581f. Nr. 421 (Original); Reg.: GP 1 S. 41 Nr. 136. Zu Petrus de Bono MaleczeK: Papst (wie Anm. 353) S. 242 mit Anm. 245, 249. Zur Legation Stefan WeIsS: Die Urkunden der päpstlichen Legaten von Leo IX. bis Coelestin III. (1049-1198), Köln/Wien 1995 (Forschungen zur Kaiser- und Papstgeschichte des Mittelalters. Beihefte zu J. F. Böhmer, RI 13), S. 259-261, 264f., 271.

357 Dr.: Salzburger UB (wie Anm. 2) Bd. 2 S. 586 Nr. 424b (Original); Reg.: GP 1 S. 42 Nr. 139. Zu Petrus von Frascati vgl. MALECZEK: Papst (wie Anm. 353) S. 244, 247, 251 u. 268; Klaus GANZER: Die Entwicklung des auswärtigen Kardinalats im hohen Mittelalter. Ein Beitrag zur Geschichte des Kardinalkollegiums vom 11. bis 13. Jahrhundert, Tübingen 1963 (Bibliothek des Deutschen Historischen Instituts in Rom 26), S. 123-125; Wilhelm JANSSEN: Die päpstlichen Legaten in Frankreich vom Schisma Anaklets II. bis zum Tode Coelestins III. (1130-1198), Köln/Graz 1961, S. 119-122, und OHnsorge: Legaten (wie Anm. 354) S. 67-85.

358 Beginn und Ende der zweiten Reise sind nicht genau datierbar; spätestens 1176 muss sie zu Ende gewesen sein. Vgl. die Vorbemerkung zu Mainzer Urkundenbuch 2/1 (wie Anm. 90) S. 596 Nr. 354. Vgl. GanzeR: Entwicklung (wie Anm. 357) S. 107; OHNSORGE: Legaten (wie Anm. 354) S. 41, 44f., 48.

359 Dr.: Mainzer Urkundenbuch 2/1 (wie Anm. 90) S. 596f. Nr. 355; Reg.: GP 1 S. 35 Nr. ${ }^{\star} 112$. Zu der darin erwähnten Papsturkunde siehe oben S. 389 mit Anm. 90. 


\section{Rezeption (Implementierung) des Gelehrten Rechts (römisches und kanonisches Recht)}

Nicht ganz sicher ist es, ob päpstliche Dekretalen tatsächlich an Salzburger Empfänger gerichtet wurden. So nennen etliche Handschriften, die eine eherechtliche Dekretale Papst Hadrians IV. überliefern, den Salzburger Erzbischof (Eberhard I.) als Adressaten, andere dagegen abweichende Namen, etwa auch Magdeburg. Salzburg kann jedoch größere Wahrscheinlichkeit für sich in Anspruch nehmen ${ }^{360}$. Außer diesem ist nur noch ein zweiter Fall anzuführen, die bereits erwähnte, von Hadrian IV. verfügte Ausweitung jener Tage, an denen Priester und Diakone geweiht werden durften (circa 1157/59) ${ }^{361}$.

Aus Urkunden lässt sich der Eindruck gewinnen, dass schon früh Begriffe und Regeln des kanonischen Rechts bekannt waren: Erzbischof Eberhard I. begründete 1153, warum es notwendig sei, die Ergebnisse einer Gerichtsverhandlung schriftlich festzuhalten (Streit zwischen Kollegiatsstift Suben am Inn und Pfarrer von Leibnitz in der Südsteiermark): Ut ea que vel per sententiam decisa vel consilio fuerint terminata, nulla tergiversatione valeant ulterius in litem revocari, ... ${ }^{362}$. Der Standpunkt des Erzbischofs weist auf das römisch-rechtliche Prinzip der res iudicata hin, das auch von Gratians Dekret übernommen wurde, wonach in einer bereits entschiedenen Sache kein neues Urteil ergehen dürfe, außer nach vorangegangener Appellation ${ }^{363}$. Die Nähe der Argumentation Eberhards zu diesem Prinzip, ohne den Terminus technicus selbst zu nennen, wirft die Frage auf, ob das Dekret schon 1153 im Erzbistum Salzburg bekannt war, denn am ehesten von dort wurden Kenntnisse des neuen kanonischen Rechts bezogen. Die Frage, wer dieses Fachwissen eingebracht hat - der Erz-

360 Zur Überlieferung vgl. GP 1 S. 26 Nr. 83 (S. 411 Addenda et Corrigenda); Dr.: X 4. 9. 1, Corpus Iuris Canonici, ed. Aemilius FriedberG, Bd. 2, Leipzig 1879 (Nachdr. Graz 1959), Sp. 691f. Vgl. Peter LANDAU: Hadrians IV. Dekretale "Dignum est" (X 4. 9. 1) und die Eheschließung Unfreier in der Diskussion von Kanonisten und Theologen des 12. und 13. Jahrhunderts, in: Collectanea Stephan Kuttner, Bd. 2, hg. v. Joseph FORCHIELli/Alphons M. STICKLER, Rom 1967 (Studia Gratiana 12), S. 511-553. Über die Zuschreibung an Alexander III. in drei kanonistischen Sammlungen ebd. S. 515f. Zur Wahrscheinlichkeit der Autorschaft Hadrians IV. - übrigens die einzige Dekretale Hadrians, die in den Liber extra aufgenommen wurde - STELZER (wie Anm. 55) S. 19.

361 Dr.: Pflugk-Harttung (wie Anm. 55) Bd. 2 S. 363 Nr. 412; Reg.: GP 1 S. 26 Nr. 81. Siehe oben Anm. 55.

362 Dr.: Salzburger UB (wie Anm. 2) Bd. 2 S. 426 Nr. 305.

363 Codex Iustinianus 7. 64. 1, Corpus Iuris Civilis, Bd. 2, ed. Paul Krueger, Berlin 1895 (Nachdr. Berlin 1954), Sp. 326; Digesta 4. 4. 18. 2, Corpus Iuris Civilis, Bd. 1, ed. Theodor Mommsen, Berlin 1902 (Nachdr. Berlin 1954), Sp. 59; Decretum Gratiani C. 2 q. 6 p. c. $41 \S 4$, ed. FriedBerg, CIC (wie Anm. 360) Bd. 1 Sp. 482: Item si sententia lata fuerit contra res prius iudicatas, a quibus provocatum non est, sententiae auctoritatem non obtinebit, et ideo ab ea appellari non est necesse. 
bischof selbst oder ein Mitglied des Umstands -, muss unbeantwortet bleiben. Insofern bleibt alles in der Schwebe, man muss in der Argumentation vorsichtig sein, aber die Ähnlichkeiten sind frappierend.

Weniger spektakulär, da viel später (1203) überliefert, ist eine appellatio a gravamin $^{364}$. Die appellatio a gravamine zählt $\mathrm{zu}$ den appellationes extraiudiciales, worunter die Anrufung eines höheren Gerichts ohne Bezug auf einen bereits laufenden Prozess zu verstehen ist ${ }^{365}$. Dieses zunächst von Alexander III. stark geprägte Rechtsmittel wurde von Innozenz III. verschiedenen Persönlichkeiten zur Anwendung empfohlen, indem er ihnen erlaubte, immer dann an den Papst zu appellieren, wenn sie befürchteten, ein gravamen zu erleiden ${ }^{366}$.

Peremptorische Zitationen finden sich ebenfalls. Drei Ladungen konnten vor der Litiskontestation, der durch die Klage und die Antwort des Beklagten begründeten Streiteinlassung ${ }^{367}$, erfolgen, wobei die jeweiligen Zeitabstände vom Richter festzusetzen waren. Die dritte Ladung hatte zumeist peremptorischen Charakter, das heißt der Richter konnte die Streitfrage an diesem Termin behandeln, auch wenn einer der Geladenen nicht erschien ${ }^{368}$. Jedoch gab es auch hier Ausnahmen: Der Beklagte wurde trotz Kontumaz ein weiteres Mal geladen (Pfarrer von Tainach 1203) 369 $^{369}$ oder es war schon der zweite Termin peremptorisch ${ }^{370}$.

364 Dr.: MDC (wie Anm. 2) Bd. 1 S. 288 Nr. 394.

365 Vgl. Knut Wolfgang NÖRR: Ein Baustein der mittelalterlichen Rechtskirche: Die appellatio extraiudicialis, in: Studia in honorem eminentissimi Cardinalis Alphonsi M. Stickler curante Rosalio Iosepho Card. CASTILlo LARA, Rom 1992 (Studia et Textus Historiae Iuris Canonici 7), S. 463-482. Der Begriff geht nach Nörr auf eine Dekretale Alexanders III. zurück (X 2. 28. 5, CIC, Bd. 2 Sp. 411). Es käme aber auch ein Diktum Gratians in Frage (C. 2 q. 6 d. p. c. 14, CIC, Bd. 1 Sp. 470) sowie eine ins Dekret aufgenommene Pseudo-Isidor-Stelle (C. 2 q. 6 c. 4, CIC, Bd. 1 Sp. 467). S. auch Josephus ZeLIAUSKas S. D. B.: De excommunicatione vitiata apud Glossatores 11401350, Roma 1967 (Pontificium Athenaeum Salesianum. Facultas Iuris Canonici. Studia et Textus Historiae Iuris Canonici 4), S. 315.

366 Rainer MURAUER: Priusquam litteras aperiret, ... ad sedem apostolicam appellavit. Zu den Zusammenhängen von Exkommuniktion, Appellation und (ad cautelam)Absolution; in: MIÖG 105 (1997) S. 393-415, hier S. 395 u. 405. Die dort angeführten Beispiele wären noch zu vermehren durch Die Register Innocenz' III., 10: 10. Pontifikatsjahr, 1207/1208. Texte, bearbeitet von Rainer MURAUER/Andrea SOMMERLECHNER gemeinsam mit Othmar HAGENEDER u. a., Wien 2007 (Publikationen der Abteilung für historische Studien des Österreichischen Kulturinstituts in Rom 2/1/10), X/36 S. 58.

367 Vgl. jetzt Steffen SCHLINKER: Litis contestatio. Eine Untersuchung ïber die Grundlagen des gelehrten Zivilprozesses in der Zeit vom 12. bis zum 19. Jahrhundert, Frankfurt am Main 2008 (Studien zur europäischen Rechtsgeschichte 233).

368 Vgl. dazu Hans Jörg BudisCHIN: Der gelehrte Zivilprozeß in der Praxis der geistlichen Gerichte des 13. und 14. Jahrhunderts im deutschen Raum, Bonn 1974 (Bonner rechtswissenschaftliche Abhandlungen 103), S. 37-39.

369 Dr.: MDC (wie Anm. 2) Bd. 1 S. 288 Nr. 394.

370 Dr.: Salzburger UB (wie Anm. 2) Bd. 3 S. 137f. Nr. 636 (1210). 
Allgemein waren die Päpste bestrebt, lokale Rechtsgewohnheiten nur dann zum Tragen kommen zu lassen, wenn sie dem kanonischen Recht nicht widersprachen. In Prozessen wurde die Berufung auf lokale Gewohnheiten meist dann angewendet, wenn eine Partei wusste, dass sie sich in Gegensatz zum kanonischen Recht und zur Auffassung des Papstes befand. Spannungen zwischen consuetudo sedis Romane und consuetudo terrae werden auch in salzburgischGurker Urkunden manifest.

\section{Zusammenfassung}

Von Erzbischof Gebhard (1073-1085) bis zur Wahl Eberhards II. (1200) zeichnete sich das Erzbistum Salzburg durch eine - mit gewissen Abstufungen - ausgesprochen papsttreue Einstellung aus, die wie schon im Investiturstreit insbesondere im alexandrinischen Schisma wirksam wurde und das gesamte Territorium in lange währende kriegerische Konflikte verwickelte: Während etwa Eberhard I. (1147-1164) prononciert alexandrinisch agierte - die 1163 ad personam erfolgte Ernennung zum ständigen Legaten im ganzen Regnum Teutonicum ${ }^{371}$ kann durchaus als Belohnung gewertet werden -, vermied sein Nachfolger Konrad II. (1164-1168), der auch öfter am Kaiserhof weilte, eine eindeutige Parteinahme. Da sich seine entschieden alexandrinisch gesinnten Wähler seiner Haltung offenbar nicht ganz sicher waren, verpflichteten sie ihn bei der Wahl, dass er cum Alexandro papa staret sicut predecessor suus ${ }^{372}$. Zumindest in gewissen Situationen wurde die Position im Schisma also weniger vom Erzbischof als von clerus et populus bestimmt, und der Erzbischof musste sich nolens volens dieser Vorgabe anschließen ${ }^{373}$.

Wie der Babenberger Konrad II. gehörte auch sein Nachfolger Adalbert III. (1168-1177, 1183-1200) als Sohn des Böhmenkönigs Wladislaw II. einem mächtigen Fürstengeschlecht an. Wiewohl durch seine Amtsführung (z. B. Verschleuderung von Kirchengut) vom kirchenrechtlichen Standpunkt mehr als angreifbar, hielt Alexander III. an ihm fest, auch als ihn ein Fürstengericht in Regensburg 1174 für abgesetzt erklärt und mit dem Propst Heinrich von Berchtesgaden einen Gegenerzbischof gewählt hatte. Für wenige Jahre gab es nun nicht nur zwei Päpste, sondern auch zwei Erzbischöfe. Der Papst hielt so lange seine schützende Hand über Adalbert, als er sich im Streit mit Barbarossa befand und sich mit einem Gegenpapst auseinanderzusetzen hatte. Das Ende

371 Ebd., Bd. 2 S. 514f. Nr. 367. Davon zu unterscheiden ist die ab 1179 regelmäßig bestätigte Berufung des jeweiligen Erzbischofs zum ständigen Legaten in seiner Kirchenprovinz: ebd., S. $580 f$. Nr. 420 u. öfter (s. oben Anm. 49, 50).

372 Annales Reicherspergenses ad. a. 1164 (wie Anm. 35) S. 471.

373 Die Formulierung der Wahlbedingung von 1164 wird allgemein Dompropst Hugo zugeschrieben. Vgl. ClaSSEN: Gerhoch (wie Anm. 113) S. 278f;; ihm folgt DOPSCH: Salzburg im Hochmittelalter (wie Anm. 11) S. $284 f$. 
des Schismas an der Spitze der Kirche beendete auch das lokale Schisma. Mit dem Frieden von Venedig wurden die beiden Rivalen abgesetzt.

Auf einen Babenberger und einen Přmysliden folgte Konrad III. von Wittelsbach, der als von Barbarossa eingesetzter Erzbischof von Mainz (seit 1161) zunächst ein Anhänger Viktors IV. war, sich ab 1165 aber zu Alexander III. bekannte. Er blieb auch nach seiner Ernennung zum Salzburger Erzbischof (1177), einer Abfindung für den Verlust des Mainzer Stuhles, der alexandrinischen Partei treu. Aus der Reihe der Salzburger Oberhirten ragt er insofern heraus, als er von Alexander zum Kardinalpriester von S. Marcello und danach zum Kardinalbischof von Sabina ernannt wurde und diese Kurienämter auch während seiner Salzburger Amtszeit beibehielt ${ }^{374}$.

Außergewöhnlich ist zudem die Wahl, die durch die Rückkehr Konrads nach Mainz nötig wurde (1183). Der sechs Jahre zuvor abgesetzte Adalbert wurde zum zweiten Mal eingesetzt, diesmal auf ausdrücklichen Befehl Barbarossas hin, der seit dem Frieden von Venedig und dem Sturz Heinrichs des Löwen (1180) nahezu unumschränkten Einfluss auf die Besetzung der Reichsbistümer ausüben konnte. In seiner zweiten Amtszeit, die ungleich harmonischer verlief als die erste, vermochte Adalbert zu Kaiser wie Papst ein ungetrübtes Verhältnis aufrechtzuerhalten ${ }^{375}$.

Die Dominanz der Zentrale über die lokale Ebene wird einmal mehr sichtbar. Konflikte auf höchster Stufe zwingen die regionalen Amtsträger zur Positionierung auf einer Seite; der Friedensschluss zwischen den höchsten Repräsentanten von Regnum und Sacerdotium ermöglichte auch den lokalen Amtsträgern ein gedeihliches Auskommen mit beiden.

Das Epochenjahr 1198, das durch die Wahl Papst Innozenz' III. und den Beginn eines fast zwei Jahrzehnte währenden Streits um den deutschen Königsthron zwischen Staufern und Welfen gekennzeichnet war und ferner durch die von hier an fast lückenlos erhaltenen Register der päpstlichen Kanzlei eine völlig neue Überlieferungssituation mit sich brachte, stellt für das Erzbistum Salzburg und sein Verhältnis zur römischen Zentrale keine entscheidende Z̈̈sur dar. Der deutsche Thronstreit forderte ähnlich wie das alexandrinische Schisma wenige Jahrzehnte vorher vom Erzbischof eine Positionierung, welche auch für die Beziehungen zur römischen Zentrale relevant war, da das Kirchenoberhaupt massiv in die Auseinandersetzung eingriff und die Reichsbischöfe zur Parteinnahme für den Welfen Otto IV. zu drängen versuchte. Anders als seine Vorgänger wahrte Eberhard II. größere Distanz zum Papst, ja widersetzte sich dessen Forderungen mit Nachdruck, als er sich den beiden

374 Christoph Waldecker: Vom Rhein zum Tiber und zurück. Die Beziehungen Erzbischof Konrads von Mainz zu Papst Alexander III. bis zum Frieden von Venedig, in: Vielfalt der Geschichte. Lernen, Lehren und Erforschen vergangener Zeiten. Festgabe für Ingrid Heidrich zum 65. Geburtstag, hg. v. Sabine HAPP/Ulrich NONN, Berlin 2004, S. 141-152.

375 Eine im wesentlichen positive Bilanz der zweiten Regierungszeit Adalberts zeichnet DopSCH: Salzburg im Hochmittelalter (wie Anm. 11) S. 304. 
Protestaktionen der staufisch gesinnten Reichsfürsten zu Speyer (1199, noch als Elekt von Brixen) $)^{376}$ und Halle (1202, nunmehr als Salzburger Erzbischof) ${ }^{377}$ anschloss. Auch später kann seine Haltung höchstens als neutral eingestuft werden. Die Bedeutung seiner langen Amtszeit (bis 1246) liegt vor allem in der Erneuerung der Organisation der Erzdiözese, die in der Gründung der Eigenbistümer Chiemsee (1216), Seckau (1218) und Lavant (1228) gipfelte, nachdem Gurk bereits 1072 unter Gebhard entstanden war. Das Bestreben der Erzbischöfe, die Eigenbistümer, die allesamt auf erzbischöflichem Grund und Boden errichtet und mit Gütern des Erzstifts ausgestattet worden waren, in eigenkirchenrechtlicher Abhängigkeit zu halten und den Bischof zu ernennen, stieß auf das Bemühen der Domkapitel, die Bischofswahl an sich zu ziehen. Im ältesten Eigenbistum Gurk wurde diese Frage in einer sich bis 1232 hinziehenden juristischen Auseinandersetzung exemplarisch entschieden, welche die Ausstellung zahlreicher Papsturkunden nach sich zog, da sich beide Parteien immer wieder an die Kurie wandten ${ }^{378}$.

Ein Anstieg der Zahl der Papsturkunden für Salzburger Empfänger nach 1198 ist zwar feststellbar, aber keineswegs so drastisch, wie man angesichts der erhöhten Überlieferungschance durch die Papstregister vermuten könnte. Der hohe Anteil der (Schutz-)privilegien an der Gesamtzahl der bekannten Urkunden ist auf deren großen und nachhaltigen Wert für den Empfänger zurückzuführen; demgegenüber hatten alle Arten von Mandaten (Delegationsreskripte, Exekutionsmandate, Zitationen etc.) mit der Erledigung des Auftrags jede Bedeutung verloren und konnten vernichtet werden. Privilegien wurden folglich auch immer wieder erneuert, das gilt für materielle aber auch immaterielle, wie etwa für die Verleihung der Würde eines ständigen Legaten an den Salzburger Erzbischof. Die erstmals 1179 von Alexander III. dem Erzbischof Konrad III. verliehene Würde wurde nicht nur nach der Wahl eines neuen Erzbischofs bestätigt, sondern auch nach einem Wechsel im Papstamt; Konrad III. erstrebte folglich von Alexanders Nachfolger Lucius III. eine Erneuerung des Privilegs, die er 1182 auch erhielt. Nach Konrads Rückkehr nach Mainz und der erneuten Wahl Adalberts III. zum Erzbischof erfolgte 1184 eine weitere Bestätigung Papst Lucius' III. ${ }^{379}$ Von Papst Gregor IX. erhielt Erzbischof Eberhard II. das Recht, sich überall ein Kreuz vorantragen zu lassen, außer wenn der Papst oder ein päpstlicher Legat anwesend war $^{380}$.

Obwohl die Augustiner-Chorherrenstifte im Erzbistum Salzburg die zahlenmäßig größte Gruppe bildeten und auch die Zisterzienser eine maßgebliche

376 RNI (wie Anm. 41) S. 33-38 Nr. 14.

377 Ebd., S. 162-166 Nr. 61.

378 MURAUER: Gurk (wie Anm. 4).

379 Siehe oben S. 383f. mit Anm. 48-50.

380 Salzburger UB (wie Anm. 2) Bd. 3 Nr. 880. 
Rolle spielten ${ }^{381}$, behielten doch die Benediktinerstifte ihre führende Rolle, allen voran St. Peter in der Stadt Salzburg. Nimmt man die Verleihungen des Papstschutzes als Kriterium für die Papstnähe eines Klosters, so müssen fast alle Klöster als papstnah eingestuft werden - mit der Ausnahme des Kollegiatsstifts Maria Saal und des Benediktinerstifts Ossiach. Ob diese beiden Institutionen nicht um den Papstschutz nachgesucht haben, dieser ihnen aus irgendeinem Grund verweigert wurde oder die entsprechenden Urkunden schlicht und einfach verloren sind, lässt sich nicht sagen; gegen das letztere Argument spricht, dass solche Privilegien ihres Wertes wegen in der Regel besonders sorgfältig aufbewahrt wurden.

Selten ging jedoch während des Untersuchungszeitraumes die Unterstellung unter den Heiligen Stuhl so weit, dass es zu einer Exemtion aus der Jurisdiktionsgewalt des Salzburger Erzbischofs gekommen wäre. Lediglich St. Zeno in Reichenhall erreichte die Exemtion von der Gerichtsbarkeit des Salzburger Archidiakons - ein Amt, das seit 1139 stets vom Dompropst bekleidet wurde ${ }^{382}$ - durch Hadrian IV. (1157) $)^{383}$ und Alexander III. (1169) ${ }^{384}$. Michaelbeuern besa $\beta$ als Eigenkloster der Grafen von Peilstein, die auch die Erbvogtei innehatten, eine Sonderstellung, da es von jeglicher erzbischöflicher Einflussnahme befreit war. Schon 1137 wurde es von Papst Innozenz II. als ad ius et proprietatem sancte Romane ecclesie specialius gehörig eingestuft; da damals auch eine jährliche Zinszahlung an den Heiligen Stuhl festgelegt wurde ${ }^{385}$, kann man dieses Benediktinerstift als einziges Kloster im Erzbistum als exemt einstufen. 1213 wurde im Zuge der Erneuerung des Papstschutzes durch Innozenz III. erstmals der eindeutige Begriff nullo mediante verwendet ${ }^{386}$. Die im 13. Jahrhundert beginnenden Auseinandersetzungen, die zur Exemtion St. Lambrechts aus der Jurisdiktionsgewalt des Diözesanherren führten, gehören nicht mehr in den Untersuchungszeitraum ${ }^{387}$.

381 Die Kartausen Geirach und Seitz in der Untersteiermark lagen zwar im Diözesangebiet des Patriarchats Aquileia, waren aber mit dem Bischof von Gurk in besonderer Weise verbunden, sodass es gerechtfertigt schien, sie in diese Darstellung aufzunehmen. Vgl. Otto FrASS: Die Kartausen von Steiermark und Krain und ihre Immunität, in: Zeitschrift des Historischen Vereins für Steiermark 64 (1973) S. 47-66.

$382 \mathrm{Zu}$ der überragenden Stellung des Propstes als Vorgesetzter in weltlichen Angelegenheiten, aber auch als Inhaber der Jurisdiktionsgewalt über alle Domherren, die seit 1122 nach der Augustiner-Regel lebten, Heinz DOPSCH: Klöster und Stifte, in: DERS.: Geschichte Salzburgs (wie Anm. 11) Bd. 1 S. 1002-1053, hier S. $1004 f$.

383 MonBoica Bd. 3 S. 537 Nr. $7 b$ (Original); Reg.: GP 1 S. 67 Nr. 4.

384 Ebd., S. 544 Nr. 13 (Original); Reg.: GP 1 S. 67 Nr. 5.

385 Salzburger UB (wie Anm. 2) Bd. 2 S. 262-264 Nr. 178.

386 Ebd., Bd. 3 S. 166f. Nr. 662. Vgl. Franz MARTiN: Die Kirchliche Vogtei im Erzstifte Salzburg, in: Mitteilungen der Gesellschaft für Salzburger Landeskunde 46 (1906) S. 339-435, hier S. 382.

387 Helmut J. MeZLER-Andelberg: Zur älteren Geschichte der Abtei St. Lambrecht; in: Carinthia I (1961) S. 534-571; Karl DinkLAGE: Zur Geschichte des Stiftes St. Lam- 
Im 12. Jahrhundert, in dem die Kirche durch zwei Papstschismen erschüttert wurde und das alexandrinische auch eine Spaltung des Erzbistums nach sich zog, mochte jedenfalls die Unterstellung unter den Schutz des Kirchenoberhaupts, selbst wenn sich dieses nicht ungeteilter Akzeptanz erfreute, von ganz besonderem Vorteil sein. Man darf das Erzbistum daher mit Recht als offen für den Papstschutz einstufen ${ }^{388}$.

Aber all dies hatte seine Grenzen; trotz der allgemeinen Romorientierung des Erzbistums ließ es sich ein machtbewusster Erzbischof wie Eberhard II. nicht nehmen, sich gegen den Papst auf die Seite des staufischen Thronanwärters zu stellen, wenn ihm dies opportun erschien.

brecht im 12. Jahrhundert, in: Zeitschrift des Historischen Vereins für Steiermark 59 (1968) S. 183-197.

388 Vgl. JOHREndT: Papsttum (wie Anm. 52) S. 214f. und $218 f$. 